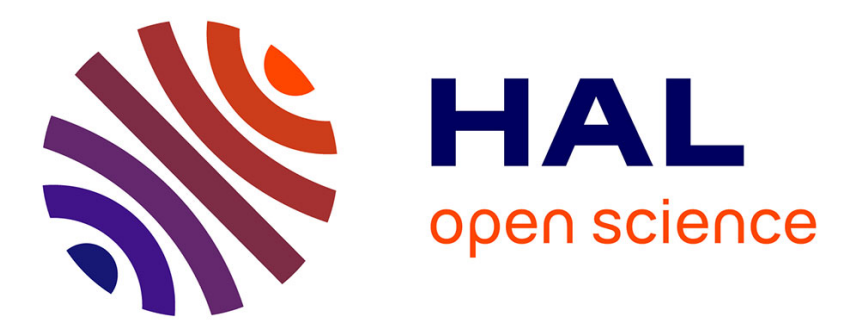

\title{
Comportements techniques et de subsistance à l'Aurignacien ancien: la couche 11 de l'abri Pataud (Dordogne)
}

\author{
Laurent Chiotti, Marylène Patou-Mathis, Carole Vercoutère
}

\section{To cite this version:}

Laurent Chiotti, Marylène Patou-Mathis, Carole Vercoutère. Comportements techniques et de subsistance à l'Aurignacien ancien : la couche 11 de l'abri Pataud (Dordogne). Gallia Préhistoire - Archéologie de la France préhistorique, 2003, 45, pp.157-203. 10.3406/galip.2003.2038 . hal-02353441

\section{HAL Id: hal-02353441 \\ https://hal.science/hal-02353441}

Submitted on 21 Jan 2020

HAL is a multi-disciplinary open access archive for the deposit and dissemination of scientific research documents, whether they are published or not. The documents may come from teaching and research institutions in France or abroad, or from public or private research centers.
L'archive ouverte pluridisciplinaire HAL, est destinée au dépôt et à la diffusion de documents scientifiques de niveau recherche, publiés ou non, émanant des établissements d'enseignement et de recherche français ou étrangers, des laboratoires publics ou privés.

\section{(1) (1) $\$$}

Distributed under a Creative Commons Attribution - NonCommercial - NoDerivatives 44.0 


\title{
COMPORTEMENTS TECHNIQUES ET DE SUBSISTANCE À L'AURIGNACIEN ANCIEN
}

\author{
La couche 11 de l'abri Pataud (Dordogne)
}

\author{
Laurent Chiotti*, Marylène Patou-Mathis ${ }^{* *}$ et Carole Vercoutère ${ }^{* *}$
}

\begin{abstract}
Mots-clés. Aurignacien, Périgord, comportements techniques, comportements de subsistance, territoire, camp saisonnier.
Résumé. Cet article concerne les comportements techniques et de subsistance des hommes préhistoriques qui occupaient l'abri Pataud durant l'Aurignacien ancien. Nous avons croisé les résultats émanant des analyses des industries lithique et osseuse et des restes fauniques découverts dans le principal niveau archéologique aurignacien : la couche 11. Le paysage d'alors était ouvert de type steppique aver, près de la Vézère, des espaces boisés. Le climat était froid mais non rigoureux et sec mais non aride. Le dépôt de cette couche pourrait avoir eu lieu durant une oscillation tempérée du Pléniglaciaire supérieur (vers $32000 \mathrm{BP}$ ). Les industries lithiques et osseuses ont montré que les matières premières travaillées dans l'abri sont essentiellement locales; certaines matières, notamment lithiques, ont été apportées de plus loin. Les outillages sont plutôt à usage domestique. Seule l'industrie osseuse a livré quelques pièces liées à la chasse. L'alimentation carnée Il es Aurignaciens qui ont occupé l'abri durant cette période reposait sur le Cheval et le Renne. Ils ont chassé à plusieurs reprises, en période 'ivernale, des rennes de tous âges présents au sein de hardes composées de femelles et de jeunes et, en période estivale, de petits groupes de chevaux composés également de jeunes et de femelles. La répartition spatiale du matériel (lithique et osseux) indique que la partie fouillée située sous l'abri correspond à des aires d'activités domestiques. Ces analyses mettent en évidence une occupation récurrente du site. L'abri Pataud peut être assimilé à un campement saisonnier, de durée plus longue en périodes hivernales qu'estivales.
\end{abstract}

Key-words. Aurignacian, Perigord, technical behaviours, subsistence behaviours, territory, seasonal camp.

\begin{abstract}
This article deals with the technical and subsistence behaviours of the prehistoric men who stayed in the abri Pataud during the early Aurignacian. All the artefacts, which have been the subject of our study, come from the main archaeological Aurignacian level : layer 11. We have crossed the results of three analyses: the study of the lithic and bone industries and archaeozoology. At that time, the landscape was an open steppe with some wooded spaces near the Vézère. The climate was cold but not harsh and dry but not arid. The deposit of this layer could have taken place during a temperate oscillation of the upper Pleniglacial (around 32000 BP). Thanks to the lithic and bone industries, we know that the objects manufactured in the shelter by prehistoric men were essentially made of local raw material, but imported material was also present. Furthermore, the majority of the tools was produced for domestic use. There are just some samples of bone industry for hunting use. The meat diet of the Aurignacians of the abri Pataud consisted of horse and reindeer. The prehistoric men hunted time and again. In the winter period, they killed female and young reindeer of all ages that comprised small herds. In the summer period, they slew some small groups of female and young horses. The spatial distribution of lithic and bone objects reveals that the excavated zone under the shelter corresponds to domestic activity areas. These analyses emphasize a recurrent occupation of the site. Therefore, the abri Pataud can be compared to a seasonal camp where the prehistoric men stayed longer in the winter period than in the summer one.
\end{abstract}

Palabras claves. Aurinaciense, Perigord, comportamientos técnicos, comportamientos de subsistencia, terrilorio, campamento estacional.

Resumen. Este artículo trata de los comportamientos técnicos y de subsistencia de los hombres prehistóricos que ocupaban el abrigo Pataud durante el Aurinaciense antiguo. Cotejamos los resultados sacados de los análisis de la industria lítica y de la industria ósea con los restos

* FRE 2676 du CNRS, Muséum national d'histoire naturelle, abri Pataud, 20 rue du Moven Âge, F-24620 Les Eyzies-de-Tayac. Mél : Ichiotti@mnhn.fr ** FRE 2676 du CNRS, Muséum national d'histoire naturelle, Institut de paléontologie humaine, 1 rue René-Panhard, F-75013 Paris. 


\begin{abstract}
faunísticos descubiertos en la capa 11, que constituye el nivel arqueológico auriñaciense de mayor importancia. En aquel entonces, el paisaje era un paisaje abierto de tipo estépico, con zonas boscosas en las inmediaciones del ró Vezere. El clima era frio, sin llegar a riguroso, y seco, que no árido. El déposito de dicha capa pudo haber tenido lugar durante una oscilación templada del Pleniglaciar superior (hacia 32000 BP). Las industrias líticas y óseas muestran que la materia prima trabajada en el abrigo era mayoritariamente local; parte de esta materia, sobretodo en el campo lítico, fue traida de sitios más alejados. Los utillajes son más bien de uso doméstico. Se hallaron algunas piezas relacionadas con la caza tan sólo en la industria ósea. Los Auriñacienses que ocuparon el abrigo en aquella época consumian carne de caballo y de reno. Cazaron, en repetidas veces, en estación invernal, renos de toda edad que vivian en el seno de manadas con hembras y crias y, en estación estival, caballos de pequeñas bandas compuestas igualmente de hembras y crias. La repartición espacial del material (lítico y óseo) indica que la parte excavada situada debajo del abrigo correspondía a aréas de actividades domésticas. Estos análisis ponen de relieve una ocupación recurrente del sitio. El abrigo puede ser considerado como un campamento estacional, ocupado de manera más duradera en invierno que en verano.
\end{abstract}

Situé au coeur du village des Eyzies-de-Tayac en Dordogne, l'abri Pataud est l'un des sites majeurs du début du Paléolithique supérieur dans le sud-ouest de la France (fig. 1). Fouillé entre 1958 et 1964 par le professeur américain $\mathrm{H}$. L. Movius, il a livré 14 niveaux principaux d'occupation, correspondant à l'ensemble de l'Aurignacien et du Gravettien, ainsi qu'au début du Solutréen. Depuis une dizaine d'années, l'abri Pataud fait l'objet de nouvelles analyses portant uniquement sur le matériel archéologique extrait lors des fouilles de l'équipe franco-américaine, puisque aucune nouvelle fouille d'importance n'a été réalisée depuis lors. Ces nouvelles études pluridisciplinaires menées par l'équipe du laboratoire de Préhistoire du Muséum national d'histoire naturelle nous ont amenés à étudier, pour la première fois, l'intégralité du matériel issu de ces fouilles.

\section{ENVIRONNEMENT GÉOLOGIQUE ET GÉOMORPHOLOGIQUE}

Le village des Eyzies-de-Tayac est situé dans la partie nord du Bassin aquitain qui correspond géologiquement aux dépôts essentiellement calcaires du Secondaire. Il s'agit de la bordure nord-est de ce bassin sédimentaire, à seulement quelques dizaines de kilomètres des terrains cristallins constitués par les premiers contreforts du Massif central. L'environnement géologique local de l'abri Pataud est constitué de formations calcaires de la fin du Crétacé. La vallée de la Vézère est creusée essentiellement dans les calcaires du Coniacien et du Santonien (fig. 2). Le Coniacien inférieur, de dix à quinze mètres de puissance, est constitué de marnes et de calcaires marneux (Karnay dir., 1999). Le Coniacien moyen et supérieur constitue un ensemble d'une cinquantaine de mètres de puissance de calcaire à éléments détritiques essentiellement quartzeux et bioclastiques, à l'origine des escarpements (localement appelés falaises) et des niveaux d'abris-sous-roche. Le Santonien a localement une puissance supérieure à celle du Coniacien $(80 \mathrm{~m})$, mais il est constitué d'horizons plus variés et plus tendres (notamment des marnes et des calcaires silteux) qui sont à l'origine de reliefs beaucoup plus doux (Konik, 1999).

Le soulèvement des calcaires du Coniacien, lors de la déformation de l'anticlinal de Saint-Cyprien, est à l'origine de la faible largeur de la vallée : moins de $500 \mathrm{~m}$ (ce qui n'est pas le cas plus en amont où cette largeur est de l'ordre de $2000 \mathrm{~m}$ ). Cette vallée est jalonnée de grands escarpements qui n'apparaissent de façon continue que dans les concavités des méandres. À l'emplacement de l'abri Pataud, cette vallée a un aspect dissymétrique.

Le versant sur lequel se trouve le site (dans la concavité du méandre) comprend une partie fortement convexe constituée par les calcaires du Santonien qui contraste avec l'escarpement du tiers inférieur s'inscrivant dans les calcaires du Coniacien moyen et supérieur (fig. 3). Cet escarpement, d'une cinquantaine de mètres de puissance, comporte plusieurs niveaux d'abris-sousroche parmi lesquels s'inscrit l'abri Pataud.

Le versant opposé, situé dans la convexité du méandre, présente un relief beaucoup plus doux. À sa base affleurent les marnes silteuses vertes du Turonien inférieur et les marnes et calcaires marneux et glauconieux du Coniacien inférieur, surmontés par les calcaires du Coniacien moyen et supérieur puis par des formations santoniennes. 


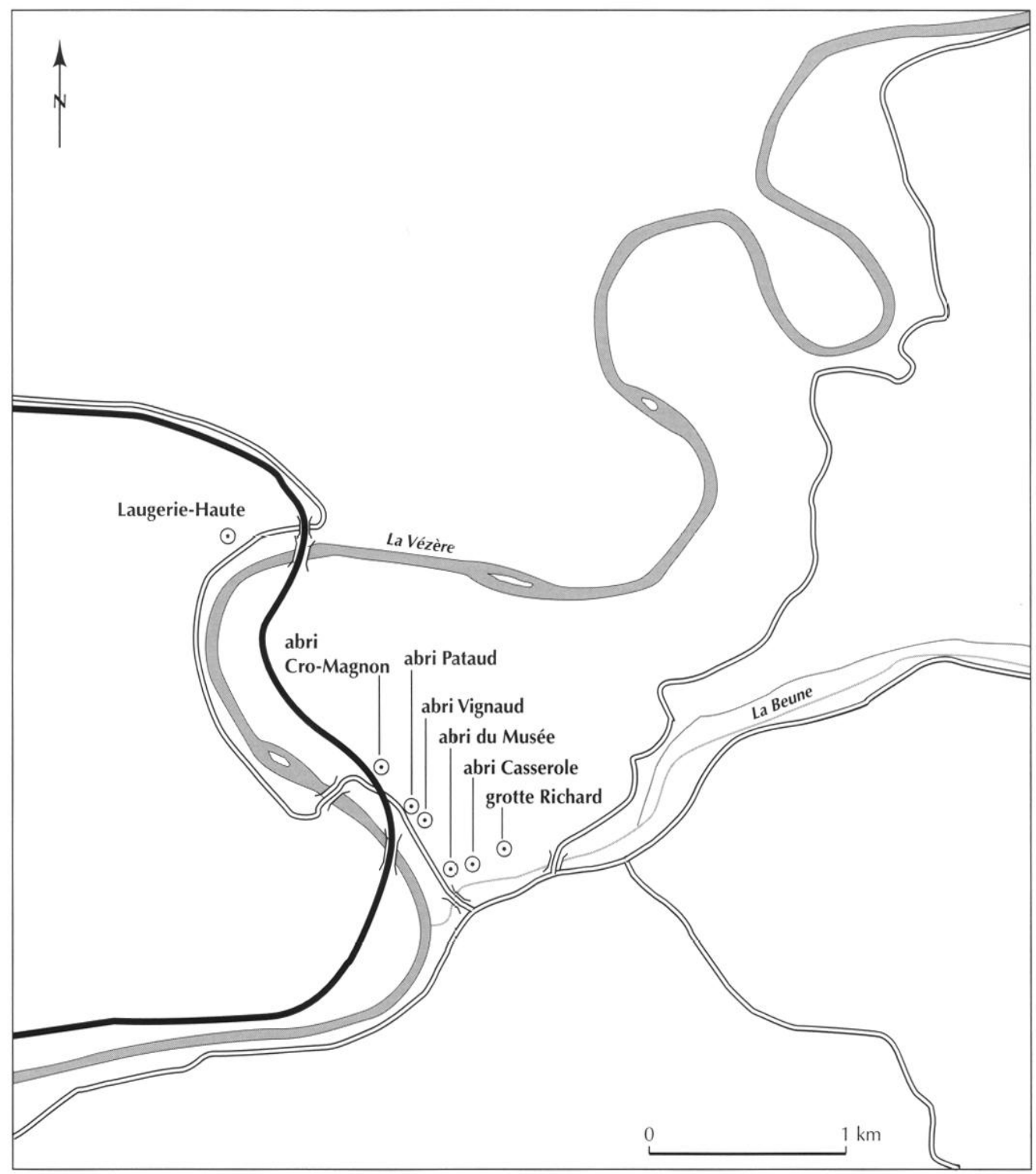

Fig. 1 - Localisation géographique du site.

Le village des Eyzies-de-Tayac se trouve au confluent de la vallée de la Vézère et de la vallée de la Beune. Le débouché de cette dernière, situé à environ $200 \mathrm{~m}$ de l'abri Pataud, a provoqué une large interruption (environ $300 \mathrm{~m}$ ) dans l'escarpement qui couvre toute la longueur de la concavité du méandre. Cette vallée présente une morphologie totalement différente de celle de la Vézère. Elle est relativement rectiligne sur une distance de $25 \mathrm{~km}$, pour une largeur d'environ $250 \mathrm{~m}$. Il s'agit actuellement d'une vallée à fond très plat, qui contient un important colmatage tourbeux approchant la quinzaine de mètres d'épaisseur (Konik, 1999). Cette tourbe qui couvre la totalité de l'époque postglaciaire s'est accumulée derrière un barrage de tufs que la Beune franchit par une série de petites cascades pour aller se jeter dans la Vézère. Les hommes du Paléolithique supérieur ont donc connu cette vallée affluente avec un tout autre aspect: une vallée beaucoup plus encaissée, avec probablement des escarpements beaucoup plus importants, présentant de nombreux abris-sous-roche. Le confluent ne présentait pas non plus le dénivelé actuel.

Deux facteurs importants ont certainement dû intervenir dans le choix qu'ont fait les hommes du Paléolithique de s'installer à l'abri Pataud: l'orientation de l'abri et les possibilités de franchissement de la Vézère.

L'abri s'ouvre à l'ouest-sud-ouest; cette orientation semble être une donnée importante dans le choix de 


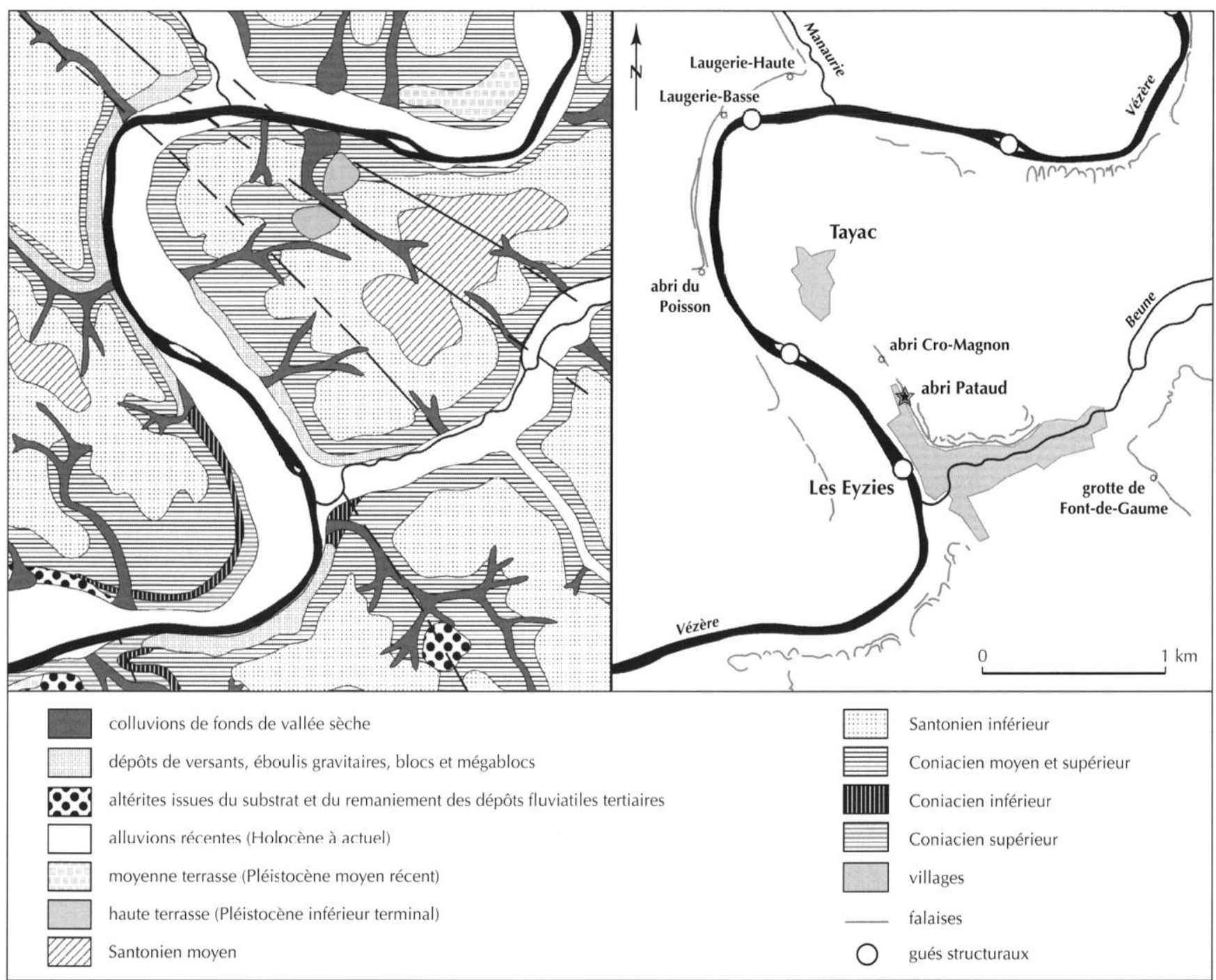

Fig. 2 - Carte géologique et géomorphologique de la région des Eyzies-de-Tayac.

l'emplacement de l'habitat. Cette donnée intuitive a été confirmée par R. White (1985), l'orientation de la majorité des abris occupés étant, dès l'Aurignacien, une orientation sud. L'orientation ouest-sud-ouest se situe dans le pic des orientations dominantes (White, id., p. 113).

Les possibilités de franchissement de la Vézère sont conditionnées par la présence de gués. Il est désormais démontré (White, id.) qu'il existe sur les rivières du Périgord, et en particulier sur la Vézère, un certain nombre de gués structuraux résultant de structures tectoniques plio-pléistocènes ou antérieures qui étaient donc déjà présents lors du Paléolithique supérieur. À proximité immédiate des Eyzies-de-Tayac, il existe trois de ces gués structuraux : un premier en face du château des Eyzies, un deuxième au niveau de l'actuel pont routier et un troisième en face du site de Laugerie-Haute (fig. 2). Lors de son étude, $\mathrm{R}$. White a également pu démontrer qu'il existait une forte relation entre la proximité de ces gués et la présence de sites paléolithiques.

\section{MÉTHODES DE FOUILLES}

La fouille de l'abri Pataud, qui a débuté en 1958, est l'une des premières fouilles européennes à avoir utilisé la méthode des coordonnées pour localiser les objets dans l'espace. Afin de pouvoir coordonner les objets, H. L. Movius a mis en place un carroyage, composé de carrés de $2 \mathrm{~m}$ de côté, sur le sol d'origine. Cependant, cette méthode n'a pas été appliquée au relevé de la 


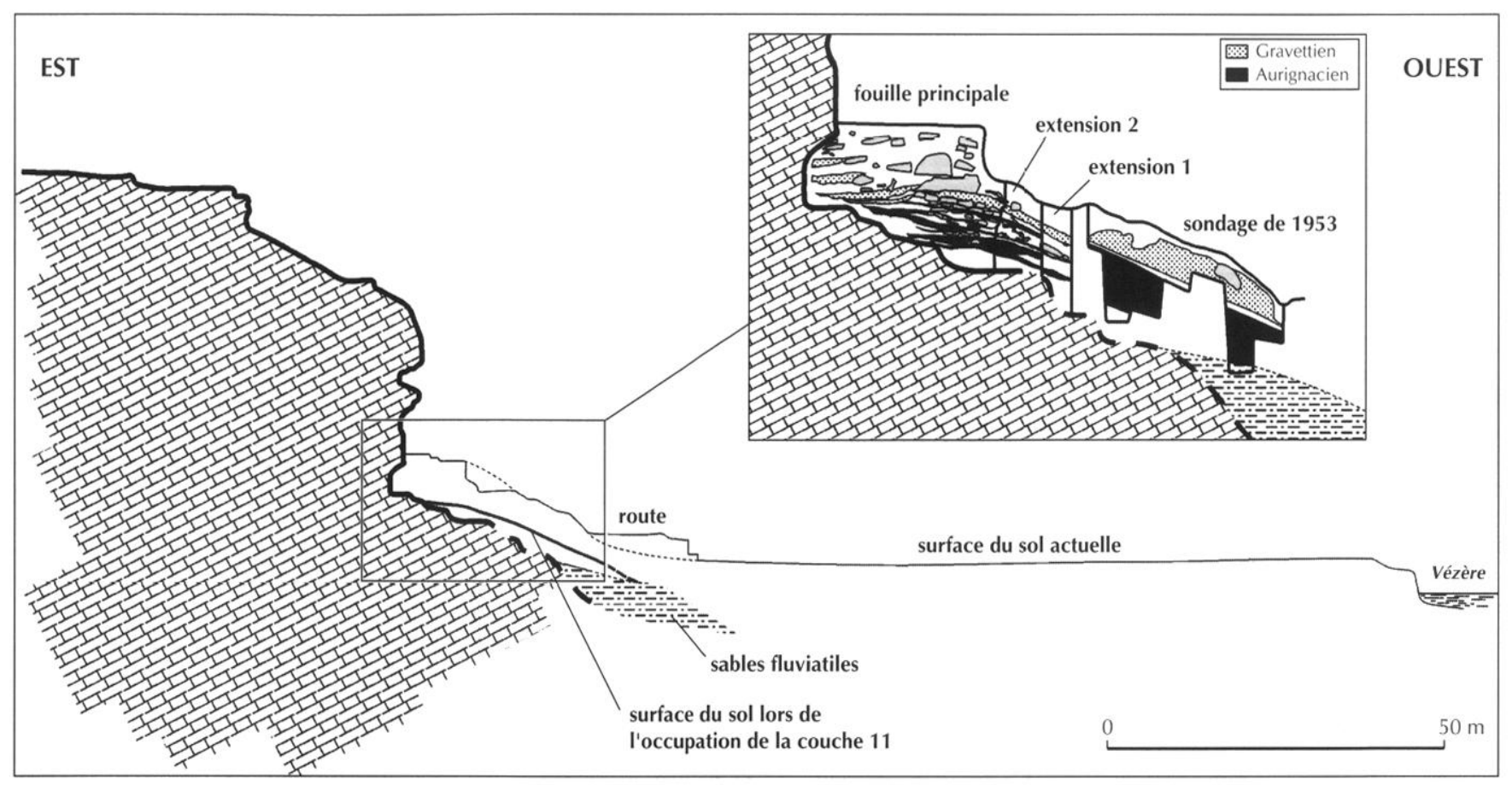

Fig. 3 - Coupe de la vallée de la Vézère à l'emplacement de l'abri Pataud.

totalité des pièces; seuls les outils reconnus lors de la fouille en ont bénéficié. Cela implique qu'une partie des outils (ceux qui n'ont pas été reconnus immédiatement) n'a pas été coordonnée et est actuellement retrouvée lors de l'étude des produits de débitage bruts pour l'industrie lithique et de la faune pour l'industrie osseuse. Outre les outils, en silex et en os, les pièces présentant un intérêt particulier tels les objets de parure ou d'art mobilier ont également été coordonnées. Le matériel qui n'était pas coordonné (faune, produits de débitage, galets, écailles peintes, etc.) a été recueilli par carré et par subdivision stratigraphique. Ce matériel a été conservé dans des sacs en toile, dont une partie s'est dégradée à cause de l'humidité régnant dans le lieu de stockage. Cette dégradation, qui a entraîné une perte d'information pour certains sacs, explique par exemple le fait qu'une partie des produits de débitage de la couche 11 ne possède plus son attribution précise, mais uniquement une attribution à la trench III en général.

L'ensemble de la fouille et en particulier les structures d'habitat ont fait l'objet de relevés systématiques sur papier millimétré, aussi bien en plan qu'en coupe.

Le tamisage des sédiments ne semble pas avoir été systématique, et lorsqu'il a eu lieu, il s'agissait de tamisage à sec.
La couche 11 se situe parmi les premiers niveaux d'occupation de l'abri, dans l'Aurignacien ancien (fig. 4).

\section{PRÉSENTATION DE LA COUCHE 11}

La couche 11, comme l'ensemble des niveaux aurignaciens, a été fouillée dans la partie centrale du site, sur une largeur de $6 \mathrm{~m}$, dans les trenches II (nord) à V (sud). Elle s'étend depuis le fond de l'abri (squares D), jusqu'à l'avant de la fouille (squares A). Elle a également été retrouvée, en 1964, dans les extensions de fouille réalisées dans le talus.

Cette couche est séparée en deux parties par une petite butte formée par l'éboulis 11/12 d'orientation nord-sud, située dans les squares B (fig. 5). À l'exception de l'Eboulis a (subdivision supérieure), qui est continu, il n'y a pas de connexion stratigraphique directe entre les dépôts situés de part et d'autre de cette butte. La partie arrière (à l'est de la butte) est dénomméc « occupation principale " et la partie avant (à l'ouest) Front eboulis.

La surface de base de la couche 11 est relativement horizontale et s'incline légèrement vers le bas dans le Front eboulis. La profondeur est sensiblement plus importante 
dans la partie nord que dans la partie sud. L' ' occupation principale ", à l'arrière du site, a vraisemblablement été aplanie par les hommes avant leur installation, comme en témoignent la troncature et le remaniement de certains dépôts sous-jacents, notamment la couche 12 qui a été entièrement tronquée dans sa partie arrière.

La couche 11 est en fait constituée de deux unités stratigraphiques principales. L'unité Dark (unité infé-

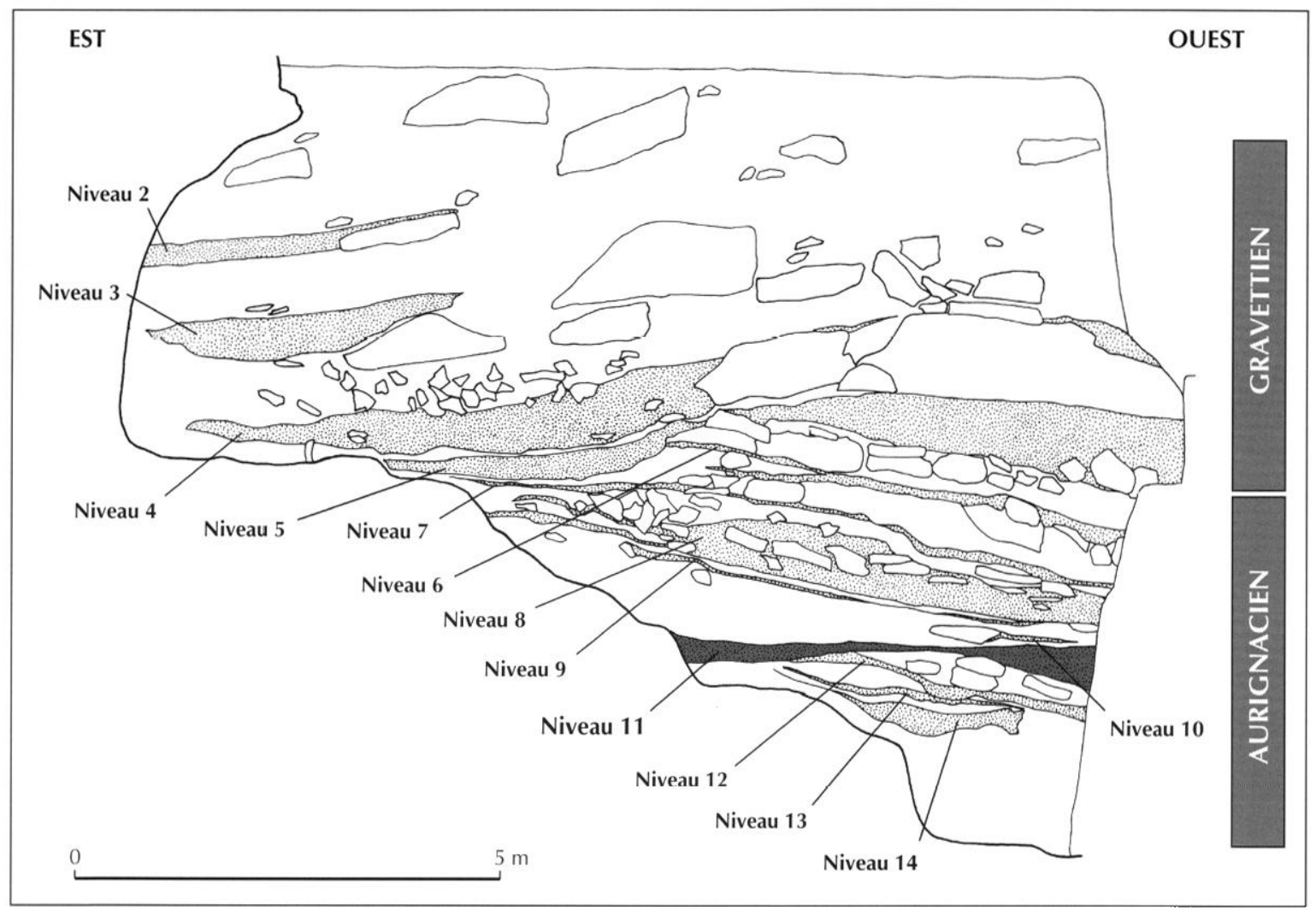

Fig. 4 - Coupe straligraphique de l'abri Pataud.

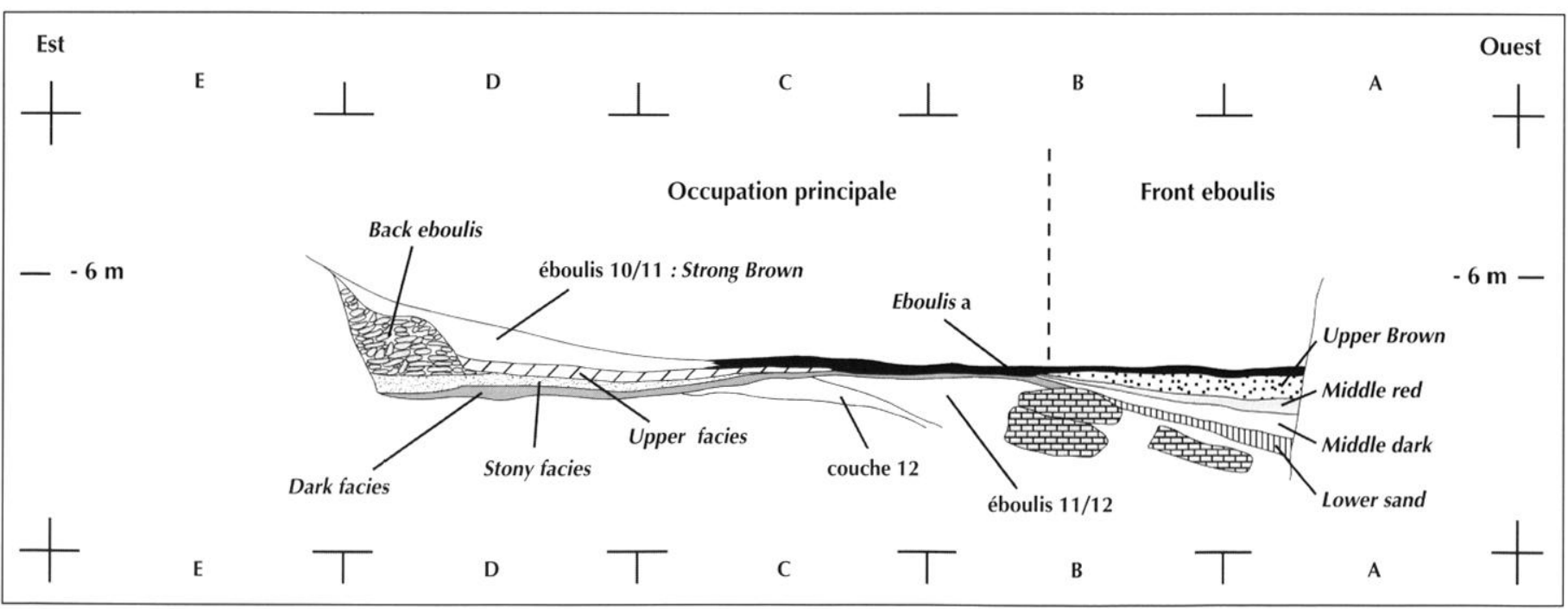

Fig. 5 - Coupe de détail de la couche 11. 
rieure) est la plus importante. Elle couvre la totalité de la surface fouillée. C'est elle qui contient l'ensemble des structures découvertes dans la couche 11 (2 fosses et une série de 7 foyers). C'est également elle qui a livré la majeure partie du matériel archéologique. L'unité supérieure (Upper) est nettement moins importante; elle contient des cendres noires, mais aucun foyer.

Étant donné certains problèmes liés à la conservation du matériel, et à la non-attribution des restes fauniques à l'une ou l'autre des deux unités (Dark ou Upper), nous avons dû étudier globalement le matériel de la couche 11 .

\section{PALÉOÉCOLOGIE ET CHRONOLOGIE}

D'après l'étude des grands mammifères (tabl. I), l'environnement durant la formation de la couche 11 correspondait à un paysage ouvert de type steppique avec, près de la Vézère, des espaces boisés. Le climat était froid mais non rigoureux et sec mais non aride. Le dépôt de cette couche pourrait avoir eu lieu durant une oscillation tempérée du Pléniglaciaire supérieur.

Le remplissage de l'abri Pataud a fait l'objet de deux études palynologiques: I'une par J. J. Donner juste après les fouilles (Donner, 1975) et, plus récemment, par H. Fellag $(1996,1998)$. La couche 11 fait partie de l'ensemble basal de J. J. Donner (1975) qui correspond à un paysage de forêt claire à bouleaux, pins et chênes, essentiellement dans les parties abritées des vallées. Les pollens arborés, qui sont peu représentés (38\% des grains), sont essentiellement des genévriers $(31,5 \%)$, puis des pins et des chênes; quant aux herbacées $(62 \%)$, ce sont principalement des Composées $(51,6 \%)$.

La couche 11 est l'une des rares pour laquelle l'étude de H. Fellag (1996) a donné des résultats (fig. 6). Six échantillons ont été prélevés dans cette couche, entre $755 \mathrm{~cm}$ et $728 \mathrm{~cm}$ de profondeur. Un seul a livré des pollens en quantité suffisante : 418 grains appartenant à 15 taxons. Les arbres sont très faiblement représentés avec moins de $3 \%$. Il s'agit de pins, de chênes, de noisetiers et de hêtres. Les herbacées atteignent $69 \%: 25 \%$ d'amaranthacées-chénopodiacées, $16 \%$ d'astéracées, $12 \%$ de poacées, $7 \%$ d'armoises et $4 \%$ de caryophyllacées. Dans son ensemble, le spectre de cet échantillon montre donc une forte dominance des taxons herbacés
Tabl. I - Dénomlrement des grands mammiferes présents dans la couche 11. NR, nombre de restes; NME, nombre minimal d'éléments; NMIf, nombre minimal d'individus de fréquence; NMIc, nombre minimal d'individus de combinaison.

\begin{tabular}{|l|r|r|r|c|}
\hline \multicolumn{1}{|c|}{ Spectre faunique } & NR & NME & NMIf & NMIc \\
\hline Mammuthus primigenius & 9 & 1 & 1 & 1 \\
\hline Equus caballus & 1368 & 531 & 17 & 25 \\
\hline Rangifer tarandus & 1369 & $>389$ & 12 & 12 \\
\hline Cervus elaphus & 8 & 5 & 1 & 1 \\
\hline Cervidés indéterminés & 41 & - & - & - \\
\hline Bison priscus & 13 & 9 & 2 & 2 \\
\hline Capra ibex & 3 & 3 & 1 & 1 \\
\hline Rupicapra rupicapra & 1 & 1 & 1 & 1 \\
\hline Sus scrofa & 1 & 1 & 1 & 1 \\
\hline Petit herbivore & 26 & - & - & - \\
\hline Grand herbivore & 65 & - & - & - \\
\hline Sous-total herbivores & $\mathbf{2 9 0 4}$ & $>\mathbf{9 4 0}$ & $\mathbf{3 6}$ & $\mathbf{4 4}$ \\
\hline Canis lupus & 11 & 10 & 1 & 1 \\
\hline Vulpes vulpes & 24 & 21 & 3 & 4 \\
\hline Alopex lagopus & 1 & 1 & 1 & 1 \\
\hline Vulpes / Alopex & 102 & - & - & - \\
\hline Panthera (leo) spelaea & 1 & 1 & 1 & 1 \\
\hline Sous-total carnivores & $\mathbf{1 3 9}$ & $\mathbf{3 3}$ & $\mathbf{6}$ & $\mathbf{7}$ \\
\hline Lepus (timidus ?) & 5 & 5 & 2 & 2 \\
\hline Indéterminé & 12 & - & - & - \\
\hline Total & $\mathbf{3 0 6 0}$ & $>\mathbf{9 7 8}$ & $\mathbf{4 4}$ & $\mathbf{5 3}$ \\
\hline
\end{tabular}

indiquant un environnement steppique établi sous des conditions climatiques froides et sèches.

Une étude anthracologique a également été menée (Théry-Parisot, 1998) sur les prélèvements effectués par l'équipe du professeur H. L. Movius dans tous les foyers de la couche 11 . Cette étude s'est révélée totalement infructueuse, tous les foyers étant remplis uniquement d'os brûlé (Théry-Parisot, $i d$. p. 436).

La sédimentologie a été étudiée par W. R. Farrand à la suite des fouilles (Farrand, 1975), puis révisée plus récemment par le même auteur (Farrand, 1995). Une nouvelle étude sédimentologique est en cours, suite à une campagne de prélèvements réalisée lors de la réhabilitation du site en 1990. Les données présentées ici sont donc celles de W. R. Farrand, révisées en 1995. Lors de son étude, il a divisé la séquence sédimentaire de l'abri Pataud en six strates géologiques (strates a à f). L'ensemble de la séquence aurignacienne compose la strate $\mathrm{f}(4,78 \mathrm{~m}$ d'épaisseur dont $1,65 \mathrm{~m}$ constitué par l'éboulis de base stérile). La strate géologique $\mathrm{f}$ présente un cortège de minéraux lourds indiquant une 


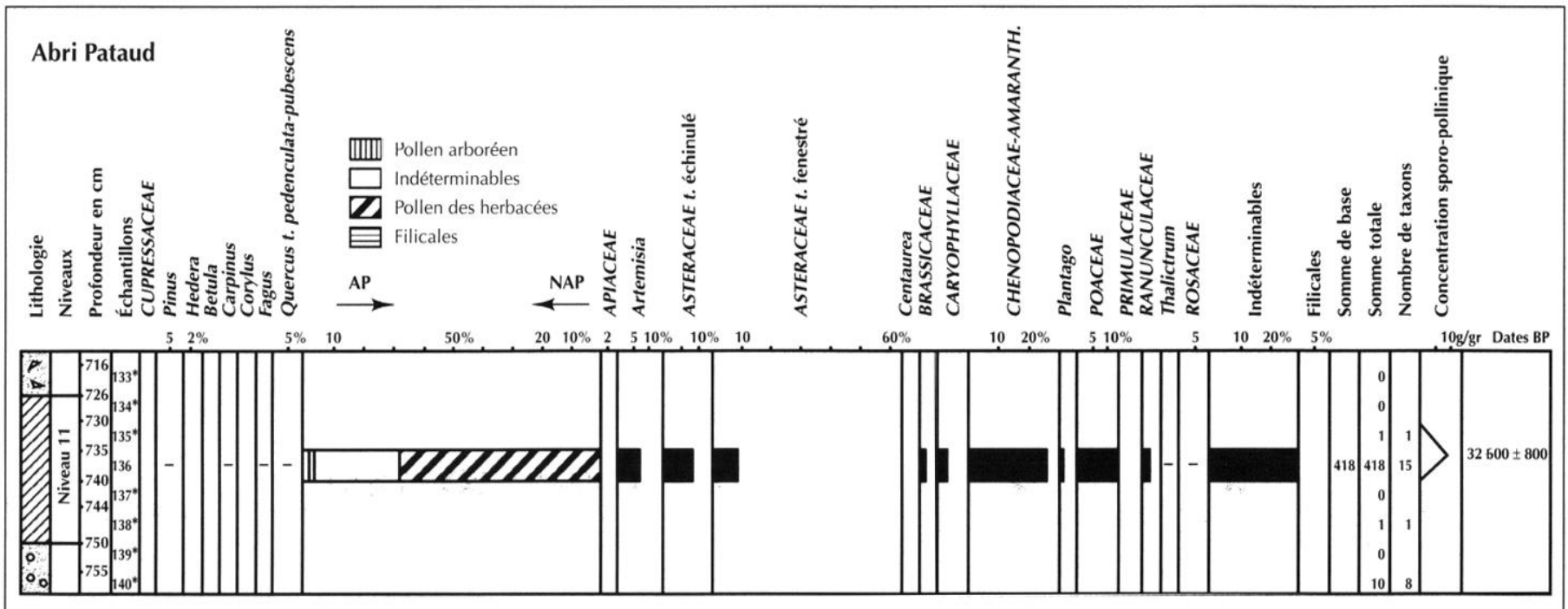

éboulis avec des cailloux $>10 \mathrm{~cm} \quad \square$ éboulis à petits cailloutis dans une matrice sablo-argileuse $\quad 0$ sable avec des cailloux de petite taille * échantillon stérile $\quad-<1 \%$

Fig. 6 - Diagramme palynologique de la couche 11 (d'après Fellag, 1996).

provenance à la fois du calcaire encaissant et/ou des sables tertiaires du plateau (anatase, zircon, tourmaline et staurotide) et de la plaine alluviale de la Vézère (hornblende et grenat transportés depuis les roches cristallines du Massif central). Aucun des échantillons de sédiments de l'abri Pataud n'ayant révélé une suite de minéraux lourds qui proviendraient exclusivement de la roche calcaire, W. R. Farrand en conclut que l'activité éolienne était un facteur continu dont l'intensité variait selon les époques. L'apport du calcaire reste cependant nettement dominant dans la majeure partie de la strate $\mathrm{f}$.

La couche 11 se situe dans une phase d'altération dénommée strate f2 (affectant essentiellement l'éboulis 10/11 et en partie la couche 11) qui constitue la seule interruption significative dans la strate $f$ au caractère par ailleurs relativement uniforme. Dans la couche 11, cette altération se traduit par un taux de $\mathrm{CaCO}_{3}$ remarquablement réduit. Il y a très peu de traces nettes d'altération en dehors de la couleur des sédiments. Il faut également noter la présence de concrétions carbonatées sur les faces des fragments de roche juste au-dessous de la couche 11. W. R. Farrand remarque que, dans tous les cas où il y a une diminution nette du taux de $\mathrm{CaCO}_{3}$, on trouve des traces claires de concrétions de carbonates dans les dépôts immédiatement sousjacents, comme c'est le cas pour la couche 11. Une telle situation implique la dissolution du calcaire de la couche supérieure, due à une dégradation atmosphérique, accompagnée simultanément par la précipitation de ce $\mathrm{CaCO}_{3}$ sur les fragments de roche de la couche inférieure, processus caractéristique de la pédogenèse.

Pour la couche 11, le laboratoire de Groningen a obtenu deux dates ${ }^{14} \mathrm{C}$ à partir d'un seul échantillon d'os brûlé : GrN-4326: $32000 \mathrm{BP} \pm 800$ et GrN-4309: $32600 \mathrm{BP} \pm 550$. J. C. Vogel et $\mathrm{H}$. T. Waterbolk admettent une valeur centrale de 33000 ans pour les couches 11 et 12 (Vogel, Waterbolk, 1967 ; Movius, 1977). Sur des bases stratigraphiques, il apparaît évident à H. L. Movius que la couche 11 est légèrement plus jeune que la couche 12, et que ces deux occupations étaient trop rapprochées dans le temps pour être différenciées par la méthode du carbone 14.

Aucune date n'a pu être obtenue par la méthode de racémisation des acides aminés (El Mansouri, 1995).

\section{TOPOGRAPHIE DE L'ABRI ET STRUCTURES D'AMÉNAGEMENT}

La forme de la falaise a fortement évolué tout au long de l'occupation paléolithique de l'abri, essentiellement sous l'effet de la gélifraction, modifiant profondément la morphologie de l'espace habitable.

Lors de l'occupation de la couche 11, l'abri Pataud devait être assez peu profond, n'offrant qu'un espace protégé relativement étroit. Il est possible que les différences notées lors de la fouille entre les dépôts de 


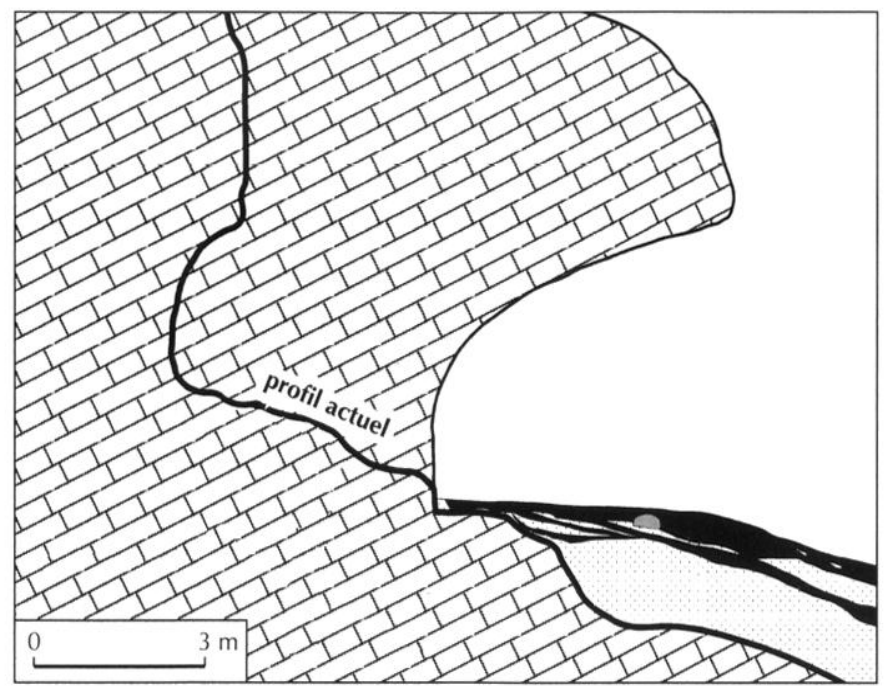

Fig. 7 - Forme estimée de l'abri lors de l'occupation de la couche 11 (d'après Farrand, inédit)

"l'occupation principale " et ceux du Front eboulis (Movius, 1977, p. 131) correspondent à la limite entre la partie couverte par le surplomb et la partie non protégée. Ceci impliquerait une largeur de cinq à six mètres pour la plate-forme abritée. Par ailleurs, le plafond de l'abri devait s'élever assez rapidement, jusqu'à près de $5 \mathrm{~m}$ de hauteur (fig. 7 ). Au vu du plan de la partie fouillée de la couche 11 (tranchée de $6 \mathrm{~m}$ ), il paraît évident que nous ne sommes en présence que d'une partie de cette occupation. Il est extrêmement difficile, voire impossible, d'estimer sa surface totale.

Lors de la fouille, la couche 11 a révélé d'importantes structures d'occupation qui se situaient toutes dans l'unité majeure: Dark (fig. 8). Il s'agit de 7 foyers (Hearth I, J, K, L, M, N et O) et de 2 fosses (Pits I et II).

\section{LES FOYERS}

Les foyers sont répartis selon deux lignes quasi régulières, dans les squares $\mathrm{C}$ et $\mathrm{D}$. Les foyers $\mathrm{L}, \mathrm{N}, \mathrm{O}$, J et I sont alignés contre la paroi de l'abri, alors que les foyers $\mathrm{M}$ et $\mathrm{K}$ forment une ligne approximativement parallèle, un peu plus en avant.

Le foyer I mesure $30 \mathrm{~cm}$ du nord au sud, $80 \mathrm{~cm}$ d'est en ouest et sa profondeur maximale est de $15 \mathrm{~cm}$. Il est installé dans une cuvette subcirculaire dont les parois sont inclinées. Il n'a été que partiellement fouillé. Le remplissage est composé essentiellement de cendres noires et d'os brûlés. Il y a également de nombreuses

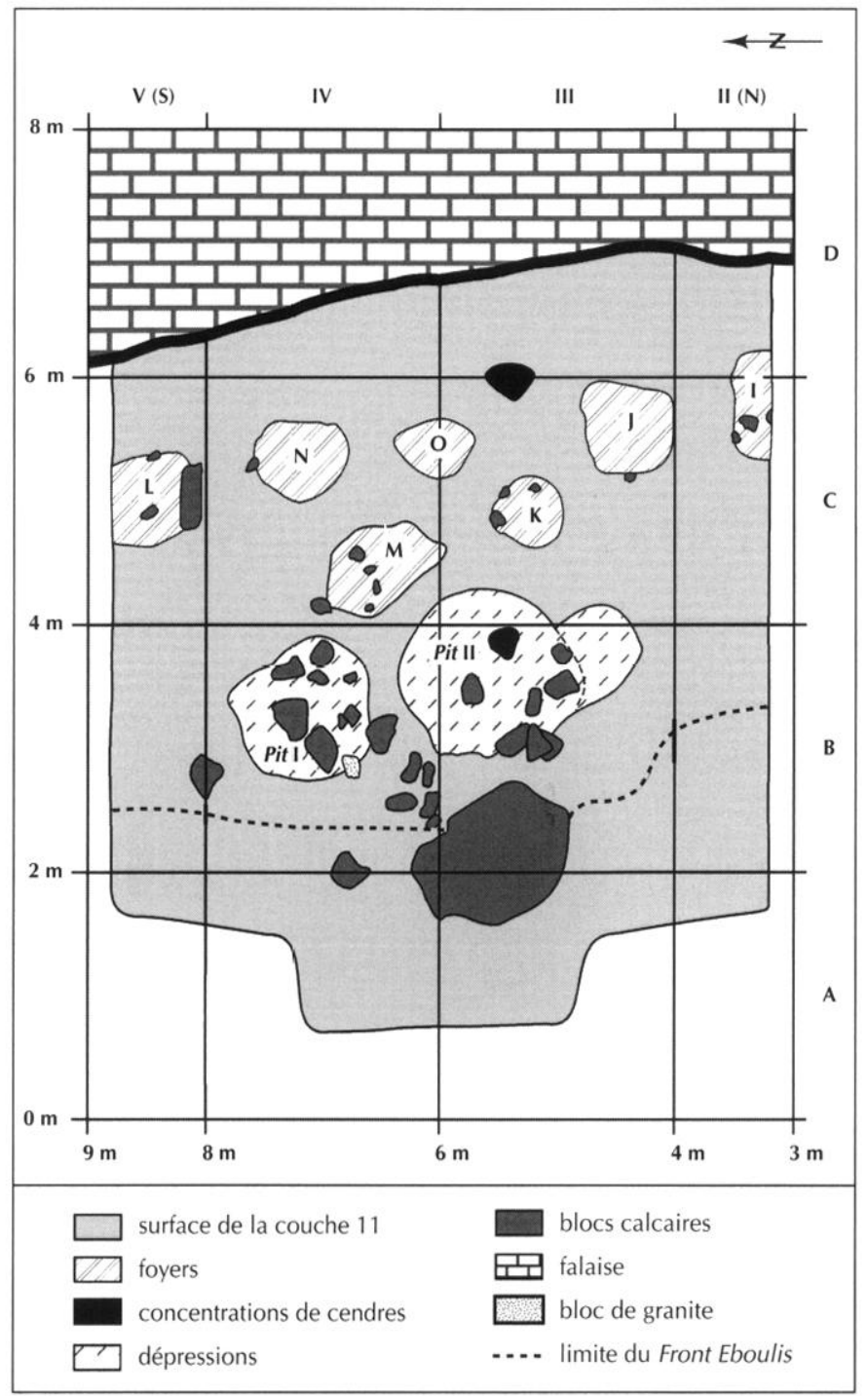

Fig. 8 - Plan des structures d'habitat de la couche 11.

pièces, très peu ou pas brûlées (en particulier une longue côte), qui ne semblent pas avoir été introduites postérieurement. Il a également livré un grand nodule de silex et quelques produits de débitage bruts.

Le foyer J mesure $70 \mathrm{~cm}$ du nord au sud, $70 \mathrm{~cm}$ d'est en ouest et sa profondeur maximale est de $20 \mathrm{~cm}$. Il est installé dans une cuvette, subovale aux bords inclinés, creusée dans l'éboulis du fond de l'abri (Back eboulis). Ce dernier est de couleur grisâtre dans ce secteur, couleur probablement due au feu. Il est rempli de cendres noires qui contiennent de l'os brûlé, peut-être du charbon, sept outils en silex et quelques produits de débitage bruts. Ce matériel semble avoir été inclus dans le foyer après son fonctionnement. 


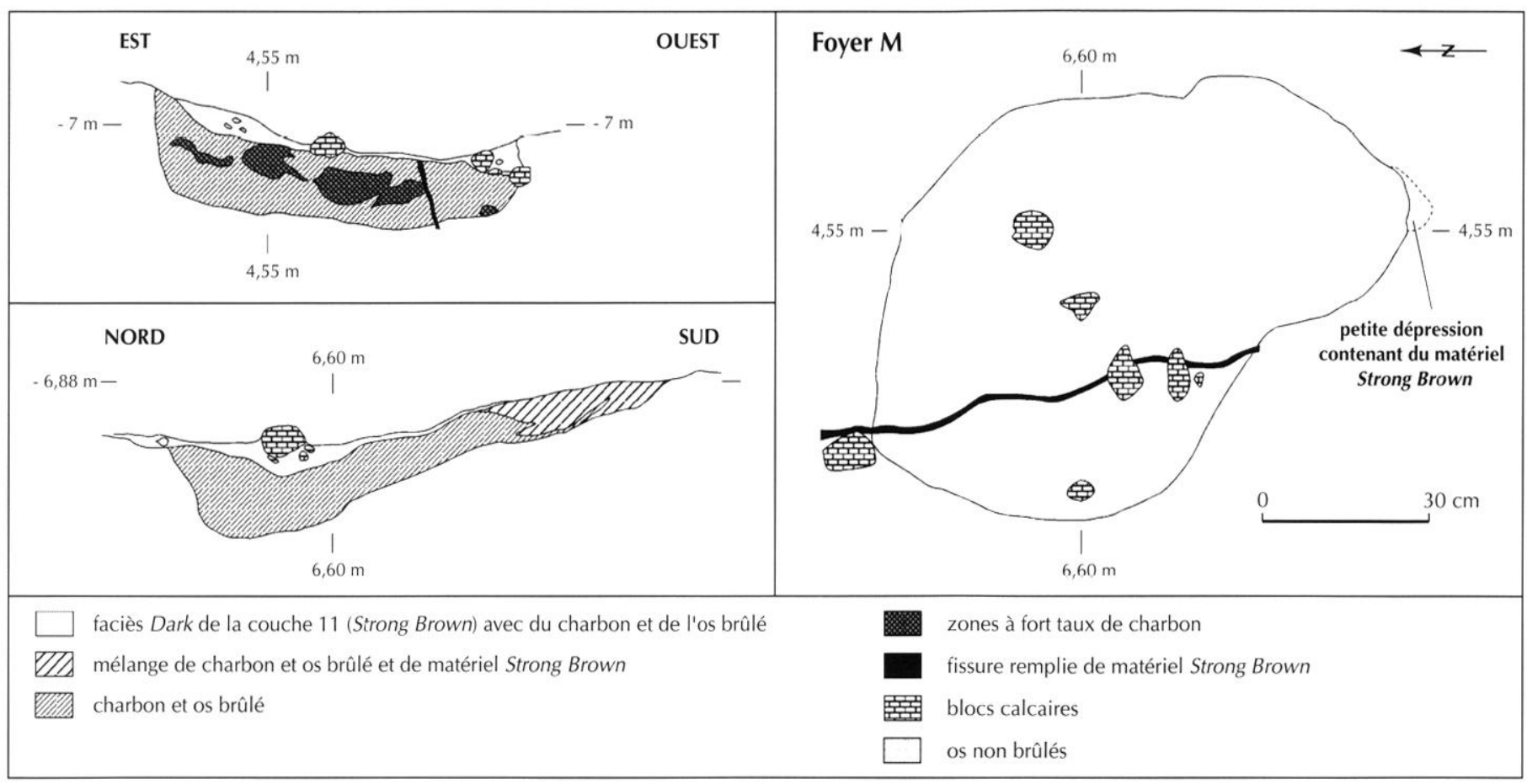

Fig. 9 - Plan et coupes du foyer $M$.

Le foyer $\mathrm{K}$ mesure $55 \mathrm{~cm}$ du nord au sud, $55 \mathrm{~cm}$ d'est en ouest et sa profondeur maximale est de $15 \mathrm{~cm}$. Il est installé dans une cuvette subcirculaire, aux bords inclinés, creusée dans l'éboulis $11 / 12$, atteignant même partiellement la couche 12. La partie nord de la cuvette renferme un matériel très meuble, composé d'os brûlés et de cendres noires avec beaucoup de fines particules d'éboulis sableux. La partie sud contient un sédiment à fort taux de charbon appelé Mixed Strong Brown qui a également été retrouvé hors de la cuvette. Il a livré deux fragments de galets.

Le foyer $\mathrm{L}$ mesure $70 \mathrm{~cm}$ du nord au sud, $70 \mathrm{~cm}$ d'est en ouest et sa profondeur maximale est de $15 \mathrm{~cm}$. C'est une cuvette aux parois inclinées, creusée dans la surface fracturée du rocher. Le bord sud est délimité par un très gros bloc placé verticalement, sur la tranche. Le remplissage, constitué principalement de cendres noires et d'os intensément brûlés, est meuble dans la moitié nord et devient compact dans la moitié sud. Il a livré quatre outils en silex, quelques produits de débitage bruts et un galet.

Le foyer $M$ mesure $90 \mathrm{~cm}$ du nord au sud, $70 \mathrm{~cm}$ d'est en ouest et sa profondeur maximale est de $15 \mathrm{~cm}$. Il est constitué d'une cuvette approximativement circulaire et d'une seconde cuvette adjacente, peu profonde, en forme de demi-cercle (fig. 9). Les parois de ce foyer, creusé dans les niveaux sous-jacents, sont partiellement verticales. Le remplissage est constitué de cendres très meubles contenant une grande quantité d'os brûlés, de petites pierres grises (probablement du calcaire très fortement brûlé) et quelques os non brûlés. Des pièces de silex craquelées par le feu sont également présentes, surtout dans la partie inférieure du foyer, ainsi que deux nucléus, un lissoir en os, une pièce à languette en bois de renne, un débris en bois de cervidé, une lame aurignacienne, des produits de débitage bruts et plusieurs fragments de galets.

Le foyer $\mathrm{N}$ mesure $70 \mathrm{~cm}$ du nord au sud, $60 \mathrm{~cm}$ d'est en ouest et sa profondeur maximale est de $12 \mathrm{~cm}$. Il s'agit d'une cuvette subcirculaire aux parois inclinées, dont le remplissage très meuble comprend trois zones (Upper; Middle et Lower). La zone Upper, constituée de cendres éparses provenant du foyer $\mathrm{M}$, mélangées à de l'éboulis et à du matériel rougeâtre, contient quelques silex brûlés et quelques os. La zone Middle, pierreuse et rougeâtre, constituée d'éboulis et de sable, avec de petits amas de charbon, renferme plusieurs gros silex et des fragments d'os. Ce matériel semble avoir été accumulé postérieurement à l'utilisation du foyer. La couleur rouge est due à la présence de calcaire brûlé, mais également de blocs ocrés. La zone Lower est entièrement composée d'os 


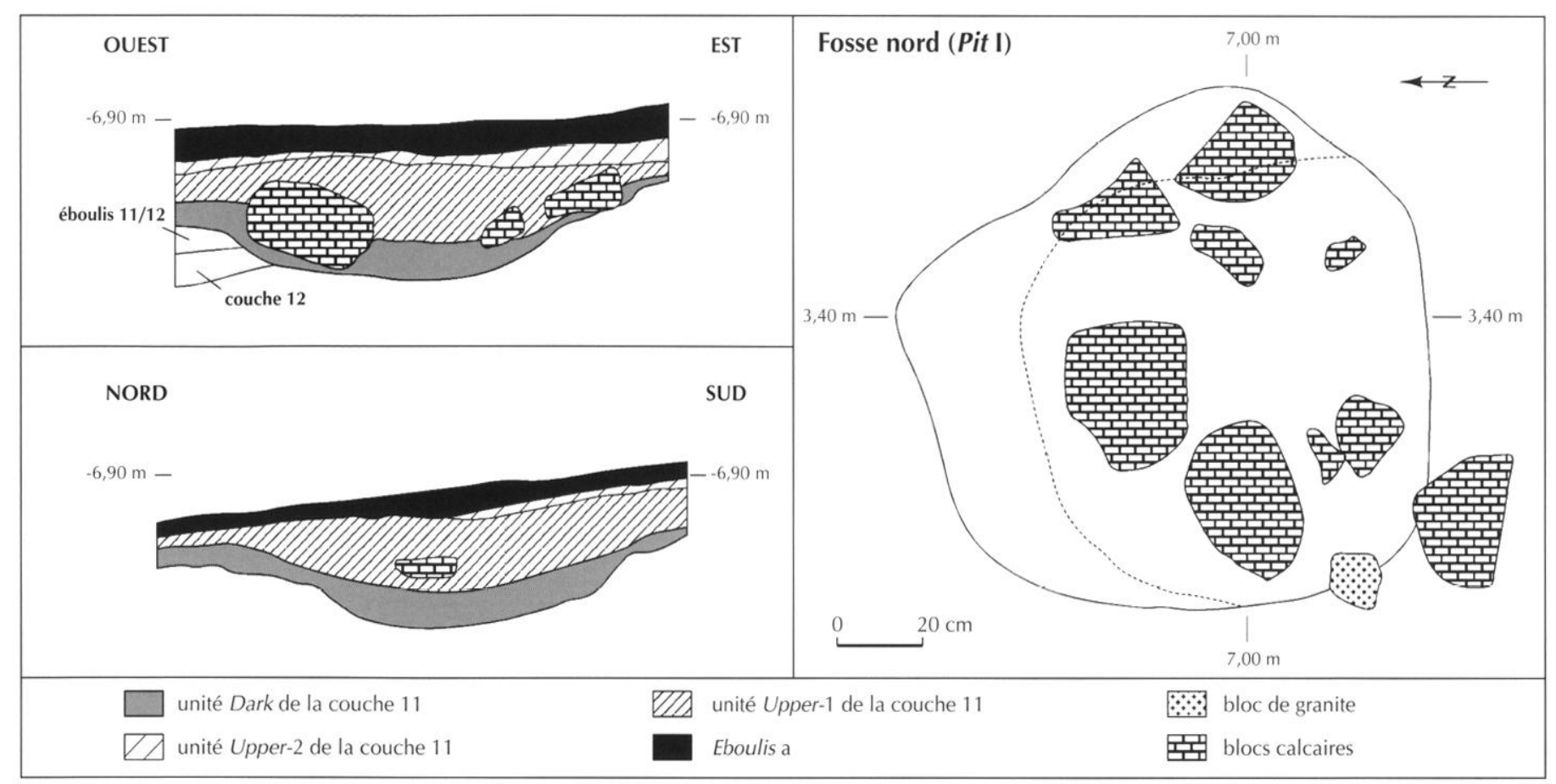

Fig. 10 - Plan et coupes de la fosse nord.

brûlés, de cendres et de très petites inclusions, matériel essentiellement concentré dans la moitié nord de la cuvette. Le calcaire à la base a été coloré par la chaleur.

Le foyer $O$ mesure $65 \mathrm{~cm}$ du nord au sud, $45 \mathrm{~cm}$ d'est en ouest et sa profondeur maximale est de $8 \mathrm{~cm}$. Il est installé dans une dépression naturelle (ou légèrement "grattée ») du rocher. Il consiste essentiellement en une couche noire cendreuse dont le composant majeur est de l'os brûlé. Il n'a livré que quelques produits de débitage bruts. Sur le fond, il y a un sable jaune résultant probablement de la décomposition du calcaire par le feu.

À l'exception de $\mathrm{O}$, l'ensemble des foyers de la couche 11: Dark est placé dans des cuvettes creusées et façonnées dans les dépôts sous-jacents (éboulis $11 / 12$ et couche 12 suivant les cas). Ils sont tous de dimensions assez constantes : entre $55 \mathrm{~cm}$ et $90 \mathrm{~cm}$ de diamètre, pour une profondeur de $15 \mathrm{~cm}$ à $20 \mathrm{~cm}$. Ils ont également comme trait commun de n'avoir pratiquement pas livré de charbons de bois. En revanche, ils contenaient tous une grande quantité d'os brûlés.

\section{LES FOSSES}

Les deux fosses de la couche 11 : Dark (Pits I et II) sont situées immédiatement en avant des foyers (trenches III et IV, squares B et extrémité ouest des squares $\mathrm{C}$ ) (fig. 8).

La fosse nord (Pit I) mesure $1,25 \mathrm{~m}$ du nord au sud, $1,20 \mathrm{~m}$ d'est en ouest et sa profondeur maximale est de $20 \mathrm{~cm}$. Il s'agit d'une fosse subcirculaire dont le bord sud est quasiment vertical, les autres parois étant inclinées (fig. 10). Elle est creusée dans l'éboulis 11/12, excepté dans un faible secteur où elle atteint la couche 12. La fosse n'a été remplie que partiellement lors de l'occupation de l'unité Dark. En effet, la majeure partie du remplissage est constituée de matériel de l'unité Upper. Elle contient beaucoup d'os, des produits de débitage bruts et des outils lithiques, généralement situés près de la base. De gros blocs et dalles de calcaire, qui ne semblent plus être dans leur position d'origine, ainsi qu'un bloc de granite ont été trouvés autour de la dépression.

La fosse sud (Pit II) mesure 2,10 $\mathrm{m}$ du nord au sud, $1,40 \mathrm{~m}$ d'est en ouest et sa profondeur maximale est de $20 \mathrm{~cm}$. Il s'agit d'une cuvette subcirculaire creusée dans l'éboulis 11/12, dont les bords les plus escarpés se situent au sud-ouest. Au sud-est, la dépression se prolonge par une extension peu profonde reposant directement sur la couche 12 (fig. 11). La plus grande partie du matériel est amoncelée contre le bord ouest de la fosse. Dans cette zone, un litage des sédiments est visible. Du sommet à la 


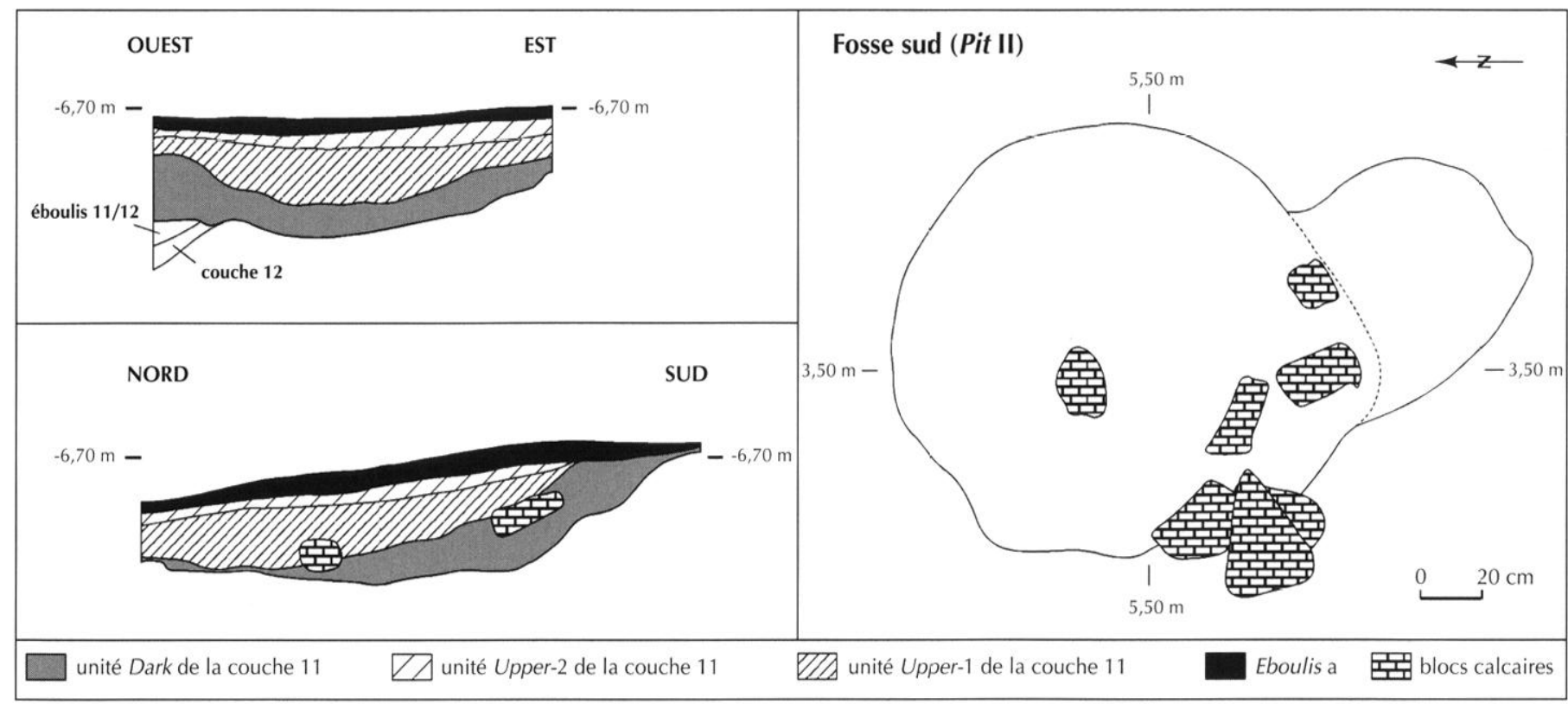

Fig. 11 - Plan et coupes de la fosse sud.

base, les fouilleurs ont $\mathrm{pu}$ distinguer une première dispersion de charbon, un faciès pierreux, une deuxième dispersion de charbon, un faciès sableux brun, une troisième dispersion de charbon et un niveau sableux brun. Ce remplissage est généralement très compact. La fosse a livré six outils osseux, quatre nucléus et trois pièces de parure. Comme dans le cas de la fosse nord, de gros blocs sont associés à cette structure. Ils sont surtout concentrés au sud-ouest.

D'après W. R. Farrand qui a examiné les blocs associés à ces deux structures (Movius, 1977, p. 129), ils sont tous en calcaire local (à l'exception du bloc en granite de la fosse nord). Lorsque les rochers ont été choisis pour être placés autour de ces structures, ils n'étaient pas fraîchement détachés de la falaise. Il s'agissait de blocs exposés à l'érosion subaérienne depuis déjà une longue période. L'un d'eux montre des traces d'altération par le feu.

H. L. Movius n'a pu avancer aucune interprétation pour ces structures qui, selon lui, sont trop petites pour représenter des habitations d'un type connu (Movius, 1977, p. 130). En outre, pour lui, les deux fosses et les sept foyers de l'unité Dark semblent avoir été plus ou moins contemporains, bien que les cendres éparses provenant du foyer $M$ aient été retrouvées recouvrant le foyer $\mathrm{N}$. Ces foyers présentent un arrangement régulier le long de la paroi de l'abri, qui n'est manifestement pas dû au hasard. Il demeure toutefois impossible de donner une explication à cette organisation, d'autant plus, qu'au vu du plan, il semble évident que seule une partie de la couche a été fouillée.

L. C.

\section{COMPORTEMENTS TECHNIQUES}

\section{INDUSTRIE LITHIQUE}

Le matériel lithique de la couche 11 comprend un total de 6759 pièces numérotées parmi lesquelles 1197 sont des outils et 206 des nucléus et des blocs. En plus de ce matériel, nous avons décompté 618 esquilles inférieures au centimètre et 712 débris ( 1330 pièces non numérotées), soit au total 8089 pièces.

\section{TYPOLOGIE}

L'étude typologique du matériel lithique de cette couche (Chiotti, 1999b) révèle des caractères qui en font une industrie de l'Aurignacien ancien en Périgord, encore appelé Aurignacien I.

Parmi l'outillage (tabl. II), les grattoirs (fig. 12) dominent avec un indice IG de 31,35 qui est l'un des plus élevé de l'Aurignacien de l'abri Pataud. Parmi ces grattoirs, les plus fréquents sont ceux sur support 
retouché, puis les grattoirs simples sur extrémité de lame. Les grattoirs aurignaciens (fig. $12, n^{\circ} 6$ ), dont la majeure partie sont des carénés, sont très peu présents (IGA $=3,18)$.

Les burins, avec un indice IB qui ne dépasse pas 1,02, sont rares. Il s'agit de burins assez frustes, généralement sur cassure ou sur pan naturel, ce qui, selon A. S. Brooks (1979), suggère qu'une véritable technologie du burin n'est pas encore développée.

Les pièces à encoches (fig. $13, n^{\circ} 2$ ) sont bien représentées, avec $17,93 \%$ de l'outillage, de même que les pièces retouchées (fig. $13, \mathrm{n}^{\circ} 4$ ), avec un total de $22,13 \%$ (types 65 et 66 de la liste type Sonneville-Bordes et Perrot, 1953).

Cet outillage contient également une grande quantité de pièces à retouches discontinues ou partielles $(18,46 \%$ de la totalité de l'outillage) n'entrant pas dans la liste type. Les pièces esquillées (fig. $13, \mathrm{n}^{\circ \mathrm{*}} 3,5$ ), avec $7,38 \%$, représentent, par ordre d'importance, la quatrième catégorie d'outils.

La couche 11 a livré une quantité relativement importante de petites esquilles dont la fracturation très particulière indique qu'elles proviennent des pièces esquillées, ce qui prouve que ces outils ont été utilisés dans l'abri. L'usage de pièces esquillées atteste qu'un travail de l'os ou du bois végétal était réalisé lors de l'occupation de l'abri (Dewez, 1985 ; Le Brun-Ricalens, 1989).

\section{MATIÈRES PREMIÈRES}

\section{Le silex local}

L'étude des matières premières de cette industrie (Chiotti, 1999b) révèle que les silex utilisés en majorité sont des silex locaux, originaires des calcaires sénoniens, disponibles en grande quantité à proximité du site. Deux sources distinctes ont été exploitées par les hommes préhistoriques.

- Des silex à cortex roulé, récoltés dans les alluvions de la Vézère, immédiatement au pied de l'abri. La gestion de cette matière est la plus simple qui soit : les blocs sont récoltés, parfois sans même être testés, puis débités en totalité dans l'abri. Ce matériau a servi essentiellement à développer des débitages d'éclats et quelques débitages laminaires simples qui n'ont généralement fourni que peu de lames.
Tabl. II - Inventaire typologique de l'industrie lithique de la couche 11.

\begin{tabular}{|c|c|c|c|}
\hline $\mathbf{N}^{\circ}$ & Type (Sonneville-Bordes, Perrot) & $\mathrm{Nb}$ & $\%$ \\
\hline 1 & grattoir sur bout de lame & 58 & 5,94 \\
\hline 2 & grattoir atypique & 11 & 1,13 \\
\hline 3 & grattoir double & 26 & 2,66 \\
\hline 4 & grattoir ogival & 2 & 0,20 \\
\hline 5 & grattoir sur lame ou éclat retouché & 127 & 13,01 \\
\hline 6 & grattoir sur lame aurignacienne & 21 & 2,15 \\
\hline 8 & grattoir sur éclat & 26 & 2,66 \\
\hline 9 & grattoir circulaire & 4 & 0,41 \\
\hline 11 & grattoir caréné & 13 & 1,33 \\
\hline 12 & grattoir caréné atypique & 7 & 0,72 \\
\hline 13 & grattoir épais à museau & 7 & 0,72 \\
\hline 14 & grattoir plat à museau ou à épaulement & 4 & 0,41 \\
\hline 17 & grattoir-burin & 4 & 0,41 \\
\hline 18 & grattoir-lame tronquée & 16 & 1,64 \\
\hline 19 & burin-lame tronquée & 1 & 0,10 \\
\hline 20 & perçoir-lame tronquée & 1 & 0,10 \\
\hline 21 & perçoir-grattoir (+pointe-grattoir) & 5 & 0,51 \\
\hline 23 & perçoir (+ pointe) & 27 & 2,77 \\
\hline 24 & perçoir atypique ou bec & 4 & 0,41 \\
\hline 29 & burin dièdre d'angle & 1 & 0,10 \\
\hline 30 & burin sur cassure ou sur pan naturel & 7 & 0,72 \\
\hline 39 & burin transversal sur encoche & 1 & 0,10 \\
\hline 41 & burin multiple mixte & 1 & 0,10 \\
\hline 60 & pièce à troncature droite & 12 & 1,23 \\
\hline 61 & pièce à troncature oblique & 17 & 1,74 \\
\hline 62 & pièce à troncature concave & 9 & 0,92 \\
\hline 63 & pièce à troncature convexe & 5 & 0,51 \\
\hline 64 & pièce bitronquée & 1 & 0,10 \\
\hline 65 & pièce à retouches continues sur un bord & 156 & 15,98 \\
\hline 66 & pièce à retouches continues sur deux bords & 60 & 6,15 \\
\hline 67 & lame aurignacienne & 14 & 1,43 \\
\hline 73 & pic & 12 & 1,23 \\
\hline 74 & pièce à encoche & 175 & 17,93 \\
\hline 75 & pièce denticulée & 28 & 2,87 \\
\hline 76 & pièce esquillée & 72 & 7,38 \\
\hline 77 & racloir & 8 & 0,82 \\
\hline 89 & lamelle à coche & 3 & 0,31 \\
\hline 92 & divers & 30 & 3,07 \\
\hline \multicolumn{2}{|c|}{ Total liste type } & 976 & 100,00 \\
\hline Hors liste & pièces à retouches discontinues ou partielles & 221 & \\
\hline \multicolumn{2}{|c|}{ Total général } & 1197 & \\
\hline
\end{tabular}

- Des silex à cortex frais récoltés sur les gîtes ou dans les dépôts de pente. La gestion de ces blocs a été différente. Ils n'ont été que très peu utilisés pour la production d'éclats (seulement 5 nucléus). En revanche, ils ont été 

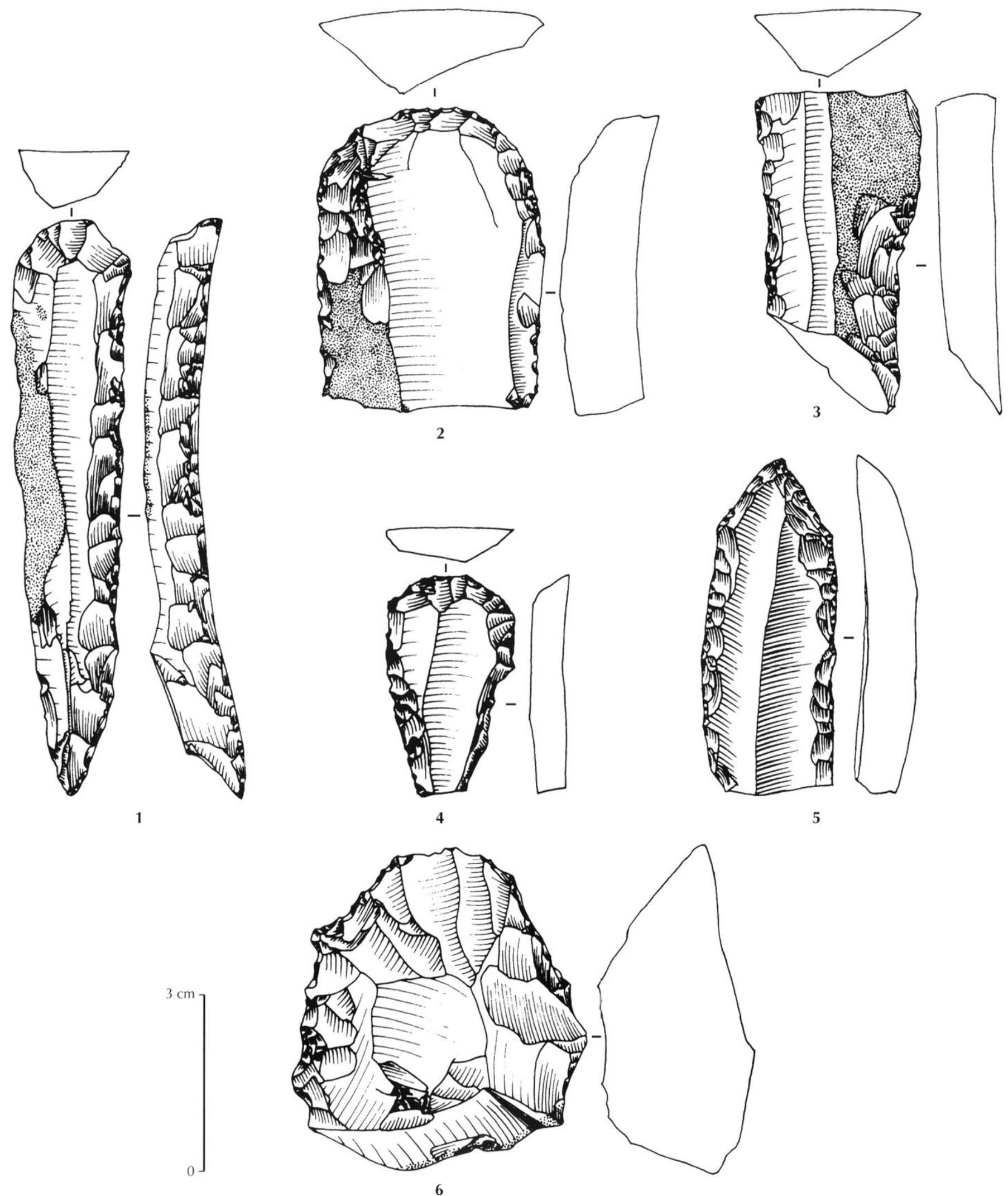

Fig. 12 - Outillage lithique de la couche $11: 1$, grattoir-pointe sur lame aurignacienne; 2 , grattoir sur lame; 3, lame aurignacienne; 4, grattoir sur lame ; 5, pointe sur lame aurignacienne ; 6, grattoir caréné (dessins : 1-4, 6, L. Chiotti ; 5, M. Dauvois). 

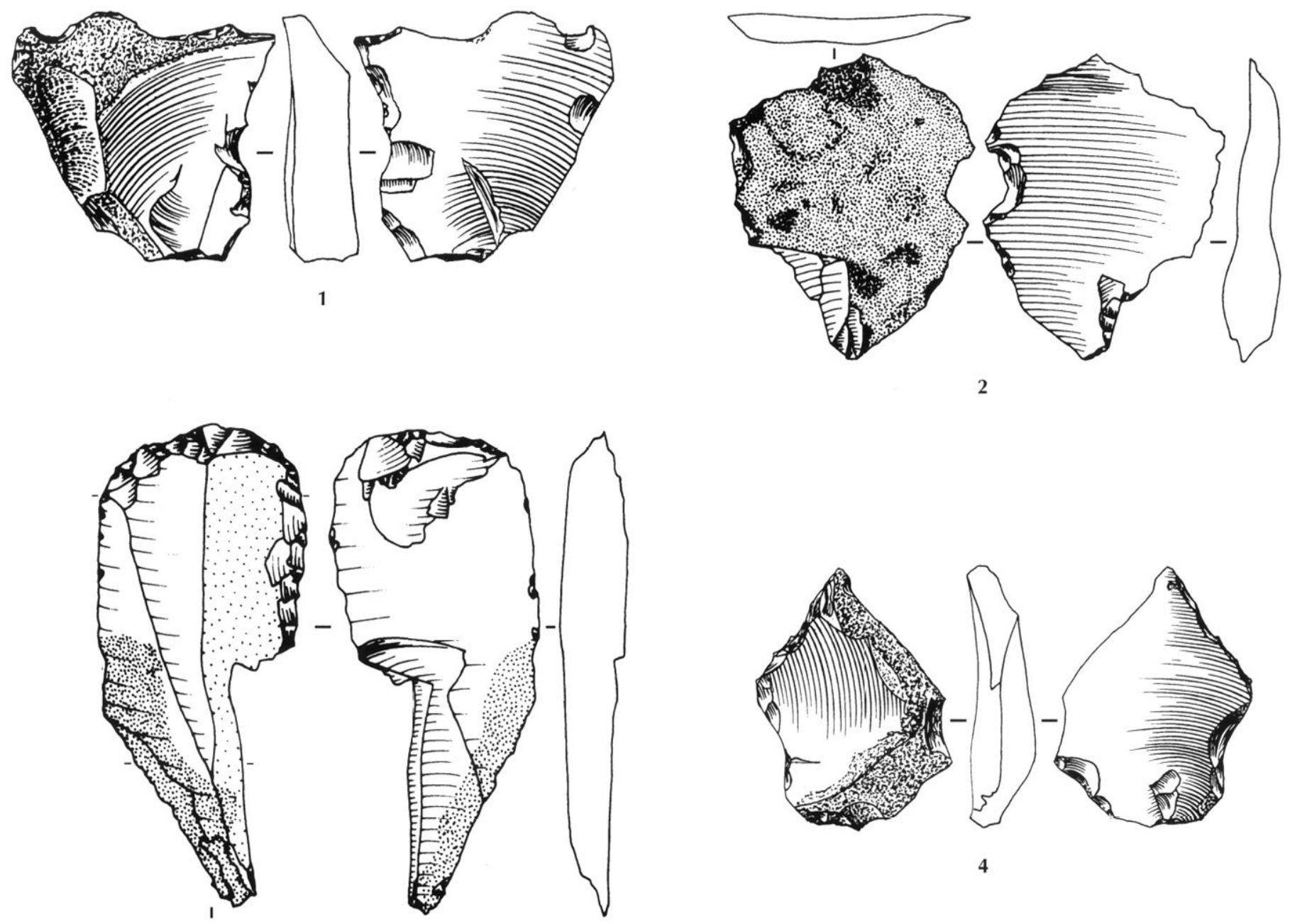

4
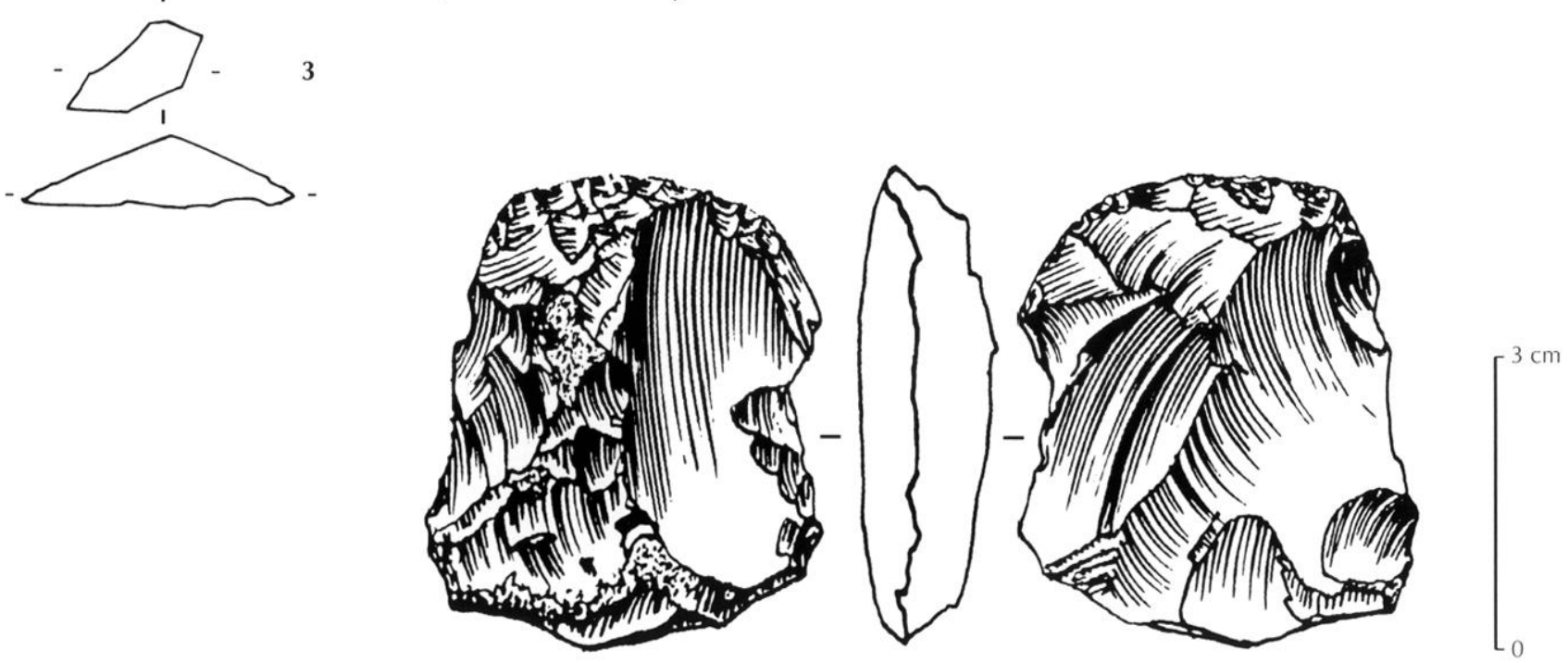

5

Fig. 13 - Outillage lithique de la couche $11: 1$, éclat denticulé ; 2, éclat à encoche ; 3, grattoir réutilisé comme pièce esquillée ; 4, éclat retouché ; 5, pièce esquillée (dessins : 2,3, L. Chiotti ; 1, 4, 5, M. Dauvois). 
fortement utilisés pour la production de lames, mais, la plupart du temps, le débitage de ces lames a été effectué hors du site. Quelle que soit la production, ce matériau a été très peu taillé dans l'abri.

\section{Le silex importé}

Malgré la quantité importante de silex local disponible, le silex importé est très présent dans cette industrie, en particulier le silex provenant de la région de Bergerac à une cinquantaine de kilomètres des Eyzies.

Ce type de silex ne représente que 4,94\% de l'ensemble des produits de débitage, mais, en revanche, il prend une très grande importance dans l'outillage, puisque $21,97 \%$ des supports d'outils sont dans cette matière, ce qui correspond au taux le plus important de tous les niveaux aurignaciens de l'abri Pataud.

La gestion de cette matière est totalement différente. Elle a été très fortement employée pour la production de lames (29,07\% des pièces en Bergeracois sont des lames pour seulement $8,58 \%$ dans le silex local). Deux petits nucléus semblent attester qu'un tel débitage a pu avoir lieu dans l'abri, mais cela reste exceptionnel. En revanche, les éclats, parmi lesquels on ne trouve pas les premiers stades de préparation des blocs, indiquent que les rares blocs introduits étaient déjà fortement préparés. Seule la fin du débitage a alors eu lieu dans l'abri.

Le silex du Bergeracois est essentiellement présent sous forme d'outils (263 pièces sur un total de 496). En regardant dans le détail les outils en silex du Bergeracois, il apparaît qu'il y a un nombre très important de variétés de silex différentes, ce qui n'est absolument pas le cas dans les produits de débitage bruts. Ceci suggère qu'à côté des rares blocs, le silex du Bergeracois a été introduit sous forme de supports déjà débités et, probablement pour la plupart d'entre eux, déjà transformés en outils. Le débitage a alors eu lieu en totalité hors de l'abri.

Il y a très peu de petites esquilles en silex du Bergeracois provenant de la retouche de fabrication des outils. Malgré l'absence de tamisage systématique, cette faible quantité d'esquilles semble bien être une réalité archéologique. Cela indique que la plupart des outils ont été fabriqués hors de l'abri, les quelques esquilles présentes correspondant plutôt à des ravivages.

Les pièces en silex du Bergeracois ont également un taux de fracturation très élevé $(65,94 \%$ contre $39,96 \%$ pour les silex sénoniens). Nous sommes donc en présence de pièces dont l'utilisation a été intense et qui ont été abandonnées en "fin de vie ". Cette matière a également été très fortement employée pour les pièces esquillées (31 pièces sur 76). Le fait que de nombreux outils aient été réutilisés comme pièces esquillées (20 sur les 31 pièces esquillées en silex du Bergeracois) montre également que ce silex importé était utilisé jusqu'à la limite de ses possibilités.

Toutes ces observations indiquent que les pièces en silex du Bergeracois rapportées dans l'abri (blocs, supports ou outils) sont des pièces que les hommes préhistoriques avaient en leur possession lors de leur arrivée. Elles font sans aucun doute partie d'un fonds d'outils et de matière première qu'ils transportaient avec eux lors de leurs déplacements. Les objets réalisés dans cette matière n'ont été abandonnés que lorsqu'ils n'étaient plus utilisables.

Le grand nombre de variétés de silex du Bergeracois est un élément en faveur de l'hétérogénéité de cet assemblage. C'est-à-dire qu'il semble indiquer que l'assemblage a été constitué par une série de passages courts et successifs dans l'abri plutôt que lors d'une seule occupation de plus longue durée.

\section{TeChNOLOGIE}

La production lithique de la couche 11 est assez peu laminaire avec seulement 9,82\% de lames dans l'ensemble de la production, l'essentiel du matériel étant constitué d'éclats $(87,66 \%)$.

Les éclats ne correspondent pas uniquement aux déchets produits par les phases de préparation de la production laminaire. Les nucléus attestent une production volontaire d'éclats, qu'il s'agisse de vrais nucléus à éclats: 4 nucléus globuleux (fig. $15, n^{\circ} 2$ ), 5 nucléus discoïdes (fig. 14, $\mathrm{n}^{\circ}$ 1) et 2 nucléus Levallois (fig. 15, $\mathrm{n}^{\circ} 1$ ), ou de nucléus informes (14 nucléus) qui ont donné des éclats au moins "en fin de vie ». Cinquante autres nucléus ont été identifiés comme étant des nucléus à tendance prismatique (fig. $14, \mathrm{n}^{\circ} 2$ ), c'est-à-dire des nucléus dont l'organisation est prismatique, mais qui, dans leur état d'abandon, semblent n'avoir donné que des éclats laminaires (certains ont cependant pu donner des lames lors de phases de débitage précédentes).

La production de lames sur le site est attestée par la présence de nucléus prismatiques (fig. 14, n 3 ). Ceux-ci, 

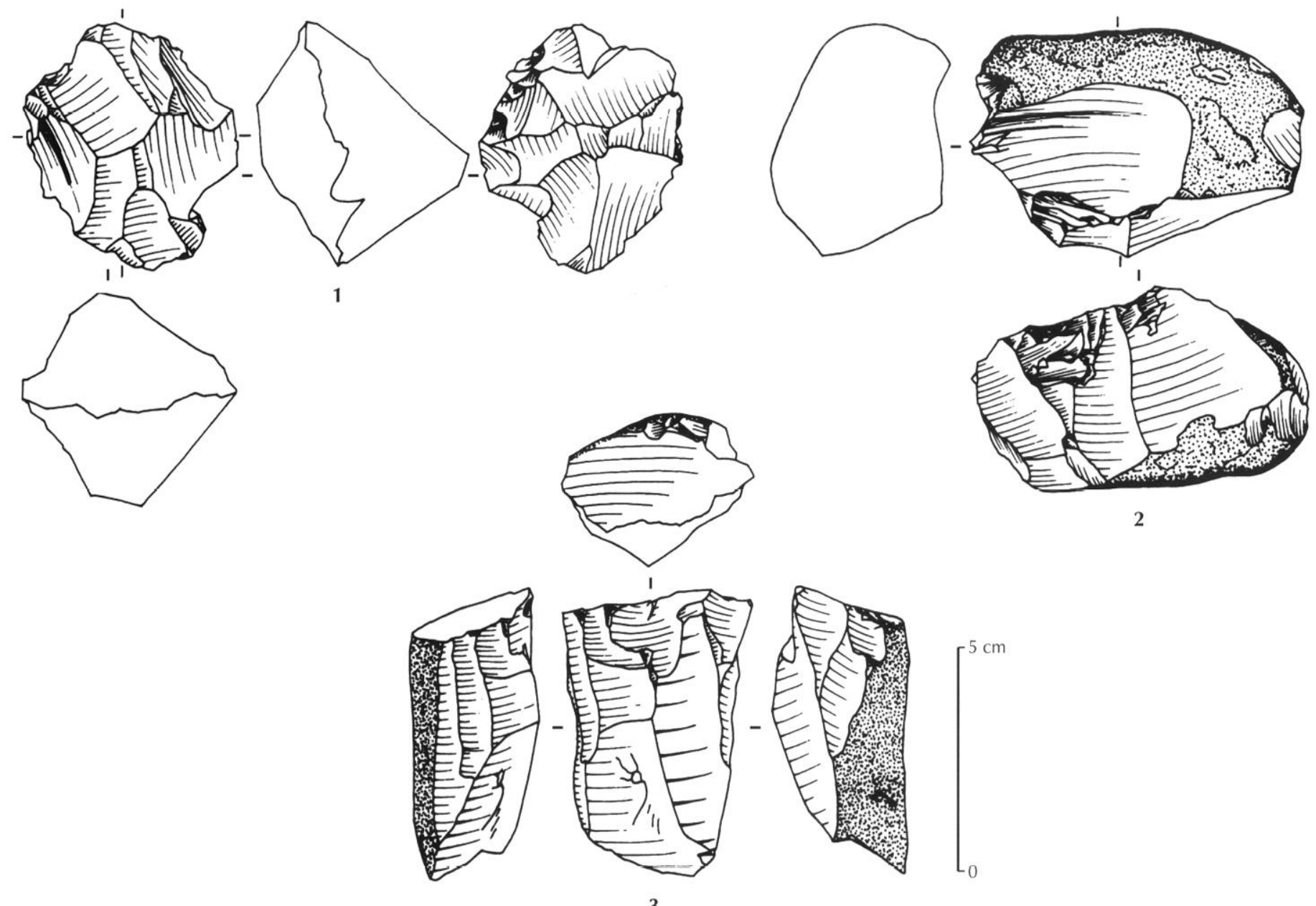

Fig. 14 - Nucléus de la couche 11 : 1, nucléus discoïde; 2, nucléus "à tendance prismatique "; 3, nucléus prismatique (dessins L. Chiotti).
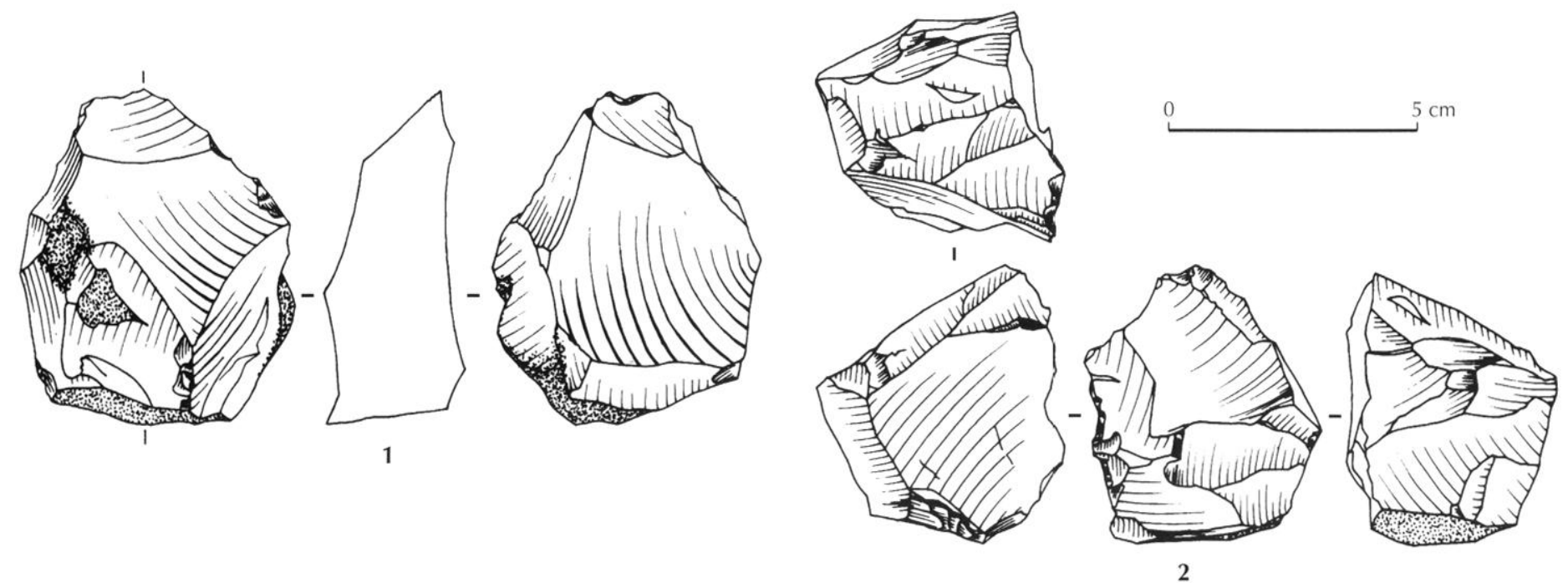

Fig. 15 - Nucléus de la couche 11:1, nucléus Levallois; 2, nucléus globuleux (dessins L. Chiotti). 


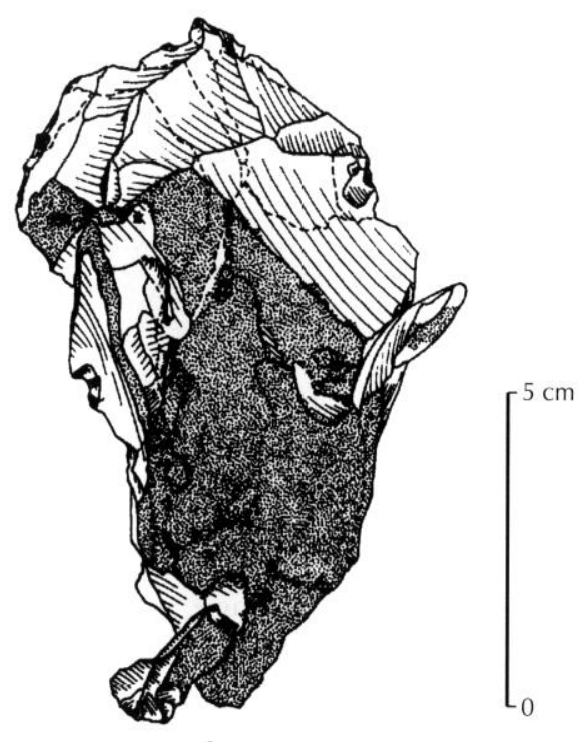

a

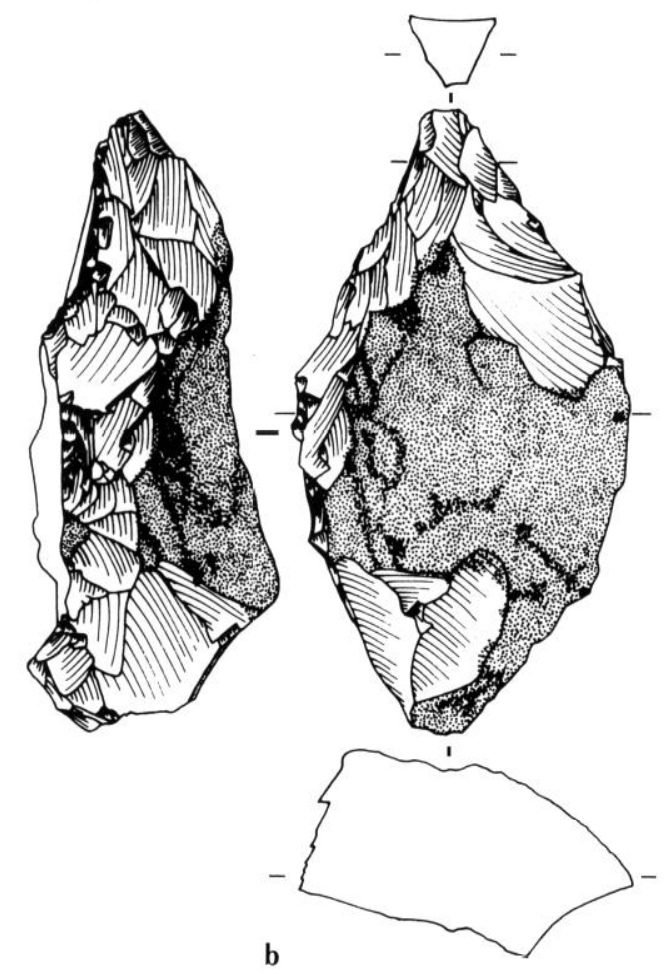

très peu nombreux (seulement 6 ), ne peuvent en aucun cas être à l'origine de l'ensemble de la production laminaire. Il est évident qu'une partie importante des lames retrouvées dans la couche 11 n'a pas été produite sur le site.

Cela est confirmé par l'état des surfaces corticales présentes sur les pièces. Six nucléus prismatiques sur sept portent un cortex fluviatile. Ces proportions sont similaires pour les éclats dont $75,25 \%$ portent un cortex

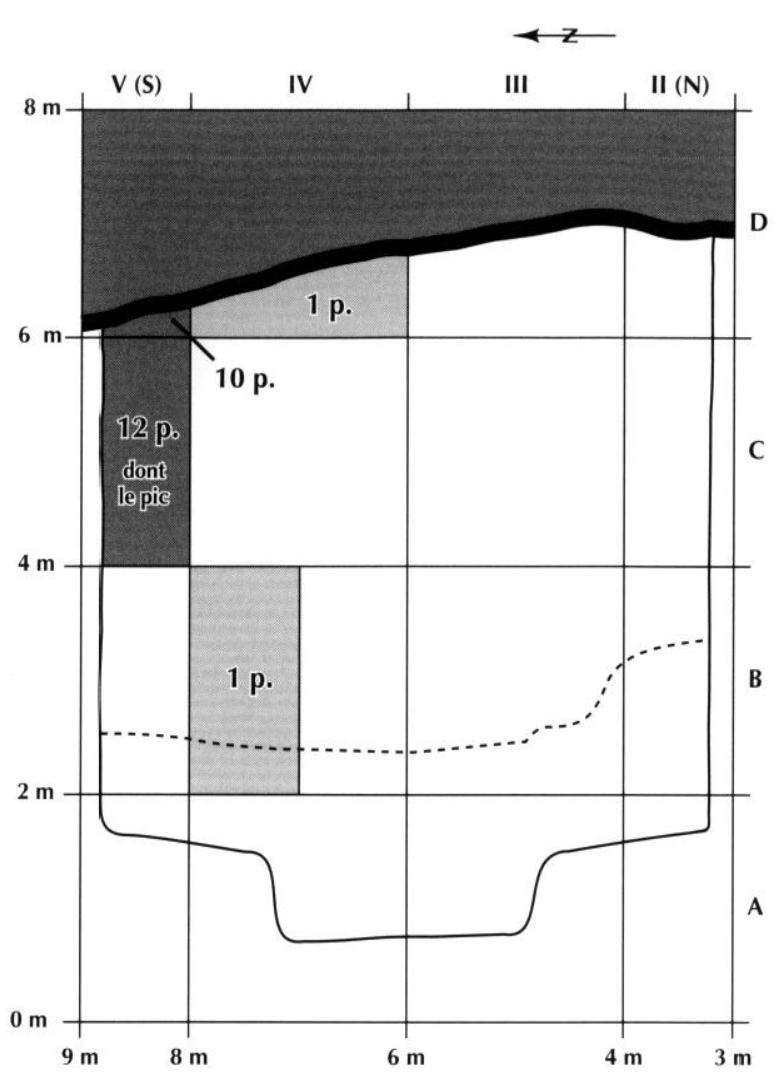

C

Fig. 16 - Remontage d'un pic (a), pic (b), et plan de répartition des pièces du remontage (c) (dessins L. Chiotti).

fluviatile et seulement $18,37 \%$ un cortex frais. En revanche, elles sont totalement différentes pour la production laminaire dont seulement $43,17 \%$ porte un cortex fluviatile et $48,02 \%$ un cortex frais. Une grosse partie des lames réalisées dans une matière récoltée directement sur les gîtes de silex n'a donc pas été produite dans l'abri, mais a été importée déjà débitée.

La production laminaire a été fortement utilisée pour la réalisation de l'outillage puisque l'indice laminaire de 
l'outillage (ILO), défini par P.-Y. Demars (1989), atteint 56,32. Il faut cependant souligner que cet II.O reste très faible pour une industrie de l'Aurignacien ancien dans laquelle il se situe généralement autour de 70 (Demars, 1998).

Les lamelles ne représentent que 2,52\% de la production totale. Elles ont été produites essentiellement à partir de grattoirs carénés (voir Chiotti, ce volume, p. 113-156). Il y a également quelques lamelles issues de nucléus prismatiques et quelques lamelles opportunistes. Toutes ces lamelles (ce qui ne représente que 209 pièces) semblent avoir été produites sur le site, mis à part peutêtre les 14 lamelles en silex du Bergeracois. Ces pièces ont été très peu utilisées comme support de l'outillage avec sculement 7 outils sur lamelles.

En conclusion, il apparaît que seule une partie du matériel de la couche 11 a été fabriquée dans l'abri : les éclats, probablement les lamelles et seulement une partie des lames. Il s'agit essentiellement de pièces fabriquées à partir de la matière première la plus proche : les galets de silex de la Vérère.

La couche 11 a également fait l'objet d'un remontage (Chiotti, 1999a) qui concerne la fabrication d'un pic aurignacien (fig. 16) : grosse pointe massive en silex sénonien portant des traces d'utilisation en percussion.

L'ensemble des pièces constituant ce remontage (le pic et les déchets de taille) a été retrouvé dans la partie la plus profonde de l'abri, à l'extrémité nord de la fouille, sur une surface n'excédant pas $3 \mathrm{~m}^{2}$ (fig. 16). Ce secteur, du fond de l'abri, qui ne contenait que relativement peu de pièces, ne semble pas correspondre à un atelier de taille. Cet outil a probablement été produit pour un usage immédiat dans ce même secteur.

L. C.

\section{INDUSTRIE OSSEUSE}

Nous avons dénombré 91 pièces d'industrie osseuse en bois de cervidé, os et ivoire. Il s'agit d'un équipement fabriqué en grande partie sur place et qui reflète aussi bien des activités cynégétiques que domestiques.

Cet outillage est varié et semble typique de l'Aurignacien ancien, tant par la nature des pièces présentes (sagaies à base fendue, pièces à languette, bâtonnets, lissoirs, poinçons, objets incisés) que par leur

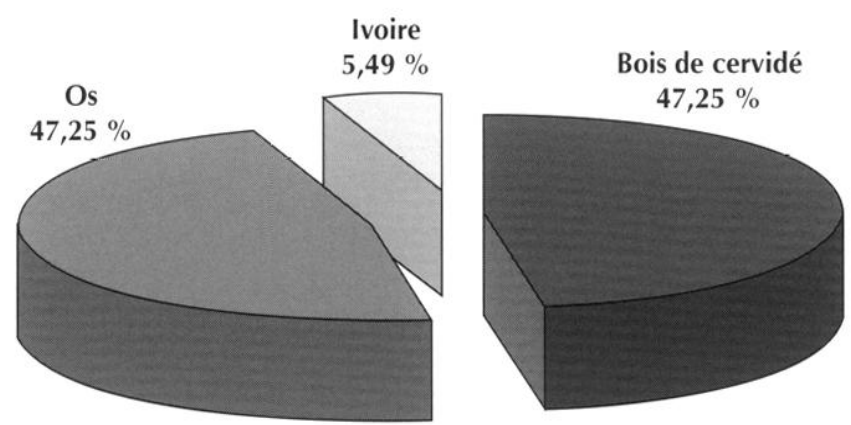

Fig. 17 - Matières premières utilisées pour la confection de lindustrie osseuse.

mode de fabrication (débitage par fracturation, technique d'incision transversale suivie de flexion présente à tous les stades de la chaîne opératoire, pas ou très peu de finition).

\section{MATIÈRES PREMIÈRES}

Trois types de matériaux ont été travaillés : le bois de cervidé, l'os, et l'ivoire.

Les 91 pièces d'industrie osseuse du niveau 11 sc répartissent équitablement entre les deux matériaux les plus utilisés qui sont le bois de cervidé et l'os (représenté chacun par 47,25\% des pièces). Quant à l'ivoire, il est très peu représenté au sein de cette industrie $(5,49 \%$ des pièces ; fig. 17). Les modes d'acquisition de ces matières premières peuvent-ils expliquer une telle disproportion entre bois de cervidé ou os et ivoire ?' C'est ce à quoi nous allons tenter de répondre.

\section{Bois de cervidé}

Nous avons scindé le groupe des pièces en bois animal en deux selon la détermination plus ou moins précise de la matière première employée pour leur fabrication. Pour les pièces de petites dimensions et/ou entièrement façonnées, la détermination s'arrête au stade de bois de cervidé (34,88\% des pièces en bois animal). Mais la majorité des objets $(65,12 \%$ des pièces en bois animal) a été rattachée au bois de renne (Rangifer tarandus).

Les 28 pièces d'industrie osseuse en bois de renne correspondent à de petits morceaux de bois de femelles et de jeunes. Nous n'avons retrouvé aucune base de bois dans notre matériel, il est donc impossible de savoir si les Préhistoriques utilisaient des bois de chute et/ou des bois de massacre. 
Tabl. III - Détermination spécifique des supports de liindustrie en os.

\begin{tabular}{|c|c|c|c|}
\hline Espèce & Élément anatomique & NR & Outil \\
\hline \multirow{5}{*}{ Equus caballus (12) } & humérus & 2 & \multirow{5}{*}{ retouchoir } \\
\hline & radius & 2 & \\
\hline & ulna & 1 & \\
\hline & tibia & 2 & \\
\hline & métapodien III & 5 & \\
\hline Rangifer tarandus (1) & humérus & 1 & retouchoir \\
\hline Bison priscus (1) & métapodien III+IV & 1 & retouchoir \\
\hline Boviné ? (2) & côte & 2 & pointe ( 1 entière +1 extrémité distale) \\
\hline \multirow{3}{*}{ Animal de grande taille (6) } & \multirow{2}{*}{ os long indéterminé } & 1 & retouchoir \\
\hline & & 1 & poinçon \\
\hline & côte & 2 & lissoir (fragments) \\
\hline \multirow{3}{*}{ Animal de taille moyenne (9) } & \multirow{2}{*}{ côte } & 2 & poinçon \\
\hline & & 5 & lissoir \\
\hline & os long indéterminé & 2 & poinçon \\
\hline \multirow{4}{*}{ Indéterminée (14) } & \multirow{4}{*}{ os compact } & 1 & poinçon \\
\hline & & 1 & épingle \\
\hline & & 5 & fragment de bâtonnet appointé \\
\hline & & 7 & débris \\
\hline Total & & 43 & \\
\hline
\end{tabular}

D'après l'étude faunique (cf. p. 195), les Aurignaciens chassaient, en période hivernale, des hardes de rennes composées de femelles et de jeunes. Ils ont donc probablement utilisé les bois portés par les animaux abattus.

\section{Os}

En croisant la détermination spécifique des os ayant servi à la confection des pièces d'industrie osseuse (Cheval, Renne, Bison ; tabl. III) avec le spectre faunique de l'étude archéozoologique (tabl. I), il apparaît que les espèces chassées dans un but alimentaire sont les mêmes que celles ayant fourni la matière première de l'industrie en os. En outre, l'analyse du traitement des rennes et des chevaux (cf. p. 196, 198) nous informe que leurs os longs ont été fracturés pour permettre la récupération de la moelle. Les esquilles alors obtenues pourraient donc avoir servi de supports pour la confection de l'équipement en os.

\section{Ivoire}

Les pièces en ivoire sont très peu nombreuses. La zone fouillée ne renfermait aucun ossement de mammouth (Mammuthus primigenius), les 9 restes attribués à cet animal (4 éléments de parure et 5 pièces d'industrie osseuse) sont exclusivement des fragments d'ivoire. Ce matériau proviendrait de collecte sur une carcasse ou plus probablement de prélèvement dans un gîte d'ivoire subfossile.

Ainsi, le net écart entre le nombre des objets en bois de cervidé ou en os et le nombre de pièces en ivoire serait le reflet de deux modes d'acquisition différents. En effet, pour l'acquisition du bois de cervidé et de l'os, les Aurignaciens auraient adopté une méthode opportuniste en récupérant la matière première parmi les restes des animaux abattus et traités dans un but alimentaire. D'où, une ressource de matière relativement importante (surtout pour les os) et dont l'acquisition ne demande aucun effort ; alors que l'ivoire se présente comme un matériau rare, d'acquisition sans doute difficile, et qui est recherché à des fins techniques.

\section{RÉSIDUS DE DÉBITAGE (NR : 10)}

Il s'agit de morceaux de bois de renne de dimensions diverses, qui présentent des traces de débitage mais aucun stigmate de façonnage.

La présence de telles pièces au sein de la couche 11 nous informe qu'au moins une partie du débitage du bois de renne avait lieu dans l'abri. 
Tabl. IV - Inventaire des pièces d'industrie osseuse.

\begin{tabular}{|c|c|c|c|c|c|c|c|c|}
\hline \multirow{3}{*}{ Catégorie } & \multicolumn{6}{|c|}{ Matières premières } & \multirow{3}{*}{ Total } & \multirow{3}{*}{$\%$} \\
\hline & \multirow{2}{*}{ Ivoire } & \multicolumn{3}{|c|}{ Os } & \multicolumn{2}{|c|}{ Bois de } & & \\
\hline & & long & côte & compacta & Cervidé & Renne & & \\
\hline fragment incisé & & & & & 1 & 1 & 2 & 2,20 \\
\hline baguette & 4 & & & & & & 4 & 4,40 \\
\hline sagaie à base fendue & & & & & 1 & 1 & 2 & 2,20 \\
\hline partie mésiale de sagaie & & & & & & 5 & 5 & 5,49 \\
\hline partie distale de sagaie & & & & & 3 & & 3 & 3,30 \\
\hline pièce à languette & & & & & & 5 & 5 & 5,49 \\
\hline pointe & & & 2 & & & & 2 & 2,20 \\
\hline pointe à base sciée & & & & & 4 & 1 & 5 & 5,49 \\
\hline poinçon & & 3 & 2 & 1 & & & 6 & 6,59 \\
\hline épingle & & & & 1 & & & 1 & 1,10 \\
\hline fragment de bâtonnet appointé & & & & 5 & & & 5 & 5,49 \\
\hline lissoir & & & 7 & & & & 7 & 7,69 \\
\hline objet à extrémité biseauté et polie & & & & & & 5 & 5 & 5,49 \\
\hline retouchoir & & 15 & & & & & 15 & 16,48 \\
\hline résidu de débitage & & & & & & 10 & 10 & 10,99 \\
\hline débris & 1 & & & 7 & 6 & & 14 & 15,38 \\
\hline Sous-Total & 5 & 18 & 11 & 14 & 15 & 28 & 91 & \\
\hline$\%$ & 5,49 & 19,78 & 12,09 & 15,38 & 16,48 & 30,77 & & \\
\hline Total & 5 & & 43 & & 43 & & 91 & \\
\hline$\%$ & 5,49 & & 47,25 & & & & & \\
\hline
\end{tabular}

\section{EQUIPEMENT}

Nous présentons ci-dessous la description morphotypologique de chaque catégorie de pièces (tabl. IV) en proposant des hypothèses de leur utilisation. En outre, nous avons classé ces objets selon leur matière première afin de déceler toute différence typologique ou fonctionnelle qui pourrait exister entre outils en bois de cervidé, os, et ivoire.

\section{Équipement en bois de cervidé}

\section{Fragments incisés ( $n r: 2)$}

Il s'agit de pièces de petites dimensions $(34,5 \mathrm{~mm}$ x 15,5 mm x $7 \mathrm{~mm} ; 35 \mathrm{~mm} \times 6 \mathrm{~mm} \times 4 \mathrm{~mm}$ ) en bois de cervidé, qui portent pour seules marques anthropiques de fines incisions courtes et obliques. Ces dernières n'affectent en rien la forme générale des pièces, qui ne sont pas façonnées.

Les incisions pratiquées sur ces morceaux de bois de cervidé brut ne sont pas nombreuses (de 2 à 6 , groupées par 2) et sont peu marquées. Aussi, elles ne semblent pas correspondre à un décor, et nous émettons l'hypothèse qu'elles pourraient être les stigmates résultant du test du tranchant d'un outil en silex sur un déchet de bois de cervidé.

\section{Sagaies à base fendue ( $n r: 2)$}

Il s'agit " d'objets allongés à partie distale pénétrante (pointue, mousse, tranchante), à fût lisse, de section souvent à tendance aplatie, à partie proximale aménagée en fente dont le plan de symétrie est parallèle au plan d'aplatissement (ou à la face spongieuse) " (Hahn, 1988).

Les pièces de l'abri Pataud (fig. 18) correspondent à : - une sagaie à base fendue en bois de cervidé (compacta uniquement), entière, à partie distale tranchante, de section subrectangulaire, et qui paraît entièrement façonnée ; cependant, cette sagaie, du fait de ses très petites dimensions ( $28 \mathrm{~mm} \times 5 \mathrm{~mm} \times 4 \mathrm{~mm}$ ), semble difficilement utilisable en tant que pointe de projectile ; - une partie mésio-proximale de sagaie à base fendue en bois de renne, de section subrectangulaire, et dont les dimensions $(76 \mathrm{~mm} \times 16,5 \mathrm{~mm} \times 7 \mathrm{~mm}$; indice 


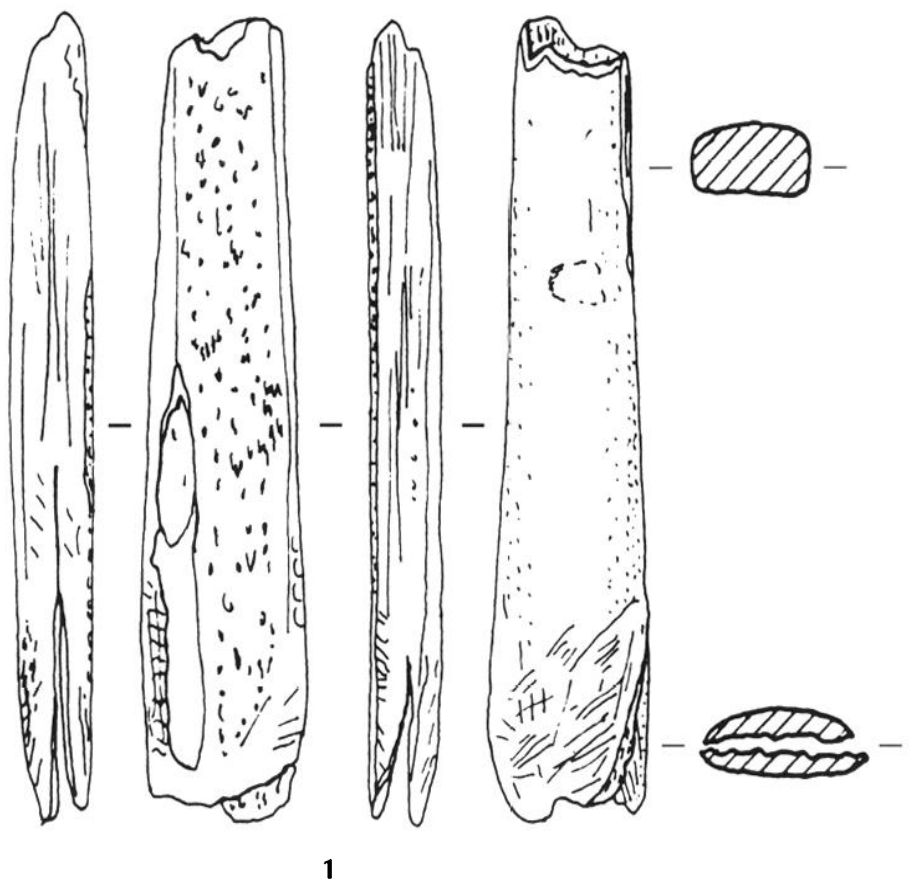

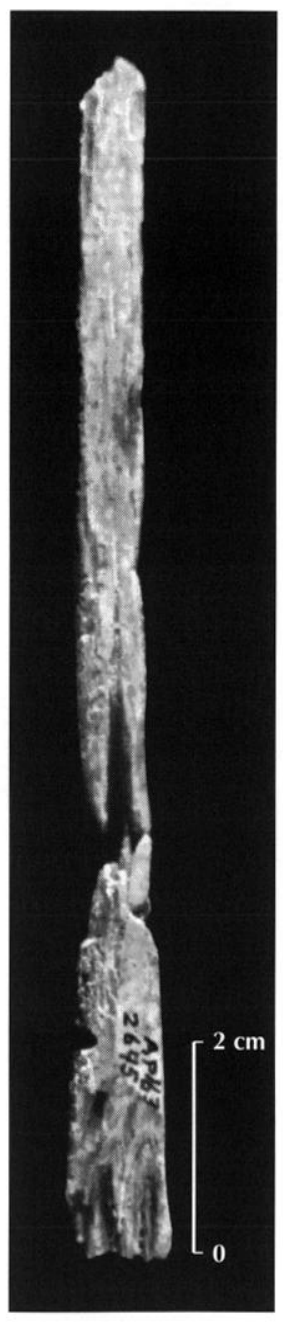

3

Fig. 18 - Industrie osseuse de la couche 11 : 1, 2, sagaies à base fendue (dessins S. (rregoriani) ; 3, sagaie à base fendue et pièce à languette raccordées (photo L. (hiotti).

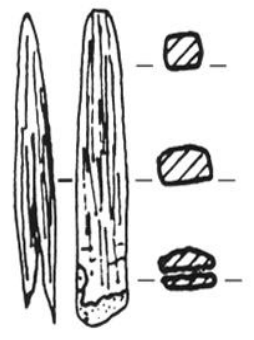

2

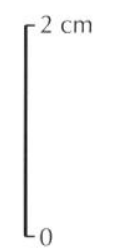

d'aplatissement : 2,36) s'insèrent parfaitement dans la variabilité morphologique des sagaies à base fendue aurignaciennes (Hahn, 1988, p. 11 ; Knecht, 1991b, p. 134).

Le choix du matériau est ici lié à ses propriétés physiques (facile à travailler et plus résistant à la fracturation que l'os). Le bois de renne est idéal pour la confection de pointes de sagaie car il leur confère un indice d'utilité (rapport entre la distance de pénétration de la pointe dans la proie et le nombre de réutilisations possibles de cette même pointe) bien supérieur à celui des pointes de projectile en os (Guthrie, 1983).

\section{Parties mésiales de sagaies ( $n r: 5)$}

Il s'agit de baguettes allongées en bois de renne, entièrement façonnées (à l'exception d'une pièce), de section ovale à subovale plus ou moins aplatie, à bords réguliers et convergents vers l'extrémité distale, avec un plan de symétrie parallèle au plan d'aplatissement de la pièce.

Cette définition nous a conduite à classer ces pièces comme des parties mésiales de sagaies.

Cette catégorie regroupe des sagaies à différents stades d'aménagement : 1 pièce en cours de fabrication (fig. 19, $\mathrm{n}^{\circ}$ 1), 3 pièces entièrement façonnées (fig. 19, $n^{\circ} 2,4,5$ ), et 1 pièce dont l'extrémité distale est en cours de réaménagement (fig. $19, \mathrm{n}^{\circ} 3$ : incision transversale à l'extrémité distale de la face supérieure).

Cependant, la morphologie et le module sont les mêmes pour chacune de ces portions de sagaies dont la largeur et l'épaisseur varient peu (tabl. V), ce qui rend cette catégorie homogène.

La matière première, la spongiosa qui subsiste au niveau de la face inférieure, la section aplatie, et les 


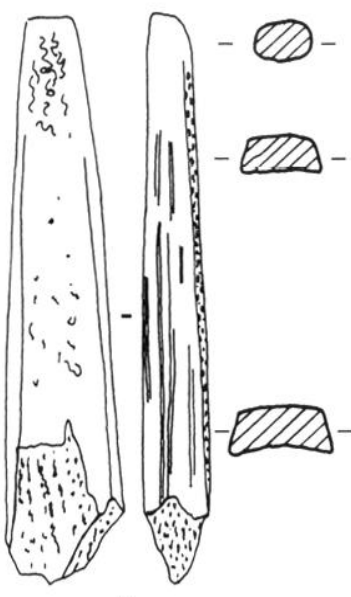

1

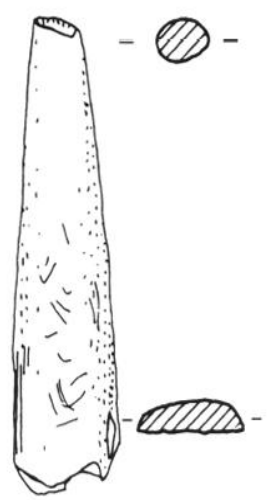

4
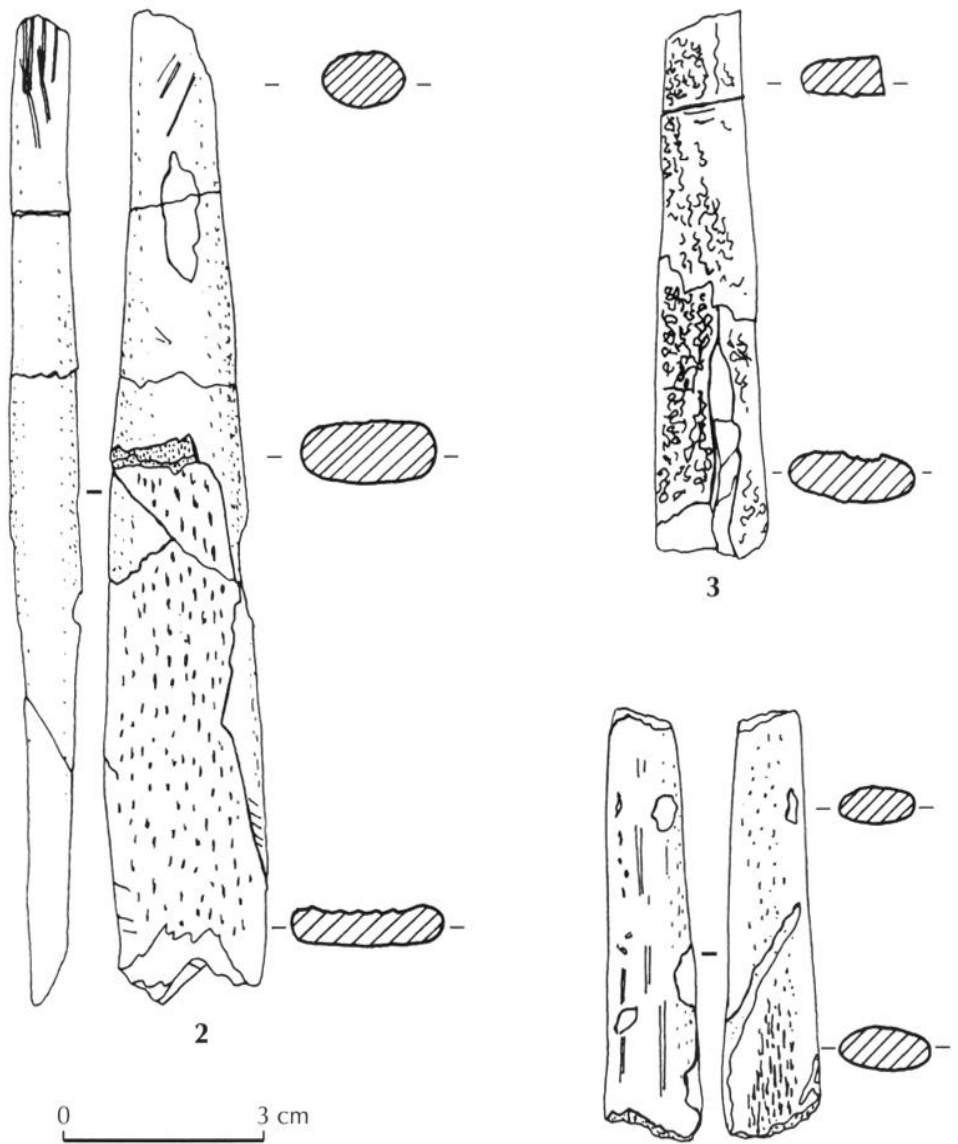

Fig. 19 - Industrie osseuse de la couche 11 : parties mésiales de sagaies (dessins S. Cregoriani).

dimensions de ces pièces sont autant de critères qui rappellent les caractéristiques des sagaies à base fendue (Hahn, 1988 ; Knecht, 1991b ; Liolios, 1999). En outre, nous verrons ultérieurement (cf. p. 186) que les traces de façonnage de ces pièces sont identiques à celles de ces mêmes sagaies. Mais, en l'absence des extrémités proximales de ces pièces, nous ne pouvons qu'émettre l'hypothèse qu'il s'agit de portions de sagaies à base fendue.

\section{Parties distales de sagaies $(n r: 3)$}

Il s'agit de baguettes en bois de cervidé (compacta uniquement), entièrement façonnées, à section ronde ou elliptique, fût lisse, extrémité distale appointée, et présentant une cassure ancienne aux deux extrémités (fig. 20, $\mathrm{n}^{\mathrm{os}} 1-3$ ).

La matière première, la morphologie et les dimensions réduites de ces pièces $(15 \mathrm{~mm} \times 5 \mathrm{~mm} \times 4 \mathrm{~mm}$; $37 \mathrm{~mm} \times 17 \mathrm{~mm} \times 16 \mathrm{~mm} ; 47 \mathrm{~mm} \times 7 \mathrm{~mm} \times 6 \mathrm{~mm}$ ) nous ont conduite à les rapprocher de parties distales de
Tabl. V - Dimensions des parties mésiales de sagaies.

\begin{tabular}{|l|c|c|c|c|}
\hline \multicolumn{1}{|c|}{$\mathbf{N}^{\circ}$} & $\mathbf{L}(\mathbf{m m})$ & $\mathbf{I}(\mathbf{m m})$ & é $^{(\mathbf{m m})}$ & Indice d'aplatissement \\
\hline 2599 & 82,5 & 17 & 9 & 1,89 \\
\hline 2967 & 67,5 & 16 & 8 & 2 \\
\hline $3189+3218$ & 142 & 23 & 9 & 2,56 \\
\hline Ext-5287 & 77 & 19 & 7 & 2,71 \\
\hline Ext-5434 & 62 & 15 & 6 & 2,5 \\
\hline
\end{tabular}

sagaies d'un module différent de celui des parties mésiales de sagaies.

L'une de ces pièces porte 7 incisions courtes, profondes et transversales. Six d'entre elles sont groupées par deux et disposées en alternance sur la longueur du fût, la septième incision se situe au niveau de la cassure de la partie proximale de la pièce (fig. 20, $\mathrm{n}^{\circ} 1$ ). Les objets incisés ne sont pas rares à l'Aurignacien (Knecht, 1993a, p. 139). Cependant, les incisions ont été pratiquées ici sur la partie distale d'une sagaie, ce qui 


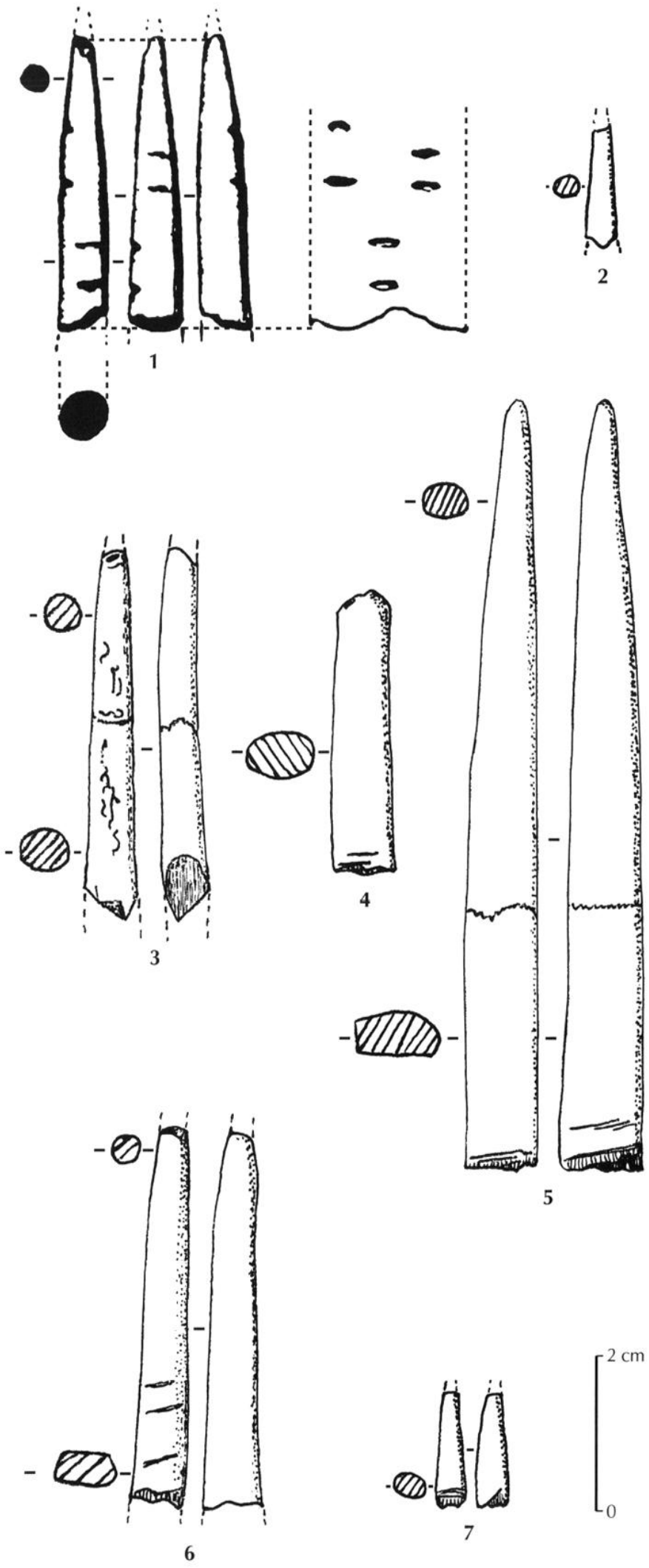

Fig. 20 - Industrie osseuse de la couche 11:1-3, parties distales de sagaies; 4-7, pointes à base sciée (dessins : 1, P. Laurent; 2-7, C. Vercoutère). entraîne la question de leur interprétation : simple décor ou incisions avec une utilité fonctionnelle?

\section{Pièces à languette (nr:5)}

Il s'agit de larges baguettes à bords parallèles en bois de renne. La partie proximale de la pièce est brute, tandis que la partie distale correspond à une languette de compacta, d'aspect rugueux. Ces deux parties sont séparées par des incisions transversales qui affectent toute la largeur de la pièce sur ses deux faces (fig. 21).

Une de ces pièces à languette présente une extrémité proximale amincie, de forme arrondie et d'aspect poli pouvant témoigner d'une utilisation secondaire de cet objet (fig. 21, $\mathrm{n}^{\circ} 1$ ).

La nature précise de ces pièces, résidu de façonnage de la base des sagaies à base fendue (Peyrony, 1928) ou résidu de débitage des clavettes servant à l'emmanchement de ces mêmes sagaies (Knecht, 1991a, 1993a, 1993b), sera discutée ultérieurement.

\section{Pointes à base sciée (nr:5)}

Il s'agit d'objets appointés, entièrement façonnés, à bords réguliers et convergents vers l'extrémité distale, qui possèdent tous une extrémité proximale présentant une ou plusieurs incisions transversales (sur une ou les deux faces de la pièce) accompagnées de petites languettes (fig. 20, $\mathrm{n}^{\text {os }} 47$ ).

Selon les dimensions de ces pointes, deux hypothèses sont possibles quant à leur nature.

Trois pièces sont de petites dimensions $(14,5 \mathrm{~mm}$ x 4,5 mm x $3 \mathrm{~mm} ; 37 \mathrm{~mm}$ x $9,5 \mathrm{~mm}$ x $6,5 \mathrm{~mm} ; 18 \mathrm{~mm}$ x $6,5 \mathrm{~mm} \times 4 \mathrm{~mm}$ ). En outre, deux d'entre elles possèdent des extrémités distales abîmées (brisées anciennement ou très émoussées; la troisième pièce présente une cassure fraîche à l'extrémité distale qui empêche de connaître l'état initial de cette extrémité). Cela permet d'émettre l'hypothèse suivante : ces pointes seraient des résidus de façonnage, ôtées par sciage transversal et flexion avant réfection de la partie distale endommagée de sagaies par exemple (Knecht, 1993a, p. 153-154).

Deux pièces sont de grande dimension (48 mm x $8 \mathrm{~mm} \times 5,5 \mathrm{~mm} ; 98,5 \mathrm{~mm} \times 11 \mathrm{~mm} \times 6,5 \mathrm{~mm})$. Il pourrait s'agir dans ce cas de sagaies brisées dont la base aurait été régularisée avant réfection (Knecht, $i d$ ). 


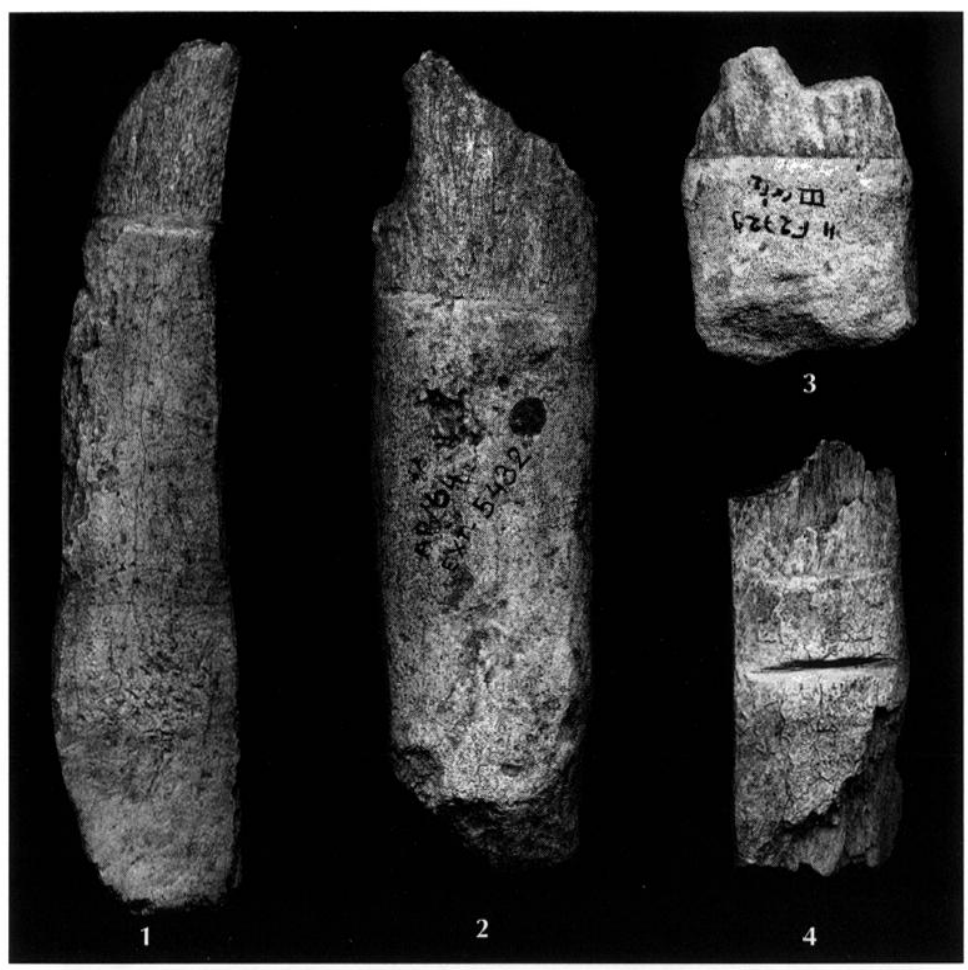

a

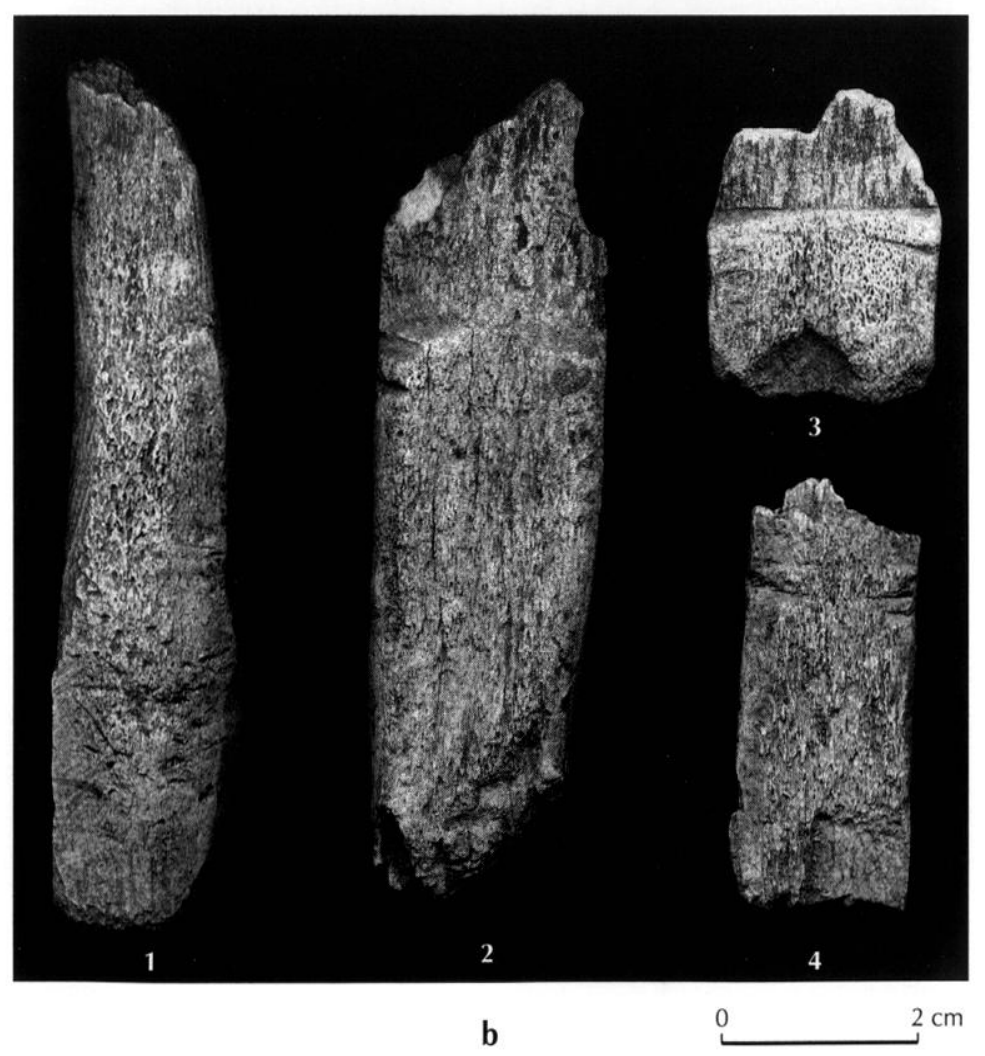

Fig. 21 - Industrie osseuse de la couche 11, pièces à languette :

$a$, faces supérieures; $b$, faces inférieures (photos $C$. Vercoutère). 


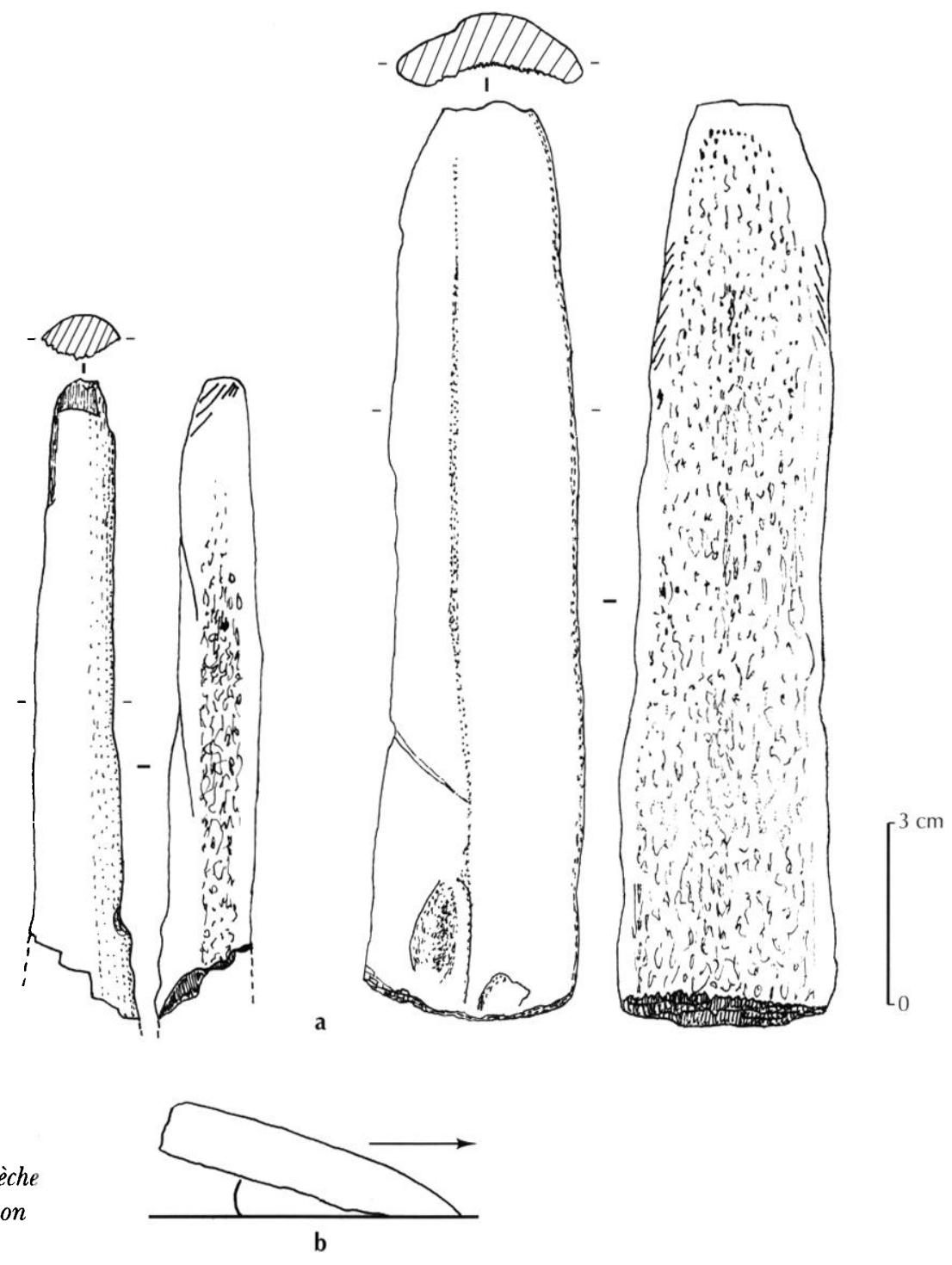

Fig. 22 - Industrie osseuse de la couche 11: a, objets à extrémité biseautée et polie; b, schéma d'utilisation : la flèche indique le sens présumé du mouvement de l'objet lors de son utilisation (dessins C. Vercoutère).

médiaires ; en outre, nous avons pu observer un émoussement (aspect lustré) des bords de cette extrémité qui ne présente pas de traces d'emmanchement; ceci tendrait à prouver que ces objets étaient tenus en main lors de leur utilisation ;

- l'extrémité distale arrondie présente un biseau sur sa face inférieure. L'étendue du biseau est polie. Les bords et/ou la face inférieure de cette extrémité portent des stries courtes, profondes et obliques qui donnent la direction du mouvement de l'outil lors de son utilisation. Enfin, en posant les biseaux à plat sur un plan horizontal (fig. 22b), nous avons pu mesurer l'angle d'attaque de ces outils (sauf pour une pièce dont le biseau est brisé) qui est compris entre $10^{\circ}$ et $20^{\circ}$, ce qui est relativement faible. présente aucun stigmate de percussion, ce qui exclut l'utilisation de ces objets en tant qu'outils inter- 
Tout ceci suggère que ces outils, tenus en main, opéraient des mouvements de va-et-vient, avec un angle d'attaque faible, sur une matière souple, ce qui provoquait la mise en forme et le polissage d'un biseau sur leur face inférieure. Des aspérités à la surface du matériau traité auraient alors pu produire les stries obliques observées.

Une hypothèse d'utilisation de ces outils serait le traitement des peaux. Le choix du bois de renne, matériau résistant et souple, apparaitrait idéal pour travailler les peaux sans les abîmer. Cependant, des études expérimentales et tracéologiques seraient nécessaires pour confirmer cette première hypothèse.

\section{Débris (nr:6)}

Il s'agit de fragments de bois de cervidé, entièrement façonnés, et qui présentent une ou plusieurs cassures anciennes. Leurs petites dimensions et/ou leur mauvaise conservation empêchent leur rattachement à un type d'objet en particulier.

L'équipement en bois de cervidé regroupe donc 43 pièces qui sont majoritairement le reflet d'activités cynégétiques ( 2 sagaies à base fendue ; 5 parties mésiales de sagaie ; 3 parties distales de sagaie; 5 pointes à base sciée) et domestiques ( 5 objets à extrémité biseautée et polie). En outre, la présence de résidus de débitage, et de pièces en cours de façonnage ou de réfection prouve que l'élaboration de cet équipement avait lieu au sein de l'abri.

\section{Équipement en os}

\section{Retouchoirs ( $n r: 15)$}

Il s'agit de fragments de diaphyse d'os longs (tabl. III) qui ne portent aucune trace de façonnage, mais présentent sur la face externe de l'os une ou plusieurs plages à impressions et éraillures (fig. $23, \mathrm{n}^{\circ} 6$; Patou-Mathis dir., 2002). Ces plages sont de forme ovalaire, leur surface est plus ou moins concave, et leur grand axe est parallèle au grand axe de l'objet. Les stigmates sont courts et plus ou moins perpendiculaires au grand axe de la pièce.

Ces objets auraient été utilisés pour la retouche d'objets lithiques (Malerba, Giacobini, 2002, p. 31), ce qui semble tout à fait plausible dans le cas de la

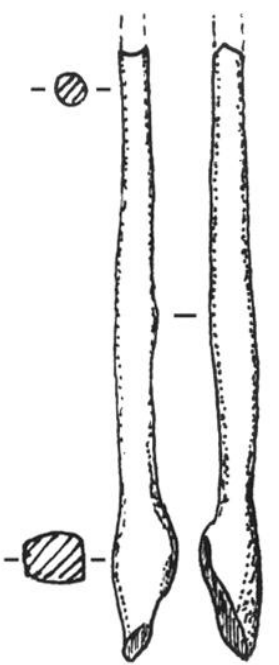

1
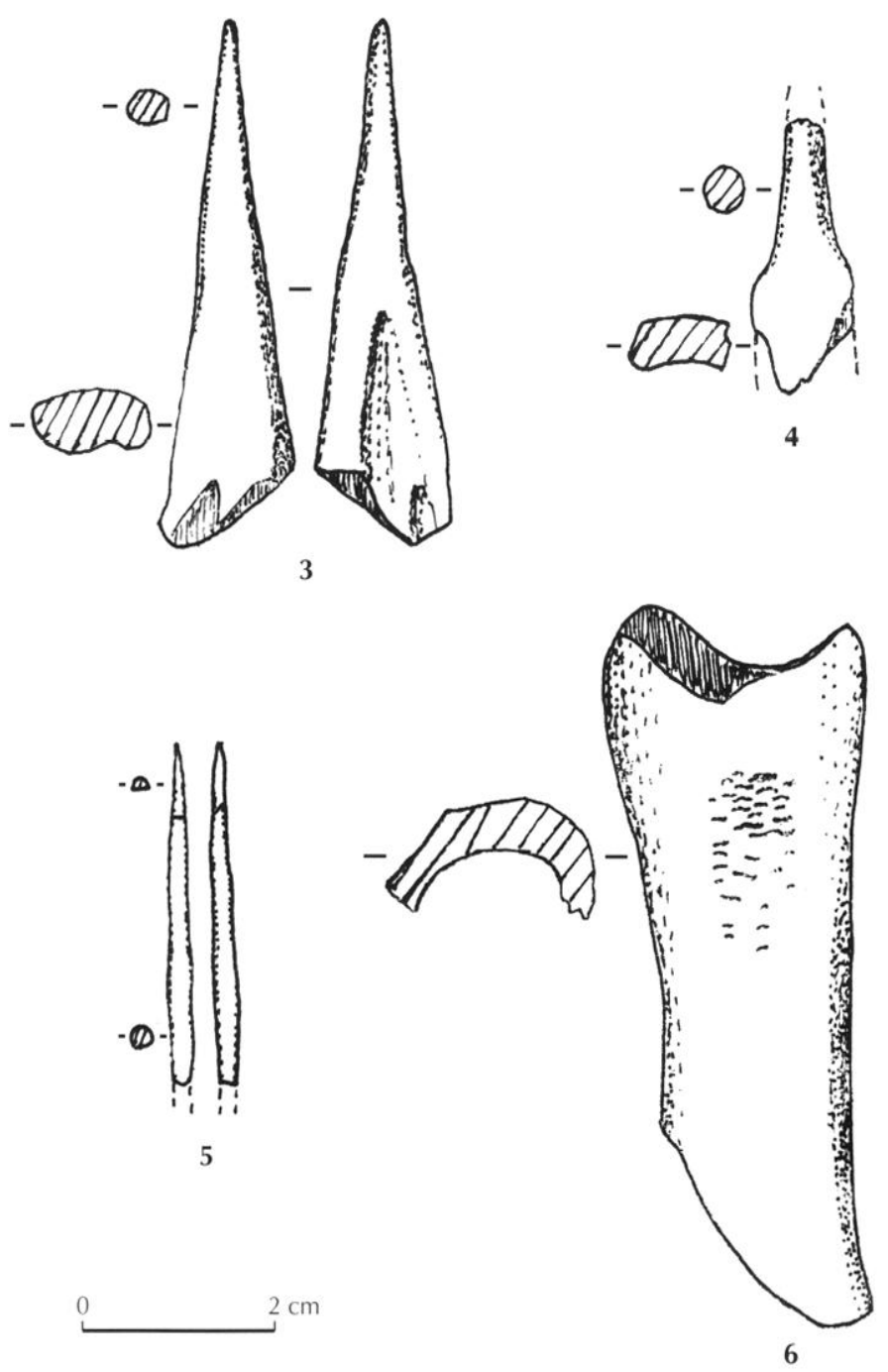

Fig. 23 - Industrie osseuse de la couche 11 :

1-4, poincons; 5, épingle; 6, retouchoir (dessins C. Vercoutère). 


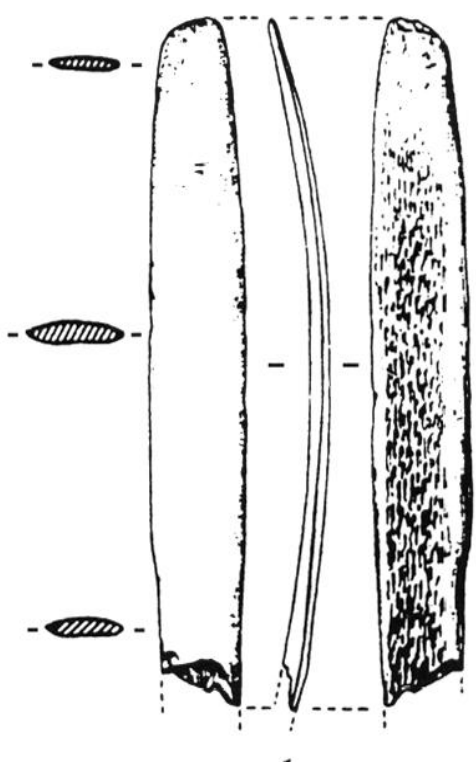

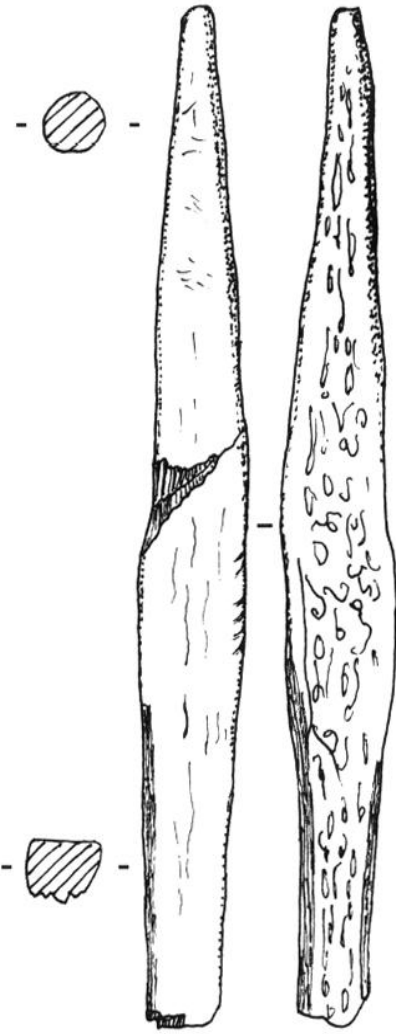

2
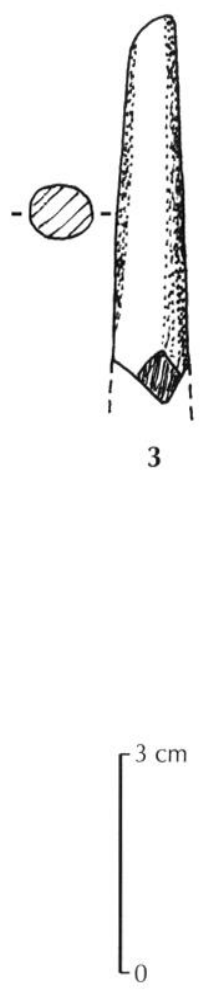

Fig. 24 - Industrie osseuse de la couche $11: 1$, lissoir ; 2, 3, pointes (dessins : 1, P. Laurent; 2, 3, C. Vercoutère). couche 11 qui contient de nombreuses pièces lithiques retouchées (tabl. II).

\section{Poinçons $(n r: 6)$}

Cinq pièces sont des esquilles de taille réduite dont seule une extrémité, de section ronde, est appointée (fig. 23, nos 2-4). Ces objets entrent donc parfaitement dans la catégorie des poinçons d'économie, dont H. Camps-Fabrer (1990) donne la définition suivante: "Objet en os ou en toute autre matière dure animale, pris sur fragment ou esquille quelconque, sans forme prédéterminée et dont une pointe a été aménagée volontairement sur une longueur de quelques millimètres, par raclage ou abrasion ".

Certains de ces poinçons d'économie présentent une extrémité proximale lustrée, stigmate attribuable à leur manipulation. Les stigmates de façonnage de la partie distale du poinçon s'estompent à son extrémité pointue qui apparaît lisse. Ce qui nous a conduite à l'hypothèse d'une utilisation pour le percement de matériaux souples (peaux par exemple).

La sixième pièce (fig. $23, \mathrm{n}^{\circ} 1$ ) ne peut être classée dans la catégorie des poinçons d'économie. En effet, elle a subi un façonnage beaucoup plus important qui affecte toute la pièce à l'exception de son extrémité proximale globuleuse. L'aspect lisse de cette extrémité atteste sa manipulation.

\section{Pointes ( $\mathrm{nr}: 2)$}

Une pièce est entière et l'autre correspond à une partie distale de pointe (fig. 24, $\mathrm{n}^{\mathrm{os}} 2,3$ ).

La pièce entière est de forme générale losangique. Elle possède une partie distale, de section circulaire, entièrement façonnée et lisse, avec des bords réguliers qui convergent vers une extrémité mousse. La partie proximale est brute et de section quadrangulaire. Un renflement se situe à la jonction de ces deux parties et présente une série d'incisions courtes, transversales, parallèles et peu marquées sur un des bords, ce qui pourrait témoigner d'un emmanchement avec une fixation à ce niveau de la pointe. Cette pièce pourrait donc correspondre à une armature de sagaie losangique. Cependant, la forte épaisseur de sa partie proximale $(8 \mathrm{~mm}$ ), ainsi que la nature de son support (côte de boviné ?) la rapprocheraient davantage du poinçon emmanché. 
La seconde pièce est la copie conforme de la partie distale de la première, ce qui nous a conduite à la rapprocher d'une partie distale de sagaie.

\section{Épingle (nr:1)}

Il s'agit d'un petit fragment de compacta $(32 \mathrm{~mm}$ x $2 \mathrm{~mm}$ x $2 \mathrm{~mm}$ ) entièrement façonné (fig. $23, \mathrm{n}^{\circ} 5$ ). L'une de ses extrémités est pointue et de section planoconvexe, l'autre, de section ronde, présente une cassure ancienne. Le renflement central de la pièce suggère que cet objet était sans doute bipointe.

La finesse de cette pièce, ainsi que la nature de la matière première dont elle est constituée (os cassant facilement), nous amène à la nommer épingle, plutôt qu'alêne.

\section{Fragments de bâtonnets appointés (nr:5)}

Il s'agit de fragments de bâtonnets d'os compact entièrement façonnés. Leurs dimensions sont réduites, leur section circulaire ou polygonale, leur extrémité proximale a été brisée anciennement (cassure transversale en dents de scie ou en sifflet) et leur extrémité distale appointée.

L'une de ces pièces (AP/63 11-2954) présente une extrémité distale globuleuse sur laquelle les traces de raclage longitudinal viennent buter. Ce bâtonnet a donc dû être cassé lors du façonnage de la pointe.

Nous ne pouvons estimer la longueur initiale des bâtonnets, mais tous les fragments ont des diamètres similaires (de $3 \mathrm{~mm}$ à $5 \mathrm{~mm}$ ), ce qui révèle une standardisation dans l'élaboration des bâtonnets sans doute façonnés par raclage longitudinal d'esquilles déjà étroites. Des fragments de bâtonnets identiques à ceux de l'abri Pataud ont été décrits dans la couche VII de la grotte du Renne à Arcy-sur-Cure, Yonne (Julien et al., 2002, p. 231-234). En outre, ce gisement a livré une matrice de ces objets (id., p. 234, fig. 137, nos 2 a et 2 b) qui confirme notre hypothèse sur le mode de façonnage des bâtonnets. Ces derniers sont assez fréquents à l'Aurignacien, mais leur fonction reste inconnue: poinçon, alêne, hameçon?

\section{Lissoirs sur lame de côte (nr:7)}

Il s'agit de fragments de lames de côte.

L'un d'eux (AP/63 11-2936) peut être considéré comme un résidu de débitage. Il n'est pas façonné, mais présente à l'une de ses extrémités quatre incisions trans- versales profondes qui témoignent du sectionnement transversal des côtes. Ces dernières devaient ensuite être fendues longitudinalement, d'où l'obtention d'un objet à fût plat et aux bords parallèles.

La seule pièce quasi entière de notre matériel (AP/63 11-3300; fig. 24, $\mathrm{n}^{\circ}$ 1) présente une extrémité distale arrondie, et possède un angle d'attaque très faible, ce qui la rattache à la catégorie des lissoirs.

Les autres pièces consistent en 3 parties mésiales et 2 fragments d'extrémité distale de lissoirs.

Le fort lustrage de ces objets laisse supposer leur utilisation sur des matériaux très souples (peau ou cuir par exemple).

\section{Débris (nr:7)}

Il s'agit de fragments de compacta, entièrement façonnés, et qui présentent une ou plusieurs cassures anciennes. Certains ont une extrémité arrondie, d'autre une extrémité appointée. Leurs dimensions très réduites empêchent leur rattachement à un type d'objet en particulier.

L'équipement en os regroupe donc 43 pièces, pour la plupart à usage domestique ( 15 retouchoirs, 6 poinçons, 7 lissoirs, 1 épingle).

Par l'origine de la matière première utilisée (cf. p. 175), et la nature même de ces objets (retouchoirs, poinçons), nous pouvons considérer que ces outils devaient être confectionnés sur place au fur et à mesure des besoins des hommes préhistoriques.

\section{Équipement en ivoire $(\mathrm{nr}: 5)$}

L'équipement en ivoire n'est représenté que par :

- 1 pièce de très petite dimension $(14 \mathrm{~mm} \times 4 \mathrm{~mm}$ x $4 \mathrm{~mm}$ ), fragmentée, qui porte des traces de façonnage, et que nous avons assimilée à un débris ;

- 4 baguettes allongées qui portent des traces de façonnage $(63 \mathrm{~mm} \times 9 \mathrm{~mm} \times 7 \mathrm{~mm} ; 70 \mathrm{~mm} \times 11 \mathrm{~mm}$ × $9 \mathrm{~mm} ; 50 \mathrm{~mm} \times 9 \mathrm{~mm} \times 7 \mathrm{~mm} ; 46 \mathrm{~mm} \times 11 \mathrm{~mm}$ x $5 \mathrm{~mm}$ ). Deux d'entre elles sont appointées et présentent un fût lisse de section subovale. Nous avons donc émis l'hypothèse qu'il pouvait s'agir de deux ébauches de pointe de sagaie. Les deux autres baguettes ont des dimensions similaires à celles de ces ébauches, mais étant donné leur morphologie (subrectangulaire et de section plano-convexe), et la forme de la matrice permettant 
l'élaboration de perles aurignaciennes (White, 1993), il est difficile de savoir si elles appartiennent véritablement à l'industrie osseuse ou si elles sont à rapprocher de la parure.

Aucune de ces pièces en ivoire n'est un objet fini, et elles présentent toutes des traces de raclage, ce qui atteste le travail de l'ivoire à l'intérieur de l'abri.

À la lumière de ces résultats, il apparaît que, quelle que soit leur origine (alimentaire ou matière collectée à des fins techniques), les trois matières dures animales présentes au sein de l'industrie osseuse (bois de cervidé, os, ivoire) ont été travaillées dans l'abri. Cependant, la répartition spatiale des pièces d'industrie osseuse ne nous a pas permis de mettre en évidence l'emplacement d'ateliers au sein de la zone fouillée.

La seule différence que nous avons décelée réside dans l'utilisation des matières premières. En effet, les pointes de projectile ont été façonnées à partir de baguettes de bois de cervidé, ce qui est à rapporter aux qualités propres à ce matériau (cf. p. 178), tandis que l'os est surtout utilisé pour la confection d'une industrie à usage domestique (poinçons, épingle, lissoirs sur lame de côte, retouchoirs).

Une caractéristique générale pour tout l'outillage est l'absence de décor (à l'exception peut-être d'une extrémité distale de sagaic).

Enfin, signalons la présence dans cet équipement de 5 objets ocrés. Mais, étant donné l'emplacement de l'ocre sur les pièces (à la surface d'objets de nature spongieuse, dans des incisions, et au niveau de cassures), nous interprétons cette coloration comme une contamination des objets par les matières colorantes rouges (oxydes de fer) que renferme le niveau 11.

\section{TeChNiQues UTILISÉES}

\section{Pour le travail du bois de cervidé}

Les stigmates observés sur les résidus de débitage et les objets à extrémité biseautée et polie nous ont permis de retrouver trois techniques mises en ouvre par les hommes préhistoriques pour le débitage du bois de renne (tabl. VI). Deux d'entre elles sont des techniques d'éclatement (Averbouh, Provenzano, 1998-1999) : la percussion lancée directe diffuse et la flexion (qui suit une incision transversale) ; quant à la troisième, il s'agit d'une technique d'enlèvement (Averbouh, Provenzano, id.) : la percussion lancée tranchante directe. Ces trois techniques se rapportent au concept de fracturation transversale, et engendrent la production de tronçons de bois de cervidé.

La fente longitudinale de ces derniers est "l'unique technique d'extraction de baguettes, supports d'outillage, durant l'Aurignacien " (Liolios, 1999, p. 90). Les bords des baguettes de bois de renne retrouvés à l'abri Pataud (objets à extrémité biseautée et polie et résidus de débitage) correspondent à des pans de fracture que nous avons assimilés aux stigmates de cette technique qui procède par percussion avec percuteur dormant ou par percussion indirecte (Liolios, $i d$ ).

Les séries de stries superficielles, longitudinales, continues, et parallèles entre elles, sont les témoins du façonnage par raclage longitudinal des sagaies et des pièces à languette (tabl. VI).

Enfin, la technique de l'incision transversale suivie de flexion est également utilisée dans les phases de façonnage et de réfection des pièces (tabl. VI).

Nous évoquerons pour conclure le problème de l'obtention des pièces à languette et donc de leur nature. En effet, à partir de l'observation des mêmes stigmates (incisions transversales et languette) deux théories ont été émises à ce sujet. La première, historiquement, est celle de D. Peyrony (1928), qui fut reprise ensuite par J. Hahn (1988). Pour ces auteurs, les pièces à languette correspondent à « la partie enlevée à la base de baguettes pour produire la fente des pointes de sagaies " (Peyrony, 1928). En pratique, il s'agit d'aménager l'extrémité proximale d'une sagaie à base fendue en réalisant deux incisions par sciage transversal (fig. 25a, $n^{\circ} 1$ ), puis en appliquant un mouvement de flexion qui permet la production de deux cassures convergentes à partir des encoches (fig. 25a, $n^{\prime \prime 2} 2,3$ ) et la séparation de la sagaie et de la pièce à languette (fig. 25a, $\mathrm{n}^{\circ} 4$; Hahn, 1988).

La seconde théorie est celle émise par $\mathrm{H}$. Knecht (1991a, 1993a, 1993b). Pour cet auteur, les pièces à languette sont des déchets issus de la fabrication de petits coins (clavettes) utilisés pour l'emmanchement des sagaies à base fendue. La séquence de production de ces clavettes est la suivante (fig. 25b) : une baguette à bords parallèles et de section biconvexe est façonnée à partir d'un segment semi-circulaire de bois de cervidé (fig. 25b, $n^{\circ} 1$ ), puis une incision transversale est pratiquée sur les 
Tabl. VI - Techniques utilisées pour la confection de l'industrie en bois de cervidé.

\begin{tabular}{|c|c|c|c|c|}
\hline Outils & Stigmates & Localisation & Technique & Phase \\
\hline sagaie à base fendue & séries de stries superficielles, longitudinales, & $\begin{array}{l}\text { sur toute la longueur des bords (envahissant } \\
\text { les } 2 \text { faces) et au niveau de la partie distale }\end{array}$ & \multirow{4}{*}{ raclage longitudinal } & \multirow{7}{*}{ 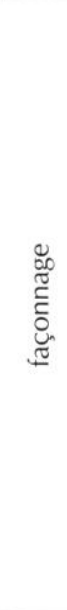 } \\
\hline $\begin{array}{l}\text { pointe mésiale de sagaie } \\
\text { (à base fendue ?) }\end{array}$ & continues, et parallèles entre elles & $\begin{array}{l}\text { sur toute la longueur des bords (envahissant } \\
\text { les } 2 \text { faces) }\end{array}$ & & \\
\hline partie distale de sagaie & $\begin{array}{l}\text { séries de stries superficielles, longitudinales, } \\
\text { continues, et convergeant vers l'extrémité distale }\end{array}$ & sur toute la surface de la pièce & & \\
\hline \multirow{3}{*}{ pièce à languette } & $\begin{array}{l}\text { séries de stries superficielles, longitudinales, } \\
\text { continues, et parallèles entre elles }\end{array}$ & $\begin{array}{l}\text { sur les bords de certaines pièces, } \\
\text { au niveau de la partie proximale }\end{array}$ & & \\
\hline & incisions transversales & $\begin{array}{l}\text { sur les } 2 \text { faces, et d'un bord à l'autre } \\
\text { de la pièce }\end{array}$ & \multirow{2}{*}{$\begin{array}{l}\text { incision transversale suivie de flexion } \\
\text { (grooving and snapping, Knecht, 1993a) }\end{array}$} & \\
\hline & mince languette de compacta, d'aspect rugueux & $\begin{array}{l}\text { en position distale par rapport aux } \\
\text { incisions transversales citées ci-dessus }\end{array}$ & & \\
\hline pointe à base sciée & $\begin{array}{l}\text { séries de stries superficielles, longitudinales, } \\
\text { continues, et convergeant vers l'extrémité distale }\end{array}$ & sur toute la surface de la pièce & raclage longitudinal & \\
\hline \multirow{4}{*}{$\begin{array}{l}\text { objet à extrémité } \\
\text { biseautée et polie }\end{array}$} & incisions transversales & $\begin{array}{l}\text { à l'extrémité proximale, sur une ou les } 2 \\
\text { faces, et allant d'un bord à l'autre de la pièce }\end{array}$ & \multirow{2}{*}{$\begin{array}{l}\text { incision transversale suivie de flexion } \\
\text { (grooving and snapping, Knecht, 1993a) }\end{array}$} & \multirow{2}{*}{$\frac{0}{\mathscr{O}}$} \\
\hline & \begin{tabular}{|l} 
cassure en languette \\
\end{tabular} & à l'extrémité proximale & & \\
\hline & $\begin{array}{l}\text { pan de fracture abrupt dont la direction est } \\
\text { parallèle à celle des fibres du bois de cervidé }\end{array}$ & sur les 2 bords & fente longitudinale & \multirow{5}{*}{ 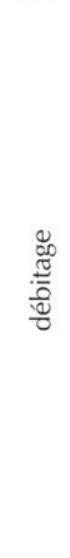 } \\
\hline & $\begin{array}{l}\text { séries d'esquillements qui se superposent } \\
\text { les uns aux autres }\end{array}$ & extrémité proximale, face supérieure & percussion lancée tranchante directe & \\
\hline \multirow[t]{3}{*}{ résidu de débitage } & $\begin{array}{l}\text { séries d'esquillements qui se superposent les uns } \\
\text { aux autres et forment une structure « en escalier », } \\
\text { qui peuvent être accompagnés ou non d'une } \\
\text { languette d'arrachement }\end{array}$ & à une extrémité, sur une ou les 2 faces & $\begin{array}{l}\text { percussion lancée tranchante directe } \\
\text { suivie ou non de flexion }\end{array}$ & \\
\hline & $\begin{array}{l}\text { pan de fracture abrupt dont la direction est } \\
\text { parallèle à celle des fibres du bois de cervidé }\end{array}$ & sur les 2 bords & fente longitudinale & \\
\hline & $\begin{array}{l}\text { pan de fracture transversal par rapport à la } \\
\text { direction des fibres du bois de cervidé, et dont la } \\
\text { ligne est irrégulière }\end{array}$ & à une extrémité, sur tout le pourtour du tronçon & percussion lancée directe diffuse & \\
\hline
\end{tabular}

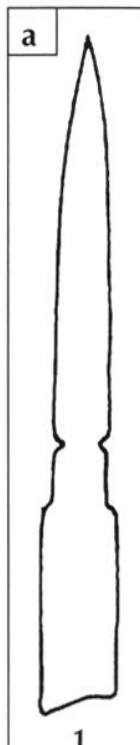

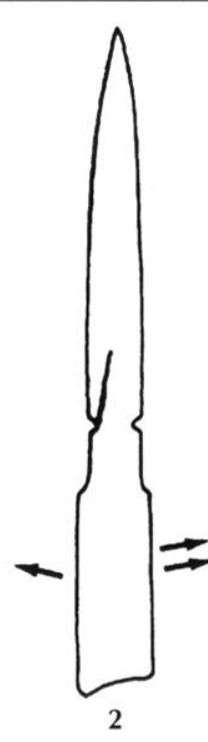

2

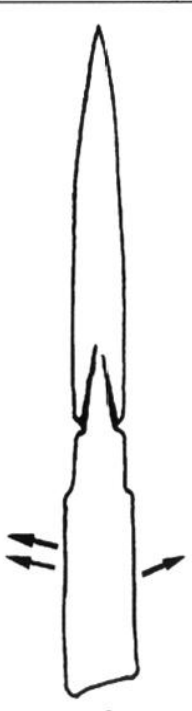

3
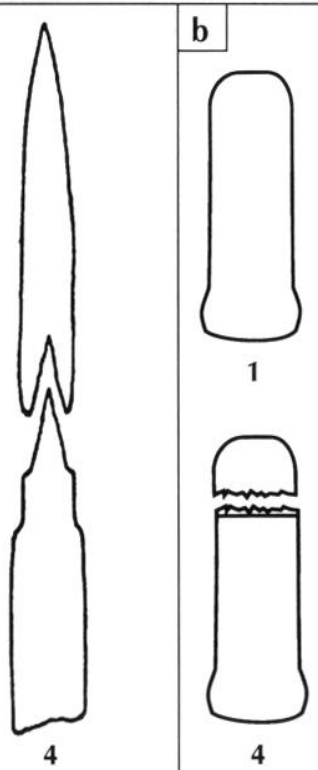

1

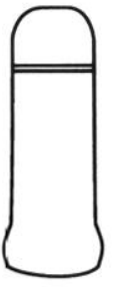

2
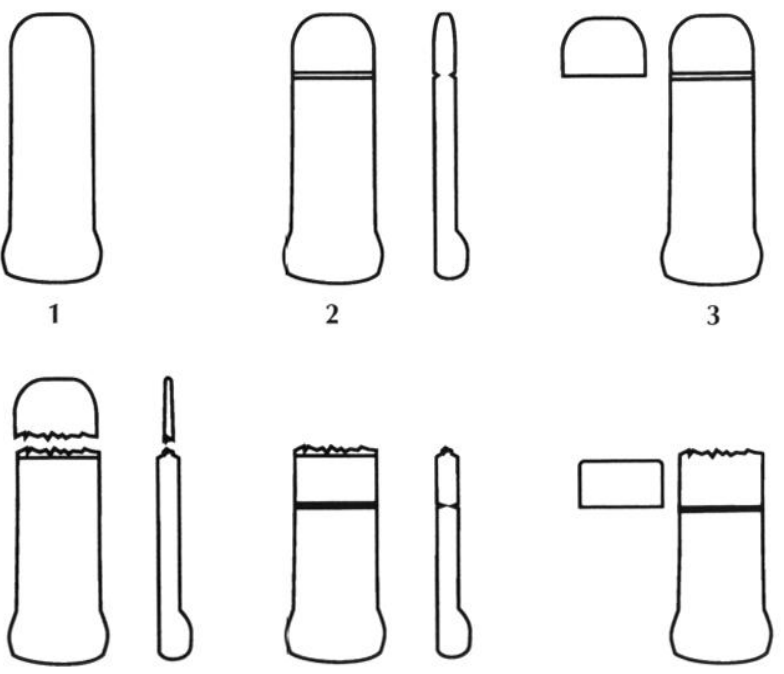

4

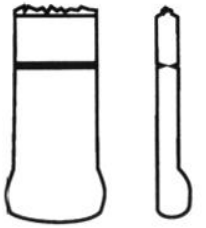

5
3
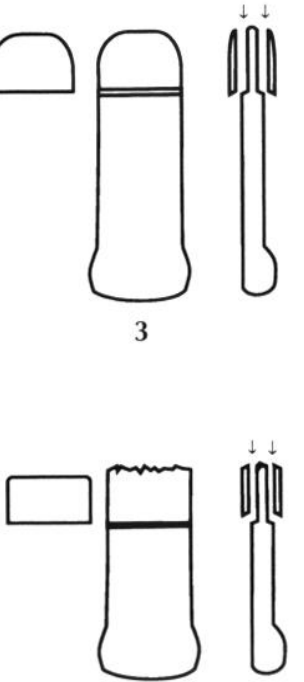

6

Fig. 25 - Obtention d'une pièce à languette : a, selon D. Peyrony (d'après Hahn, 1988) ; b, selon H. Knecht (d'après Knecht, 1993a). 
Tabl. VII - Techniques utilisées pour la confection de l'industrie en os.

\begin{tabular}{|c|c|c|c|c|}
\hline Outils & Stigmates & Localisation & Technique & Phase \\
\hline retouchoir & impact de percussion & sur un bord de certaines pièces & $\begin{array}{l}\text { percussion lancée } \\
\text { directe diffuse }\end{array}$ & débitage \\
\hline poinçon & $\begin{array}{l}\text { séries de stries superficielles, longitudinales, } \\
\text { continues, parallèles entre elles, puis } \\
\text { convergeant vers l'extrémité distale }\end{array}$ & toute la surface de la partie distale & raclage longitudinal & façonnage \\
\hline pointe & $\begin{array}{l}\text { pan de fracture abrupt dont la direction est } \\
\text { parallèle au grand axe de l'os }\end{array}$ & sur les 2 bords de la partie proximale & fente longitudinale & débitage \\
\hline épingle & $\begin{array}{l}\text { aspect poli } \\
\text { léger biseau }\end{array}$ & $\begin{array}{l}\text { sur toute la surface de la pièce à une } \\
\text { extrémité }\end{array}$ & $\begin{array}{l}\text { abrasion selon un mouvement } \\
\text { d'avant en arrière }\end{array}$ & façonnage \\
\hline $\begin{array}{l}\text { fragment de bâtonnet } \\
\text { appointé }\end{array}$ & $\begin{array}{l}\text { séries de stries superficielles, longitudinales, } \\
\text { continues, parallèles entre elles, puis } \\
\text { convergeant vers l'extrémité distale }\end{array}$ & toute la surface de la pièce & raclage longitudinal & façonnage \\
\hline lissoir & incisions transversales & $\begin{array}{l}\text { sur les } 2 \text { faces d'une extrémité, } \\
\text { et en bordure de son pan de fracture }\end{array}$ & $\begin{array}{l}\text { incision transversale } \\
\text { suivie de flexion }\end{array}$ & débitage \\
\hline
\end{tabular}

faces inférieure et supérieure de cette baguette (fig. 25b, $\mathrm{n}^{\circ} 2$ ), et deux petites pièces plates et rectangulaires (clavettes) sont retirées de la partie distale de la baguette grâce à une technique de fente (splitting and wedging), ce qui entraîne la production d'une pièce à languette (fig. 25b, $\mathrm{n}^{\circ} 3$ ) ; par la suite, la languette est brisée par flexion (fig. 25b, ${ }^{\circ} 4$ ) et l'on peut répéter l'opération précédente pour obtenir de nouvelles clavettes (fig. 25b, $\left.\mathrm{n}^{\text {os }} 5,6\right)$.

Nous n'avons pas retrouvé de clavettes dans le matériel de la couche 11. En outre, une des pièces à languette se raccorde avec une sagaie à base fendue (fig. 18, $\mathrm{n}^{\circ} 3$ ). Cependant, devant le faible nombre de pièces ( 2 sagaies à base fendue et 5 pièces à languette), et en l'absence d'une étude tracéologique poussée de l'intérieur de la fente de la sagaie se raccordant à la pièce à languette, il serait hasardeux de nous prononcer en faveur de l'une ou l'autre de ces deux hypothèses.

\section{Pour le travail de l'os}

Les retouchoirs portent des impacts de percussion qui témoignent de la fracturation par percussion lancée directe diffuse des os longs de cheval, renne et bison dont ils sont issus (tabl. VII). En outre, ceci confirme l'origine alimentaire du support, puisque la fracturation de ces mêmes os longs pour la récupération de la moelle est attestée par l'étude archéozoologique (cf. p. 195).
Le façonnage des poinçons et des fragments de bâtonnets s'est fait par raclage longitudinal d'une esquille de taille réduite, sans doute, elle aussi, issue des restes du traitement boucher. Une autre de ces esquilles a été abrasée pour produire une épingle (tabl. VII).

Des fragments de côte ont également servi de support pour l'élaboration de pointes et de lissoirs. D'après D. Liolios (1999, p. 87), à l'Aurignacien, la fente longitudinale d'une côte s'effectue par " percussion latérale de la tranche de la côte ". Les pans de fracture observés sur une des sagaies de notre matériel sont sans doute à rattacher à cette technique (tabl. VII). En l'absence de traces caractéristiques, la technique utilisée pour le façonnage de ces sagaies et lissoirs n'a pas pu être clairement identifiée. Nous pouvons seulement supposer, au vu de la technique employée pour l'aménagement des poinçons, qu'il s'agit de raclage longitudinal.

\section{Pour le travail de l'ivoire}

Les seules traces identifiées sur les objets en ivoire sont des stries superficielles, longitudinales, continues, et parallèles entre elles, qui sont localisées sur la face supérieure, voire sur la totalité des baguettes, et qui attestent un raclage longitudinal des pièces.

Nous sommes à présent à même de reconstituer les chaînes opératoires de production de l'outillage en bois 


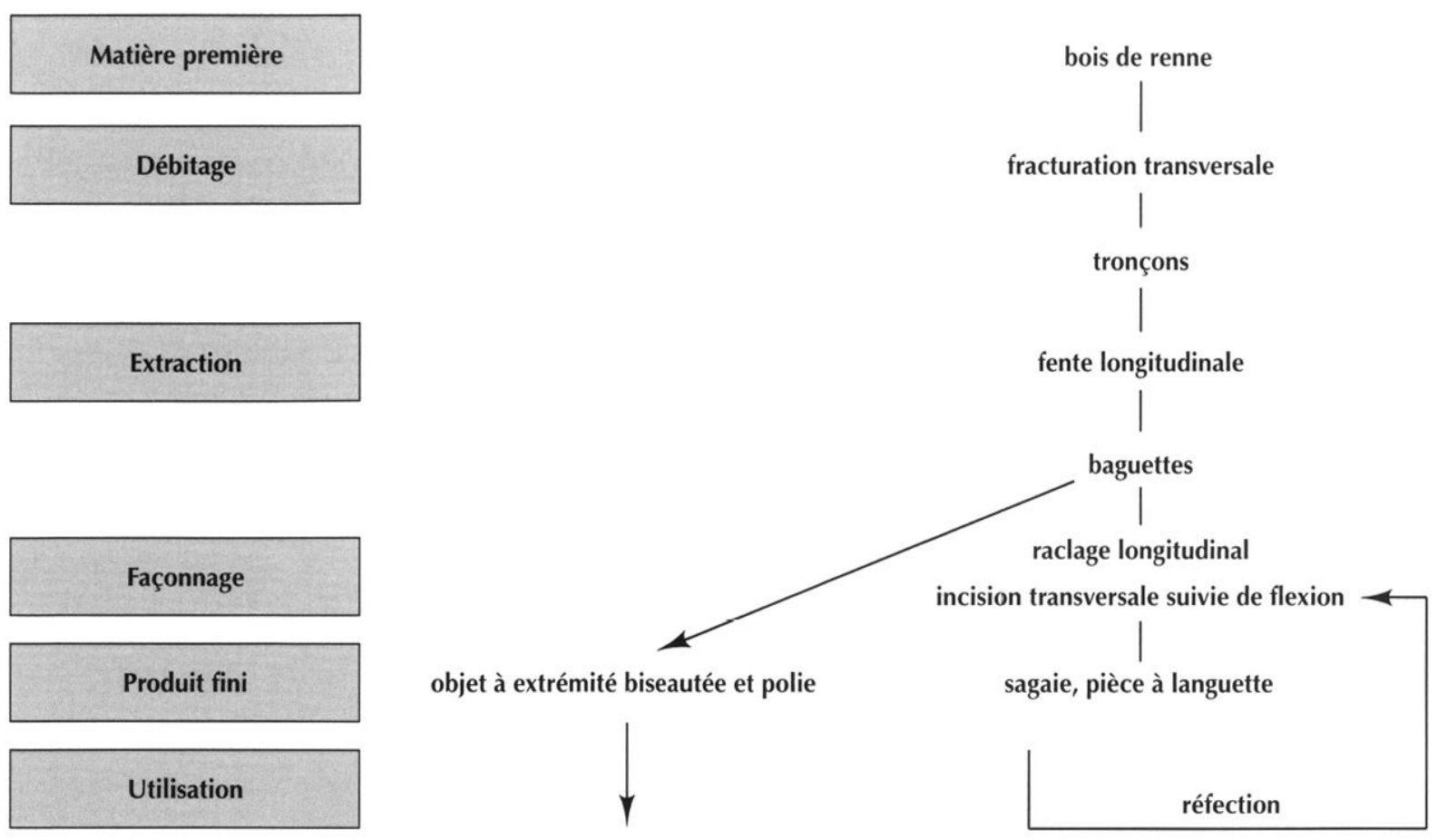

Fig. 26 - Chaîne opératoire de production de l'industrie en bois de cervidé.
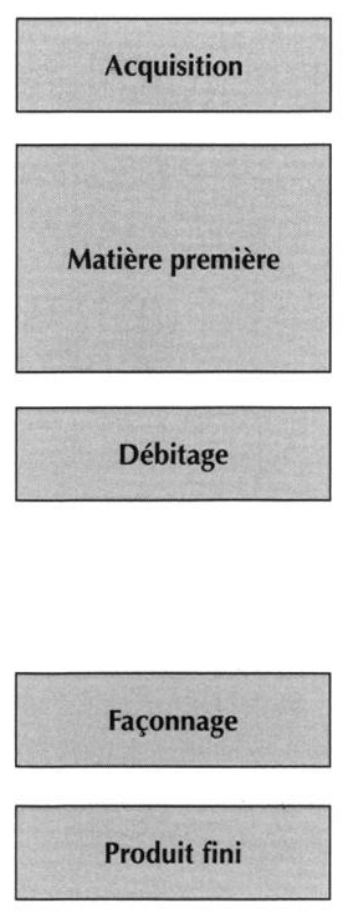

Utilisation 
de cervidé et en os (fig. 26 et 27). Les Aurignaciens maîtrisaient différentes techniques de débitage du bois de cervidé et de l'os. Mais ces dernières s'apparentent toutes au même concept de fracturation (Liolios, 1999, p. 88-91 ; Averbouh, Provenzano, 1998-1999, p. 9-13). Pour le façonnage des objets, les hommes préhistoriques procédaient en général par raclage longitudinal, quelle que soit la nature du support. L'abrasion a également été utilisée pour l'os. Quant à la technique d'incision transversale suivie de flexion, on la retrouve à tous les stades de la chaîne opératoire de production des objets en bois de cervidé (débitage, façonnage et réfection). Enfin, la finition de l'outillage nous a paru peu poussée. En effet, les traces laissées par les techniques de débitage et de façonnage sont encore visibles sur de nombreux objets finis.

\section{SYNTHÈSE}

La recherche de la matière première animale non alimentaire (bois de cervidé et os) ne semble pas, au vu de cette étude, avoir été l'objectif déterminant dans l'acquisition du gibier. Quant à l'ivoire, il apparaît que les hommes préhistoriques ont apporté avec eux des morceaux de défenses prélevés sur des carcasses fraîches de mammouth ou, plus probablement, récupérés dans des gîtes d'ivoire subfossile.

Les équipements en bois de cervidé et en os ont tous deux été façonnés dans l'abri. Les pointes en bois de cervidé sont le reflet d'activités cynégétiques, alors que l'équipement en os se rapporte à des activités domestiques.

En ce qui concerne l'attribution chronologique de la couche 11, les différentes catégories d'outils et d'armes décrites (tabl. IV) attestent son appartenance à l'Aurignacien (Leroy-Prost, 1975 ; Knecht, 1993a, p. 139). La présence de sagaies à base fendue et les techniques de débitage employées, relevant toutes du même concept de fracturation, témoignent de l'ancienneté de ce niveau. Celle-ci est confirmée par l'utilisation de la technique d'incision transversale suivie de flexion à différents stades de la chaine opératoire de production des objets en bois de renne (Knecht, 1993a, p. 152-154). D'où l'attribution du matériel osseux du niveau 11 à l'Aurignacien ancien (Aurignacien I). Ceci s'accorde avec les résultats de l'étude de l'industrie lithique (cf. p. 168).

C. V.

\section{PARURE}

Les éléments de parure sont peu représentés dans le niveau étudié ( 15 pièces). Ils sont cependant variés, tant par leurs formes (ronde, hémisphérique, rectangulaire, allongée, crochue), que par leur nature (bois de cervidé, ivoire, os, dents) (tabl. VIII).

\section{MATIÈRES PREMIÈres}

Quatre types de matériaux ont été utilisés pour la confection des éléments de parure : le bois de cervidé, l'ivoire, l'os, et les dents.

Notre but est ici de discuter des modes d'acquisition de ces matières premières, et de leur représentation au sein de la parure.

\section{Bois de cervidé et os}

Comme nous l'avons établi précédemment pour l'industrie osseuse, ces deux matériaux sont issus d'une acquisition par la chasse.

Le bois de cervidé est peu utilisé, puisque seulement deux pièces ont été réalisées dans ce matériau (tabl. VIII). Quant aux os utilisés, ils sont plus nombreux (nr: 5) et constituent des "préformes " peut-être choisies pour leurs qualités esthétiques, et qu'il suffit d'aménager en les perçant.

\section{Dents}

Plusieurs hypothèses sont possibles quant à l'origine des dents (tabl. VIII) : matière première provenant des animaux abattus (canine de renard), ou matière première récupérée sur des carcasses proches de l'abri (canine de lion des cavernes, canine de renard), ou encore pièces que les hommes préhistoriques ont apportées avec eux à l'abri Pataud (incisive de bison, canine de lion des cavernes, canine de renard).

Comme dans le cas des os, nous émettons l'hypothèse que le choix de cette matière première s'est fait à partir de critères esthétiques et/ou pratiques.

\section{Ivoire}

L'ivoire de mammouth est un matériau collecté et importé (cf. p. 176). 
Tabl. VIII - Inventaire des éléments de parure.

\begin{tabular}{|c|c|c|c|}
\hline \multicolumn{2}{|r|}{ Types d'objets } & NR & Matière première \\
\hline \multirow{2}{*}{$\begin{array}{l}\text { supports et } \\
\text { ébauches (5) }\end{array}$} & fragments de baguette & 3 & bois de cervidé (2) ; ivoire (1) \\
\hline & ébauches de perles en panier & 2 & ivoire \\
\hline \multirow{2}{*}{$\begin{array}{l}\text { objets de grande } \\
\text { dimension (2) }\end{array}$} & plaque perforée & 1 & ivoire \\
\hline & fragment d'os perforé & 1 & tête humérale de bison ou cheval \\
\hline \multirow{8}{*}{ pendeloques (8) } & \multirow{5}{*}{ os perforés } & \multirow{5}{*}{5} & tête fémorale de renne juvénile (1) \\
\hline & & & métapodien vestigial de renne (1) \\
\hline & & & phalange proximale vestigiale de renne (1) \\
\hline & & & humérus de renard (1) \\
\hline & & & métacarpien $\mathrm{V}$ droit de renard (1) \\
\hline & \multirow{3}{*}{ dents perforées } & \multirow{3}{*}{3} & canine inférieure droite de Vulpes vulpes (1) \\
\hline & & & canine supérieure gauche de Panthera (Leo) spelaea (1) \\
\hline & & & incisive inférieure droite de bison (1) \\
\hline Total & & 15 & \\
\hline
\end{tabular}

Bien que rare dans le niveau étudié, il a servi à la confection de quatre pièces (tabl. VIII), dont trois sont en cours de façonnage et attestent le travail de l'ivoire dans l'abri.

La rareté de ce matériau contribuait sans doute à lui donner une grande valeur et, par là même, à le réserver pour la confection d'élément de parure (objets symboliques et à caractère social).

\section{TYPES D'OBJETS}

\section{Supports et ébauches}

\section{Fragments de baguettes $(n r: 3)$}

Il s'agit de petits fragments de forme rectangulaire, à bords parallèles et réguliers, de section plano-convexe ou subovale, et dont les deux extrémités portent des incisions transversales (sur une ou les deux faces) accompagnées d'une cassure en languette.

Deux de ces pièces, en bois de cervidé, ont des dimensions quasi identiques : $16 \mathrm{~mm} \times 8 \mathrm{~mm} \times 6 \mathrm{~mm}$ et $16 \mathrm{~mm} \times 9 \mathrm{~mm} \times 6 \mathrm{~mm}$ (fig. $28, \mathrm{n}^{\mathrm{os}} 2,3$ ). La troisième pièce, en ivoire, est un peu plus grande : $23 \mathrm{~mm} \times 11 \mathrm{~mm}$ x $8 \mathrm{~mm}$ (fig. 28, $\mathrm{n}^{\circ} 4$ ). Cependant, les bords des 3 fragments portent des séries de stries superficielles, continues, et parallèles entre elles. Ce qui atteste le façonnage de ces fragments par raclage longitudinal. En outre, les stigmates localisés à leurs extrémités (incisions transversales et cassure en languette) suggèrent un même mode de débitage par incision transversale suivie de flexion.
Par comparaison avec la séquence de production des perles aurignaciennes en bois de cervidé de l'abri Castanet, Dordogne (Liolios, 1999), on peut penser que ces pièces, de petites dimensions et de forme standardisée, ont été produites en série. Une baguette, préalablement façonnée par raclage longitudinal, aurait servi de matrice. Le sectionnement de cette baguette par incision transversale, à écart régulier, suivi de flexion aurait alors produit les fragments décrits ici. Si cette hypothèse s'avère correcte, ces derniers pourraient être des supports de perle.

\section{Ébauches de perles ( $\mathrm{nr}: 2)$}

Il s'agit de deux petits fragments d'ivoire (fig. 28, $\mathrm{n}^{\circ} 5$ ). Le premier se présente sous la forme d'un cylindre (14 mm x $6 \mathrm{~mm} \times 5 \mathrm{~mm}$ ), d'aspect poli, qui porte des traces de sciage à chacune de ses extrémités. La seconde pièce est de dimensions similaires $(13 \mathrm{~mm}$ x 5 à $7,5 \mathrm{~mm}$ x 3 à $6,5 \mathrm{~mm}$ ), mais l'une de ses extrémités a été aplatie par raclage (présence de stries superficielles et parallèles entre elles sur les deux faces). On note également une incision transversale au niveau d'une face de cette même extrémité.

Il semble donc que les deux fragments décrits cidessus ont été produits de la même manière, mais qu'ils représentent deux stades de façonnage différents d'un même objet de petite dimension. En nous rapportant à la séquence de production des perles en panier décrite par R. White (1993), nous avons pu identifier ces deux objets en ivoire comme deux ébauches de ces perles aurignaciennes. 

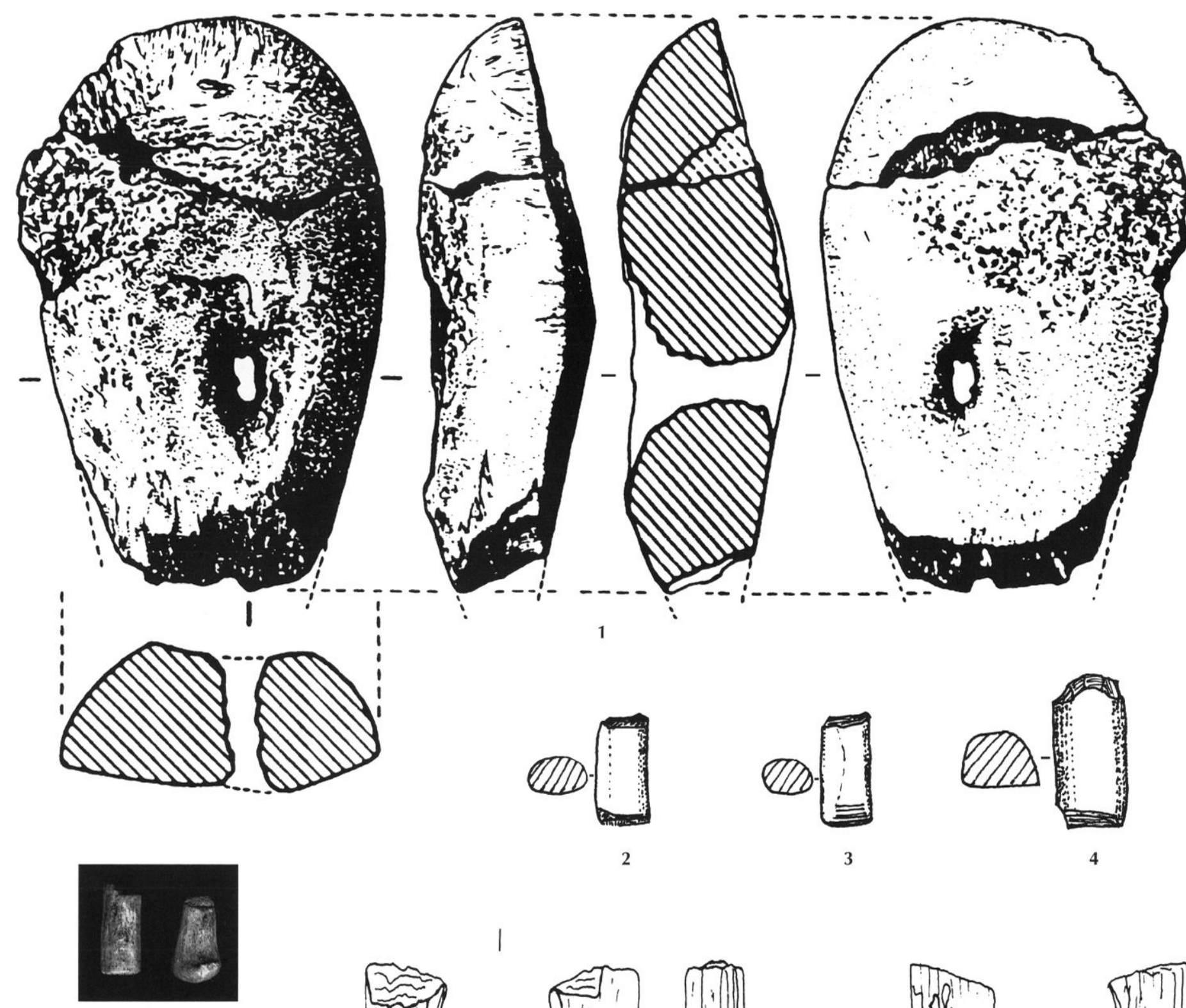

5
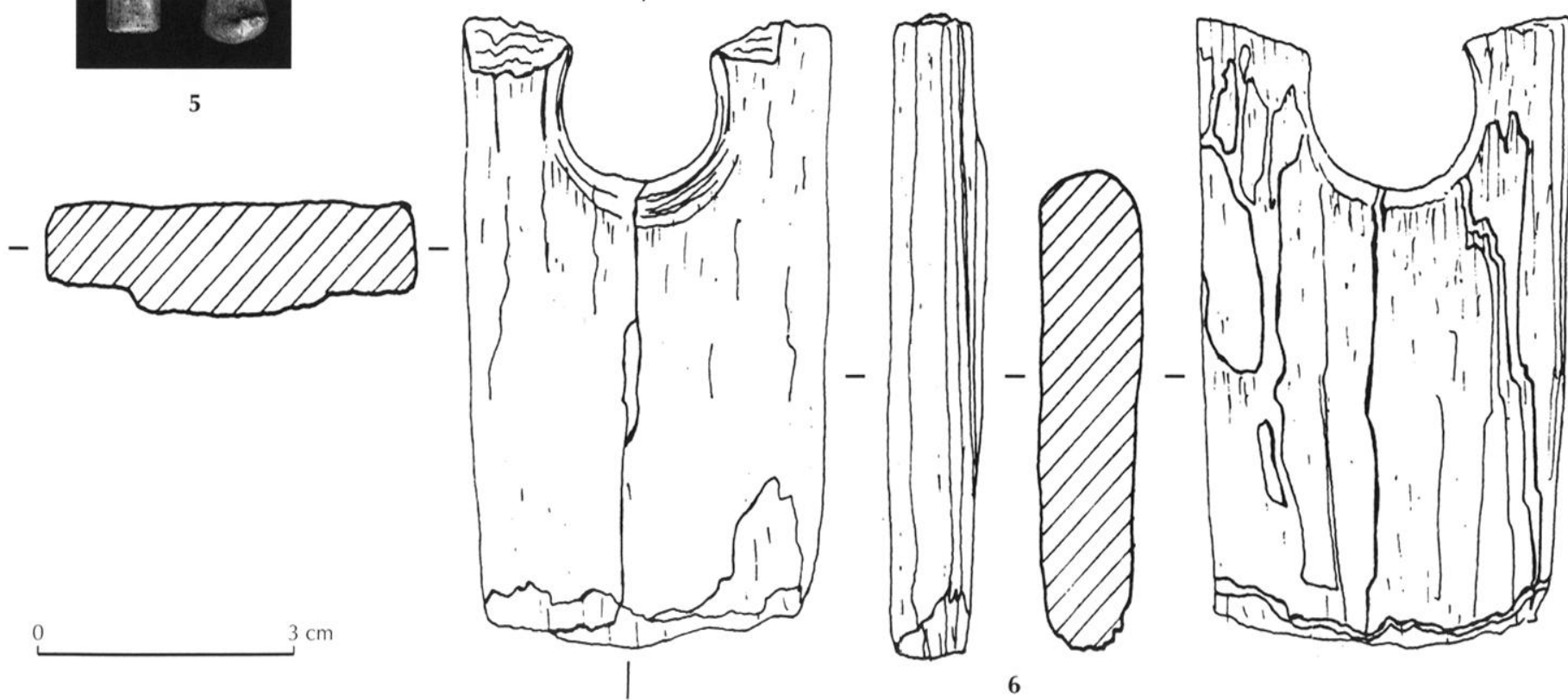

Fig. 28 - Parure de la couche $11: 1$, os perforé ; 2-4, fragments de baguette; 5, ébauches de perles en panier; 6, plaque perforée (dessins : 1, P. Laurent; 2-4, C. Vercoutère; 6, S. Gregoriani, photo C. Vercoutere). 


\section{Objets de grandes dimensions}

\section{Plaque perforée $(n r: 1)$}

Il s'agit d'une plaque en ivoire, de forme rectangulaire, et dont la perforation circulaire est brisée (fig. 28, $\mathrm{n}^{\circ} 6$ ).

Si l'on se réfère aux travaux de Y. Taborin (1995, p. 69-70), il apparaît que cette plaque perforée trouve sa place parmi les pendeloques allongées plates à bords parallèles (forme 1, variété $1 \mathrm{~A}$, de la classification morphologique des éléments de parure en ivoire).
Cependant, étant donné les dimensions de cette pièce (68 mm x $46 \mathrm{~mm} \times 12 \mathrm{~mm}$ ) et surtout celles de sa perforation (diamètre d'environ $19 \mathrm{~mm}$ ), nous émettons une réserve quant à sa nature " d'objet à suspendre ".

Une autre hypothèse se dégage de sa comparaison avec les anneaux en ivoire découverts dans les couches VII (Aurignacien) et $\mathrm{X}$ (Châtelperronien) d'Arcy-sur-Cure, Yonne (White, 2002, p. 258-260). La plaque perforée de l'abri Pataud pourrait correspondre à une première étape dans la chaîne opératoire de production d'un contour découpé. Des études
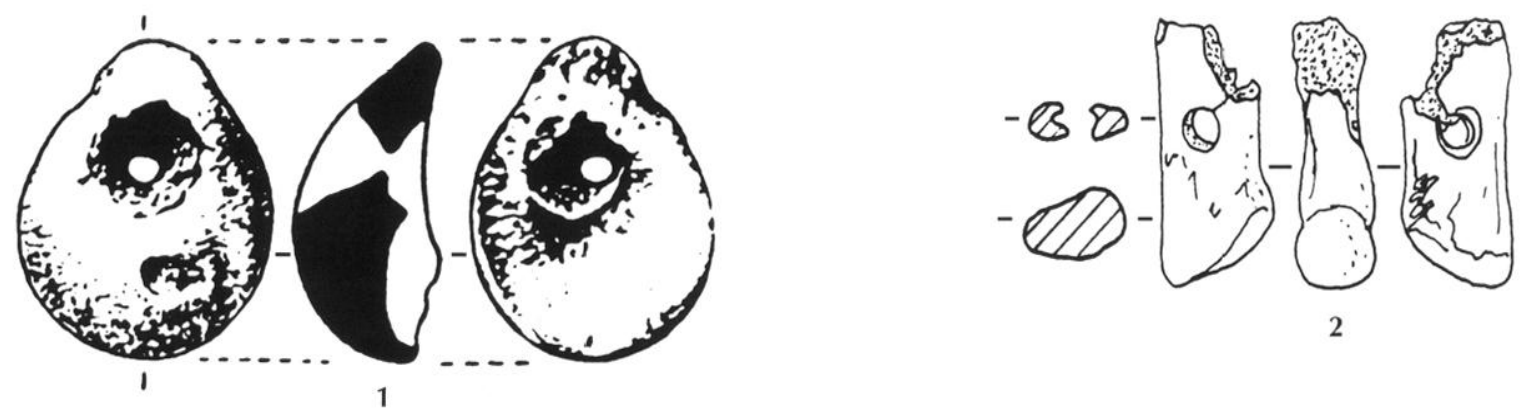

2

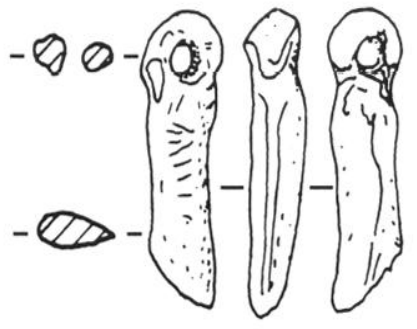

3
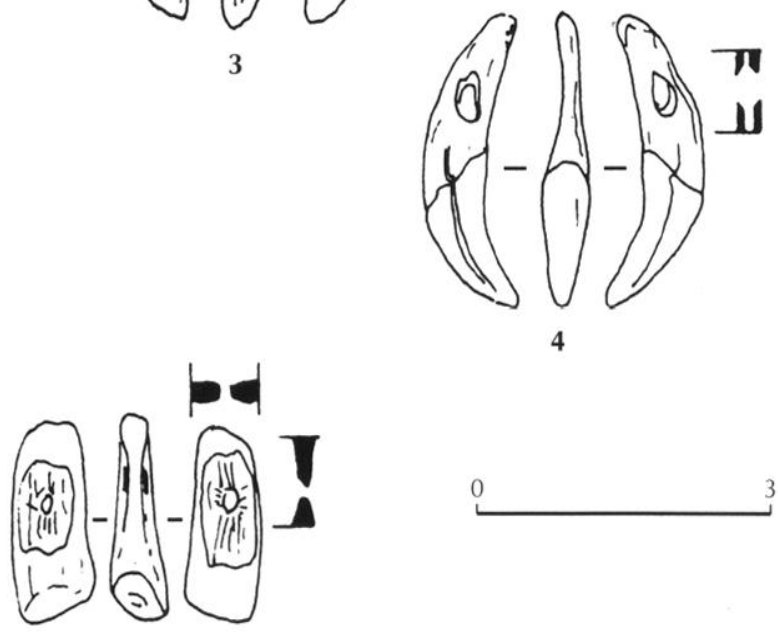

4

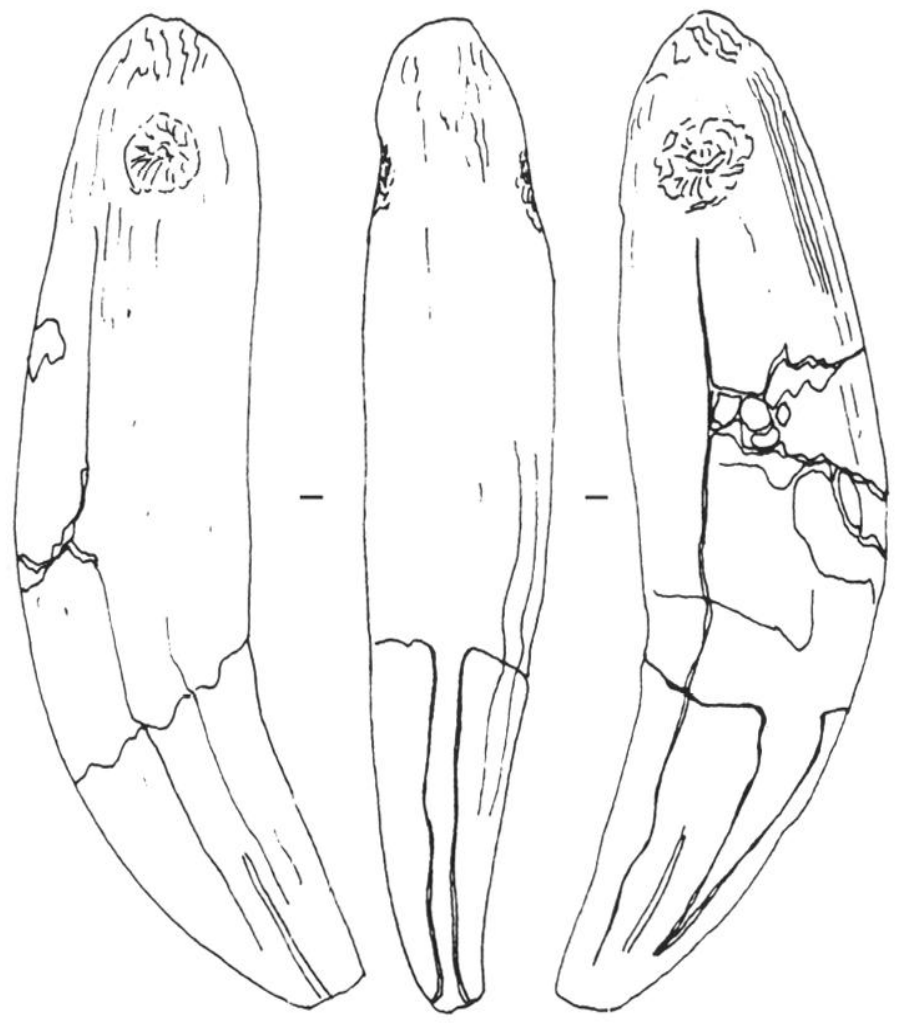

6

Fig. 29 - Parure de la couche 11. Os perforés: 1, tête fémorale de renne; 2, phalange proximale vestigiale de renne; 3, métapodien vestigial de renne. Dents perforées: 4 , canine de renard commun ; 5 , incisive de bison ; 6 , canine de lion des cavernes (dessins : 1, P. Laurent ; 2-6, S. (Gregoriani). 
microscopiques nous permettront peut-être de trancher en ce qui concerne la nature exacte de cette pièce.

\section{Fragment d'os perforé (nr:1)}

Cette pièce de forme ovale, à face supérieure globuleuse et face inférieure aplatie (fig. $28, \mathrm{n}^{\circ} 1$ ), présente, en son centre, une perforation. Elle fut, tout d'abord, décrite comme "os perforé ", et rapprochée des éléments de parure (Brooks, 1979), puis présentée comme un "objet sur meule de bois de Cervidés" (Leroy-Prost, 2002).

Après réexamen de l'objet, nous émettons l'hypothèse qu'il s'agit d'une tête humérale d'un animal de grande taille (Bison ou Cheval). Se pose également le problème de l'origine de la perforation de cette pièce. Aucune trace de façonnage n'étant visible, l'orifice pourrait correspondre à un foramen naturel élargi par l'action de l'eau.

Une étude microscopique de cette pièce est en cours et nous permettra sans doute de déterminer la nature exacte de cet objet, les causes de sa perforation, et, s'il y a lieu, sa fonction.

\section{Pendeloques}

\section{Os perforés ( $n r: 5)$}

Il s'agit de petits os allongés ou globuleux, dont la forme naturelle n'a pas été modifiée, et dont le seul aménagement consiste en une perforation circulaire.

Leur rattachement à la catégorie des éléments de parure ne pose, semble-t-il, aucun problème.

La nature anatomique et spécifique de ces pièces est variée :

- tête fémorale de renne juvénile $(30 \mathrm{~mm} \times 27 \mathrm{~mm}$ x $15 \mathrm{~mm}$; fig. $29, \mathrm{n}^{\circ} 1$ );

- phalange proximale vestigiale de renne $(25 \mathrm{~mm}$ x $7 \mathrm{~mm} \times 11 \mathrm{~mm}$; fig. $\left.29, \mathrm{n}^{\circ} 2\right)$;

- métapodien vestigial de renne $(28 \times 8 \times 5,5 \mathrm{~mm}$; fig. $\left.29, n^{\circ} 3\right)$;

- humérus de renard (29 mm x 14,5 mm x $10 \mathrm{~mm}$ );

- métacarpien $\mathrm{V}$ droit de renard $(34 \mathrm{~mm} \times 7 \mathrm{~mm}$ x $6 \mathrm{~mm}$ ).

En ce qui concerne leurs techniques de perforation, la tête fémorale de renne a été percée à partir de ses deux faces et présente une perforation biconique; la phalange proximale vestigiale de renne a été perforée en sa partic mésiale selon un mouvement rotatif (stries concentriques sur le pourtour de l'orifice circulaire) à partir d'une face, et par enlèvements successifs d'esquilles (petits enlèvements sur le pourtour de l'orifice) à partir de l'autre; l'articulation distale du métapodien vestigial de renne a été perforée par mouvement rotatif à partir des deux faces (traces concentriques sur le pourtour de l'orifice circulaire) ; l'humérus de renard possède un orifice naturel au niveau de son extrémité distale (foramen supratrochléaire) qui a simplement été régularisé et présente une forme parfaitement circulaire; la perforation du métacarpien $\mathrm{V}$ droit de renard étant brisée, nous n'avons pas pu déterminer le mode de perforation de cet os.

Toutes ces perforations circulaires attestent la grande minutie dont ont su faire preuve les Aurignaciens lors de la confection de ces pendeloques.

\section{Dents perforées ( $n r: 3)$}

La morphologie naturelle de ces dents n'a pas été modifiée, et le seul aménagement de ces pièces consiste en une perforation.

La première de ces pendeloques est une canine inférieure droite d'un jeune renard commun (Vulpes zulpes; $27,5 \mathrm{~mm} \times 4 \mathrm{~mm} \times 6 \mathrm{~mm}$ ), qui est intacte et possède une forme crochue (fig. $29, \mathrm{n}^{\circ} 4$ ). Elle a été perforée au niveau de l'apex de sa racine par enlèvements successifs d'esquilles à partir de sa face vestibulaire (petits enlèvements sur le pourtour de l'orifice qui est irrégulier).

La première incisive droite de bison est très usée (chicot), ce qui confère à la pièce une forme rectangulaire (18 mm x 5,5 mm x $7 \mathrm{~mm}$; fig. $\left.29, \mathrm{n}^{\circ} 5\right)$. La perforation subcirculaire de sa racine semble avoir été obtenue par incision radiaire à partir des deux faces.

Enfin, la canine supérieure gauche de lion des cavernes (Panthera (leo) spelaea; fig. 29, $\mathrm{n}^{\circ} 6$ ) est en cours de perforation. Elle présente, au niveau de l'apex de sa racine et sur chacune des faces, un cône dont les bords montrent des incisions radiaires. De profil, ces deux cônes apparaissent l'un en face de l'autre, et à terme la perforation de cette dent aurait sans doute eu une forme « en diabolo ».

Comme dans le cas des os perforés, l'aménagement de ces dents a sans doute demandé une grande minutie.

Enfin, nous tenons à signaler la présence de deux dents perforées supplémentaires : une crache gravée de cerf (Cervus elaphus), et une incisive de loup (Canis lupus). Malheureusement, la localisation stratigraphique 
de ces pièces étant floue (respectivement couches 11-14 et couches 11-12), nous les avons exclues du décompte des éléments de parure de la couche 11.

\section{SYNTHÈSE}

Bien que peu nombreux, les éléments de parure présentent une grande diversité de matière première (bois de cervidés, os, dents, ivoire) et de forme.

Parmi ces objets, la canine en cours de perforation attribuée au lion des cavernes, les trois fragments de baguette, et les deux ébauches de perles prouvent que les Aurignaciens façonnaient leurs éléments de parure dans l'abri. Même si, comme pour l'industrie osseuse, la répartition spatiale ne montre aucun agencement particulier, si ce n'est la présence de trois objets autour de la fosse sud (Pit II), et ne permet donc pas l'identification d'atelier de confection d'éléments de parure.

Le faible nombre d'éléments de parure n'est donc pas à rapprocher d'une faible production de ces objets, mais plutôt, soit de la faible durée d'occupation du site, soit d'une non-découverte de la totalité des pièces. Ceci est, peut-être, à mettre en relation avec la méthode de fouille de la couche (fouille partielle et absence de tamisage systématique) ou avec la nature de la zone fouillée (aire de consommation et de boucherie; cf. p. 199).

C. V.

\section{COMPORTEMENTS DE SUBSISTANCE}

Avec $94,9 \%$ les herbivores sont abondants et relativement diversifiés (tabl. I) alors que les carnivores, essentiellement des renards, ne sont représentés que par 139 restes. Comme, en outre, aucune marque de rongement n'a été observée sur les ossements, on peut estimer que les carnivores n'ont joué aucun rôle dans l'assemblage osseux de cette couche.

Deux espèces dominent le spectre faunique: le Cheval et le Renne (plus de 97,7 \% du NMEH et 80,5\% $\mathrm{du} \mathrm{NMICH}$ ). Les autres herbivores, Cerf élaphe, Bison, Bouquetin, Chamois, Sanglier et Mammouth, ne sont présents que par quelques ossements qui peuvent provenir de prélèvements de morceaux sur des carcasses d'animaux tués par d'autres prédateurs que l'homme (charognage) ou de chasses occasionnelles (opportu- nisme) ou encore, pour l'incisive perforée de bison et les 9 fragments d'ivoire, d'éléments importés (cf. p. 190).

Les Lièvres (variables?) ne sont représentés que par 5 restes correspondant à au moins deux individus (tabl. I). Ces derniers ne portent aucune marque extrinsèque d'origine anthropique ou animale. Cependant, le pourcentage de chances d'observer une trace extrinsèque sur un si petit nombre d'ossements est très faible. Ces lagomorphes ont pu être soit des proies de carnivores, soit un gibier occasionnel pour les Préhistoriques, ou encore des animaux intrusifs.

Nous avons dénombré 127 restes de Renard correspondant à au moins cinq individus (tabl. I) que nous avons attribués soit au Renard commun (Vulpes vulpes), soit à l'Isatis (Alopex lagopus). Ces deux espèces étant très proches, certains restes sont demeurés spécifiquement indéterminés. L'unique reste d'Isatis est un fragment de maxillaire droit portant la Ml. Bien que d'autres ossements, comme ceux de l'autopode, puissent appartenir à l'Isatis, nous ne pouvons raisonnablement proposer une interprétation quant à son origine (anthropique, animal intrusif, manuport?). On observe, pour le Renard commun, un net déficit d'ossements en particulier ceux de l'autopode (tabl. IX).

Ce constat peut refléter plusieurs réalités :

- une dispersion des os dans le sédiment ;

- l'absence de tamisage systématique lors des fouilles impliquant la non-découverte de la totalité des restes ;

- la localisation de ces ossements dans une partie de l'abri différente de la zone fouillée (zone de couchage par exemple, où les os de l'autopode seraient attenants aux peaux utilisées).

Cependant, nous avons observé que les os longs dominent, devant ceux du squelette céphalique. En outre, deux ossements de Renard présentent des marques d'origine anthropique. Une phalange proximale porte des traces de dépouillement, et un humérus, des stries de désarticulation et de décharnement. Il semble donc qu'au moins un renard a été traité et consommé par les Aurignaciens de l'abri Pataud. Ce statut d'animal consommé (occasionnellement) est assez inhabituel, les canidés étant surtout chassés pour leur peau ou leurs canines. D'ailleurs, deux os et une canine juvénile de Renard sont perforés (cf. p. 194).

L'alimentation carnée des Aurignaciens qui ont occupé l'abri durant cette période reposait donc sur le Cheval et le Renne. 
Tabl. $\mathbf{X}$ - Répartition anatomique des restes de renards communs (Vulpes vulpes) de la couche 11.

$N R$ : nombre de restes; NMIc : nombre minimum d'individus de combinaison; $G:$ gauche $; D:$ droit $(e) ; C:$ canine; $P:$ prémolaire ; $M$ : molaire ; $E P$ : extrémité proximale ; $D P:$ diaphyse proximale; $D M:$ diaphyse médiale; $D D:$ diaphyse distale; ED : extrémité distale.

\begin{tabular}{|c|c|c|c|c|c|c|c|}
\hline \multicolumn{2}{|c|}{ Éléments anatomiques } & NR & Latéralité & Détail & Stries anthropiques & Traitement & NMIc \\
\hline \multirow{4}{*}{ 莺 } & jugales supérieures & 1 & $\mathrm{D}$ & P4 & & & 1 \\
\hline & hémi-mandibule & 4 & $3 \mathrm{D}$ et $1 \mathrm{G}$ & $\begin{array}{l}1 \text { portant } \mathrm{M} 1 \text { et } \mathrm{M} 2 \mathrm{D} \\
1 \text { fragment portant } \mathrm{M} 1 \text { et M2 D } \\
1 \text { fragment portant M2 D } \\
1 \text { portant } \mathrm{M} 2 \mathrm{G}\end{array}$ & & & 3 \\
\hline & jugales inférieures & 1 & G & M1 & & & 1 \\
\hline & labiales & 1 & $\mathrm{D}$ & C inférieure $D$ de jeune & & & 1 \\
\hline 产 & coxaux & 4 & $2 \mathrm{D}$ et $2 \mathrm{G}$ & $\begin{array}{l}1 \text { acétabulum D } \\
1 \text { ilium D } \\
1 \text { fragment de l'ischium à l'acétabulum G } \\
1 \text { fragment de l'ilium à l'acétabulum G }\end{array}$ & & & 1 \\
\hline \multirow{3}{*}{ है } & scapula & 1 & $\mathrm{D}$ & Extrémité ventrale & & & 1 \\
\hline & humérus & 3 & $2 \mathrm{D}$ et $1 \mathrm{G}$ & $\begin{array}{l}1 \text { tête articulaire D } \\
1 \text { ED G } \\
1 \text { DD+ED D }\end{array}$ & $\begin{array}{l}\text { Stries courtes, fines, obliques, } \\
\text { sur épicondyle médial } \\
\text { Stries courtes, fines, obliques, } \\
\text { sur DD et } \mathrm{ED} \\
\text { faces crâniale et médiale }\end{array}$ & $\begin{array}{l}\text { désarticulation } \\
\text { décharnement }\end{array}$ & 1 \\
\hline & ulna & 1 & G & olécrane + DP & & & 1 \\
\hline \multirow{4}{*}{ 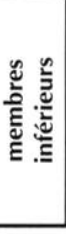 } & fémur & 1 & G & fragment DM & & & 1 \\
\hline & tibia & 3 & $1 \mathrm{D}$ et $2 \mathrm{G}$ & $\begin{array}{l}1 \mathrm{EPD} \\
1 \mathrm{DM}+\mathrm{DD}+\mathrm{ED} \mathrm{G} \\
1 \mathrm{ED} \mathrm{G}\end{array}$ & & & 2 \\
\hline & calcaneus & 3 & $3 \mathrm{G}$ & 3 calcaneus entier & & & 3 \\
\hline & talus & 1 & G & talus entier & & & 1 \\
\hline & Total & 24 & & & & & 4 \\
\hline
\end{tabular}

\section{ACQUISITION ET TRAITEMENT DES RENNES}

\section{AcQuisition}

Le Renne est représenté par 1369 restes appartenant à au moins douze individus (tabl. I).

La courbe de mortalité (fig. 30) est de type catastrophique (proche de celle d'une population vivante). Elle atteste une prédation d'origine humaine (avec plus de $58 \%$ d'adultes dans la force de l'âge). La présence d'un humérus de fotus prouve l'abattage d'une femelle gravide. La composition de cette population est assez similaire à celle d'une population naturelle (Miller, 1974 ; Skuncke, 1953 in Bouchud, 1975) avec une dominance des animaux de 6 ans au plus (8/12). Les fragments de bois (de massacre et/ou de chute) appartiennent à des femelles et à des jeunes. La morphométrie des ossements ne permet pas de constater la présence de mâles. On peut supposer que ces restes proviennent de l'abattage d'animaux au sein de petites hardes composées de femelles et de jeunes.
D'après l'étude des dents lactéales, de la dimension de l'humérus fotal $(32 \mathrm{~mm})$, des bois et de la composition de la harde, un abattage hivernal (après le rut et avant la mise bas) peut être envisagé.

\section{Traitement}

D'après la conservation des ossements (fig. 31), ces rennes ont été rapportés entiers à proximité de l'abri pour y être dépecés, à l'extérieur de la zone fouillée (déficit des os du crâne, de ceux du squelette axial et de ceux de l'autopode, exception faite des métapodiens). Par contre, la désarticulation, le décharnement et la fracturation des os à moelle ont eu lieu à l'intérieur de l'abri.

La relative abondance des os riches en viande et en moelle atteste une consommation sur place d'une grande partie des animaux abattus. Cependant, la courbe obtenue en prenant en compte le rapport \% MAU /\% MGUI (fig. 32) se rapproche de celle de la stratégie nutritive de type masse inverse (Binford, 1978, 1981). Ce 


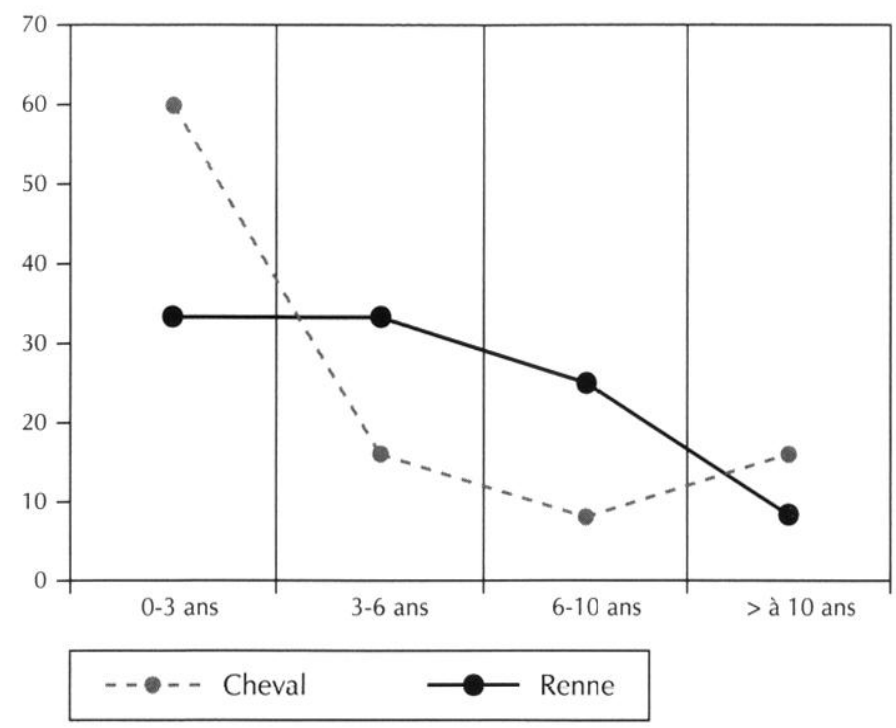

Fig. 30 - Comurbes de mortalité des rennes et des chevaux de la couche 11 (en pourcentages).

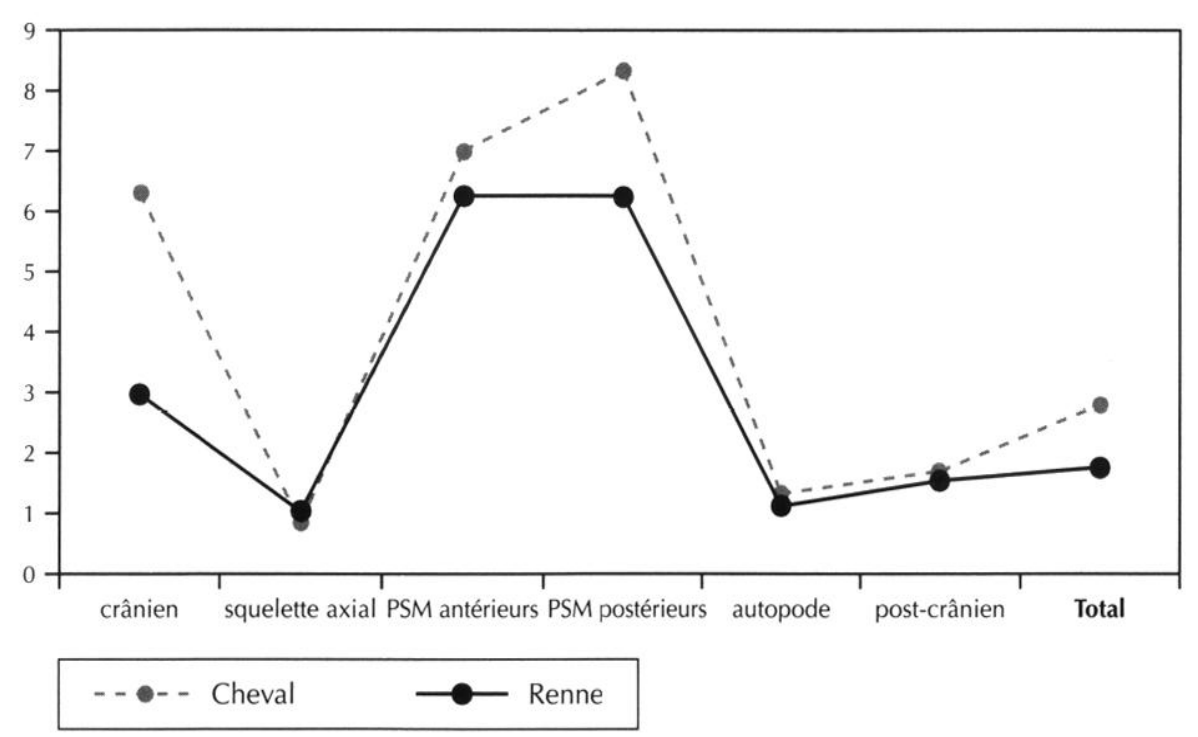

Fig. 31 - Comparaison de la conservation des grandes parties squelettiques (en $M A U$, Minimum animal unit) des rennes et des chevaux de la couche 11. PSM, partie supérieure des membres. type est associé aux sites de boucherie où le traitement des animaux a été total (Lyman, 1994).

Nous avons estimé le poids de viande et de graisse à respectivement $459 \mathrm{~kg}$ et $69,8 \mathrm{~kg}$ (d'après les données de Spiess, 1979).

Quarante-cinq os de Renne portent des stries de boucherie. Dix-sept de ces marques résultent d'une désarticulation au niveau de toutes les parties principales (trois cranio-mandibulaire, deux de la colonne vertébrale, deux humérus-radius/ulna, deux fémur-tibia, un tibia-tarse, un métacarpien-phalange proximale, un tarsemétatarsien, trois $1^{\mathrm{re}}-2^{\mathrm{e}}$ phalange, deux $2^{\mathrm{e}}-3^{\mathrm{e}}$ phalange). Cette observation confirme l'apport d'animaux entiers.
Vingt-trois os témoignent du décharnement (stries sur des humérus, des radius, des fémurs et des tibias). Une phalange intermédiaire porte des stries qui résultent soit de l'enlèvement de la peau soit du retrait d'un tendon. En outre, 4 métatarsiens présentent des stries de raclage.

Tous les os longs sont fracturés; quarante-six os portent des impacts de percussion (13 humérus, 6 radius, 8 fémurs, 13 tibias et 6 métapodiens). En outre, l'analyse des esquilles indéterminées (de la taille du Renne) met en évidence une nette dominance de celles de taille inférieure à $5 \mathrm{~cm}$ (plus de $91 \%$ ) ; 4,43\% d'entre elles sont brûlées. 


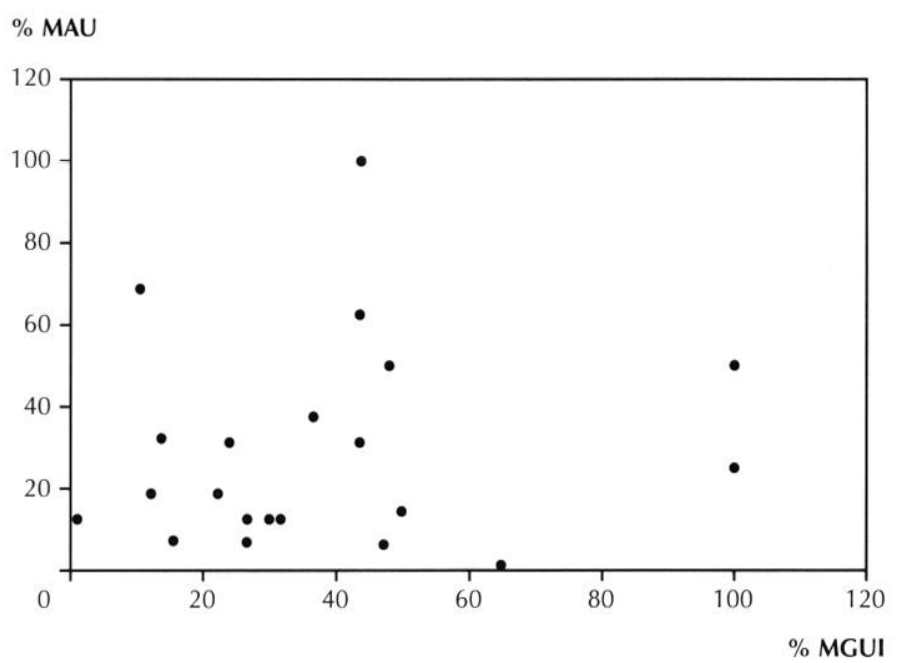

Fig. 32 - Stratégie nutritive : apport alimentaire des rennes de la couche 11. MAU, Minimum animal unit ; $M G U I$, Modified general utility index.

Ces résultats suggèrent que, durant des périodes hivernales, les Aurignaciens chassaient des rennes de tous âges appartenant à des hardes composées de femelles et de jeunes. Les rennes devaient séjourner dans la région, probablement dans la vallée (lieu d'hivernage). On note qu'une femelle gravide a été abattue, ce qui témoigne de la recherche d'éléments nutritifs rares (présents dans le placenta, lait...). Les rennes ont été apportés entiers dans l'abri pour y être traités. Une partie de la viande et de la graisse, partie qui reste à déterminer, a probablement été préparée pour être consommée ultérieurement (dans un autre site). Rappelons que les femelles et les jeunes sont, au début de l'hiver, plus riches en graisse que les mâles. En outre, d'après l'abondance des marques de décharnement, une partie de la viande a été prélevée probablement crue (préparation de biltong? ; Binford, 1981). Le traitement de ces cervidés a été complet, voire poussé (phalanges désarticulées, recherche intensive de la moelle).

\section{ACQUISITION ET TRAITEMENT DES CHEVAUX}

\section{ACQUisition}

Le Cheval est représenté par 1368 restes appartenant à au moins vingt-cinq individus (tabl. I).

La courbe de mortalité (fig. 30) est de type catastrophique (life assemblage; Levine, 1983). Les jeunes de moins de 3 ans dominent (60\%), un seul mâle a été

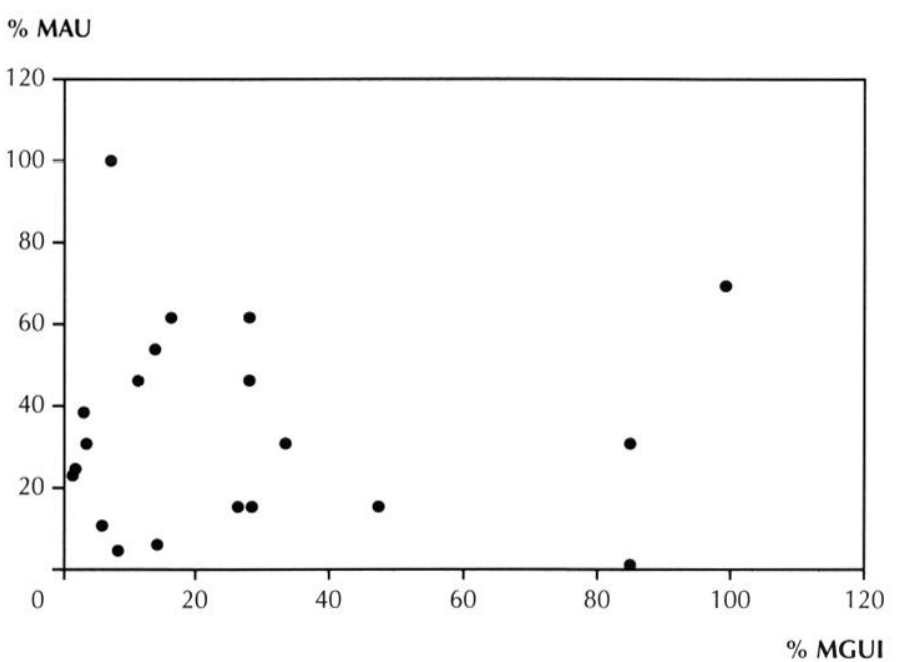

Fig. 33 - Stratégie nutritive : apport alimentaire des chevaux de la couche 11. MAU, Minimum animal unit ; MGUI, Modified general utility index.

identifié. La composition de cette population, essentiellement des jeunes et des femelles, correspond au modèle family group (Levine, id.).

D'après ce modèle et l'étude des dents lactéales, des abattages durant des périodes estivales peuvent être envisagés.

\section{TraITEMENT}

D'après la conservation des ossements (fig. 31), ces chevaux ont été dépecés sur leur lieu d'abattage, à proximité de l'abri (NR/NMIc faible, dû à " l'effet transport »). Comme pour les rennes, la désarticulation du crâne, du tronc et de l'autopode a eu lieu à l'extérieur de l'abri (déficit des éléments squelettiques de ces parties, exception faite des métapodiens III). Par contre, la désarticulation, le décharnement et la fracturation des os à moelle ont eu lieu à l'intérieur.

La relative rareté des os riches en viande et en moelle atteste à la fois une faible consommation sur place et un transport vers un autre lieu (MGUI d'après Outram et Rowley-Conwy, 1998). La courbe obtenue en prenant en compte le rapport \% MAU / \% MGUI (fig. 33) se rapproche de celle obtenue pour le Renne, c'est-à-dire d'une stratégie nutritive de type masse inverse.

Nous avons estimé le poids de viande et de graisse à respectivement $2400 \mathrm{~kg}$ et $120 \mathrm{~kg}$ (d'après les données de Spiess, 1979). Ce poids de viande confirme la pratique de chasses récurrentes. 
On observe des marques de boucherie sur 79 ossements de Cheval. Vingt-neuf os portent des stries résultant de la désarticulation (sept cranio-mandibulaire, quatre humérus-radius/ulna, quatre radius/carpe, trois carpe/métacarpien III, quatre fémur/tibia, deux tibia-tarse, trois tarse/métatarsien III, un métapodien III $/ 1^{\text {'c }}$ phalange, un carpe ou tarse/ métapodien III). Cinquante ossements présentent des stries de décharnement (six humérus, neuf radius, deux ulna, un fémur, huit tibias, onze côtes, une vertèbre, douze métapodiens III). D'après l'abondance de ces marques, une partie de la viande a probablement été prélevée crue (stockage pour un transport ultérieur vers un autre lieu).

Tous les os longs sont fracturés ; quarante-sept d'entre eux portent des impacts de percussion (six humérus, six radius, un ulna, un fémur, quatorze tibias et dixneuf métapodiens III).

Le déficit en extrémité d'os longs (parties spongieuses riches en graisse) peut s'expliquer par la confection par les Préhistoriques de bouillons et/ou une recherche de graisse (celle-ci, de bonne qualité, se conserve durant plusieurs mois).

On note également la présence de traces de calcination sur 9 ossements (deux déciduales, une côte, trois humérus, deux fémurs, un tibia).

La pratique par les Aurignaciens de chasses estivales récurrentes de petits groupes de chevaux composés de jeunes et de femelles peut être proposée. Après un dépeçage sur le lieu d'abattage, Les chevaux ont été traités à proximité ou dans l'abri et partiellement consommés. Leur traitement apparaît moins poussé que celui des rennes, ceci est peut-être à mettre en relation avec la période de chasse, estivale. En revanche, une grande partie de la viande de ces animaux (plus que pour celle des rennes) semble avoir été préparée pour être transportée ultérieurement vers un autre site.

\section{CONCLUSION}

L'abri Pataud se trouve à un carrefour de biotopes, les troupeaux d'herbivores devaient passer par la vallée de la Vézère lors de leurs migrations annuelles. Les rennes migrent deux fois par an, au printemps, avant la mise bas, et en automne, après le rut. De même, les chevaux effectuent de petites migrations en fonction de l'herbage. D’après les saisons de chasse de ces deux espèces mises ici en évidence et la paléoécologie, on peut avancer l'hypothèse selon laquelle les rennes étaient abondants dans cette région durant la période hivernale et les chevaux durant la période estivale. Les Aurignaciens ont donc fondé leur stratégie d'acquisition d'aliments carnés sur deux espèces locales. Ceci dénote une mobilité assez. réduite sur un territoire assez restreint.

Les stratégies nutritives, type masse inverse, mises en évidence pour les rennes et pour les chevaux et les observations liées au traitement boucher (désarticulation des membres, décharnement et fracturation des os à moelle à l'intérieur de l'abri) permettent d'assimiler l'abri Pataud à un site de boucherie et de consommation partielle durant des périodes hivernales et estivales (ces dernières apparaissant de plus courte durée).

Enfin, les rennes et les chevaux ont fourni plus de $2860 \mathrm{~kg}$ de viande et $190 \mathrm{~kg}$ de graisse ce qui confirme l'occupation récurrente de l'abri.

M. P.-M.

\section{DISCUSSION}

Les études de l'industrie lithique, de l'outillage osseux, et de la parure s'accordent sur l'attribution culturelle du niveau 11 à l'Aurignacien ancien (Aurignacien I).

Les hommes préhistoriques ont privilégié le choix de matières premières locales (galets de silex sénonien, os, bois de cervidé) pour produire, au sein de l'abri, des outillages lithiques et osseux reflétant leurs activités domestiques et cynégétiques. Cet équipement devait répondre aux besoins des Aurignaciens lors de leur séjour à l'abri Pataud. Ces derniers ont également apporté des matériaux (blocs de silex du Bergeracois, fragments d'ivoire) et des objets finis (outils en silex du Bergeracois, certains éléments de parure).

La couche 11 est riche en os brûlés, on note par ailleurs une sous-exploitation du bois, élément indispensable au démarrage des foyers. Le nombre important d'ossements disponibles (déchets de boucherie) a probablement favorisé leur utilisation comme combustible. Combustible lent, les restes osseux ont peut-être été employés préférentiellement pour fumer de la viande crue (ce qui facilite sa conservation et son transport).

Pour H. L. Movius (1977, p. 130), les fosses ne sont pas, à cause de leur faible diamètre, des fonds de 
cabanes. Dans celles-ci, notamment celle des carrés BIII-BIV, beaucoup d'ossements, aussi bien de Renne que de Cheval, ont été découverts ainsi que des pièces lithiques (plus d'outils que de déchets de débitage) et des charbons d'os. Ces éléments permettent de proposer comme hypothèses fonctionnelles que ces fosses correspondent soit à des zones culinaires, soit à des zones de rejets (dépotoirs). Cette dernière hypothèse semble moins probable, ces fosses se trouvant à l'intérieur de l'abri. Elles correspondent peut-être à deux grands " foyers ", au-dessus desquels la viande était fumée (litages de charbons relevés dans pit II).

La répartition spatiale des outils lithiques ou osseux et de la faune indique que la partie fouillée correspond à des aires d'activités (autour des foyers). En revanche, il est impossible de distinguer les différentes zones et leur fonction car la succession d'occupations induit un brouillage des zones d'activité. Les extensions, en avant de la fouille principale, très riches en matériel (lithique et osseux), se situent déjà sur la pente.

Cette étude nous conduit à une hypothèse comportementale qui rejoint celle proposée par R. White (1992, in Demars, 1998), à savoir que pendant la belle saison les groupes, ici aurignaciens, étaient plus mobiles et les campements de plus courte durée. En outre, la mise en évidence de chasses saisonnières à double orientation, avec notamment l'abattage de rennes en période hivernale, conforte l'hypothèse d'un abandon de la région par ces cervidés (déplacement pour la mise bas vers le Massif central). À l'abri Pataud, la diversité des espèces chassées en période estivale n'est pas probante, le Cheval étant nettement dominant; les autres herbivores, Cerf élaphe, Bison, Bouquetin, Chamois et Sanglier, n'ont pas fourni de données de saisonnalité, peut-être sont-ils associés majoritairement aux chevaux et non aux rennes. Cependant, d'après le traitement des chevaux, les occupations paraissent courtes et le site se rapprocherait, alors, plus d'un site de boucherie que d'un site de consommation. Ce constat semble en accord avec les conclusions émises par P-Y. Demars (1998). Le fait que les outils en silex importés (zone éloignée: Geneste, 1989) ne soient pas réalisés sur place ainsi que la grande diversité et la relative abondance de ces matières sont également des arguments en faveur d'occupations brèves et multiples.

\section{Remerciements}

Cet article résulte d'un travail mené au sein du

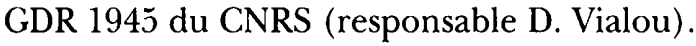

Nous remercions W. R. Farrand qui nous a confié des documents inédits et a accepté que nous les utilisions. 


\section{BIBLIOGRAPHIE}

Aitrboly A., Provenzano N.

1998-1999 : "Propositions pour une terminologie du travail préhistorique des matières osseuses -1Techniques ». Préhistoire Anthropologie méditerranéennes, 7-8, p. 5-25.

BINFORD L. R.

1978 : Nunamiut ethnoarchaeology. New York, Academic Press, 509 p.

1981 : Bones ancient men and modern myths. New York, Academic Press, (Studies in Archaeology), $312 \mathrm{p}$

BOLCHLD J.

1975 : «Étude de la faune de l'abri Pataud ", in Movils H. L. Jr. (ed.), Excavation of the abri Pataud, Les Eyzies (Dordogne) : Contributors. American School of Prehistoric Research, Peabody Museum, Harvard University, Cambridge, Massachussetts, 30, p. 69-153.

BROOKS A. S.

1979 : The significance of variability in Paleolithic assemblages: An Aurignacian example from southwestern France. Thesis of Department of Anthropology, Harvard University, Cambridge, Massachussetts, 1057 p.

CAMPS-Fabrer H.

1990 : "Fiche : Poinçon d'économie », in CAMPS-FABRER H., RAMSEYER D., STORDELR D. (dir.), Fiches typologiques de l'industrie osseuse préhistorique, Cahier III : Poinsons, Pointes, Poignards, Aiguilles. Aix-en-Provence, éd. de l'Université de Provence.

\section{Chiottr L.}

1999a: "Remontage d'un pic dans l'Aurignacien ancien de l'abri Pataud (Les Eyzies-de-Tayac, Dordogne) ". Préhistoire du Sud-Ouest, 6-1, p. 57-77.

$1999 \mathrm{~b}$ : Les industries lithiques des niveaux aurignaciens de l'abri Pataud, Les Eyziesde-Tayac (Dordogne) : étude technologique et typologique. Thèse de doctorat du
Muséum national d'histoire naturelle, Paris, 2 vol., 839 p.

2003 : "Les productions lamellaires dans l'Aurignacien de l'abri Pataud, Les Eyzies-de-Tayac, Dordogne ". Gallia Préhistoire, 45, p. 113-156.

DEMARS P.-Y.

1989 : «L'indice laminaire de l'outillage dans le Paléolithique supérieur en Périgord ". Paléo, 1, p. 17-30.

1998 : "Circulation des silex dans le nord de l'Aquitaine au Paléolithique supérieur. L'occupation de l'espace par les derniers chasseurscueilleurs ". Gallia Préhistoire, 40, p. 1-28.

DrwF\% M.

1985 : "Les pièces esquillées dans le Paléolithique supérieur de Belgique ". Bulletin de la Société préhistorique française, 82, 5, p. 131-133.

DON.NER J. J.

1975 : "Pollen composition of the abri Pataud Sediments. The last Glacial Compared with the Postglacial Pollen Stratigraphy of Beune Valley ", in Movius H. L. Jr. (ed.), Excavation of the abri Pataud, Les Eyzies (Dordogne) : Contributors. American School of Prehistoric Research, Peabody Museum, Harvard University, Cambridge, Massachussetts, 30, p. 161-186.

El. MANSOLRI M.

1995 : Étude paléobiochimique des ossements de l'abri Pataud. Conservation de la matière organique et datation par la racémisation des acides aminés. Thèse de doctorat du Muséum national d'histoire naturelle, Paris, $137 \mathrm{p}$.

FARRAND W. R.

1975 : "Analysis of the abri Pataud Sediments ", in Movil's H. L. Jr. (ed.), Excavation of the abri Pataud, Les Eyzies (Dordogne): Contributors.
American School of Prehistoric Research, Peabody Museum, Harvard University, Cambridge, Massachussetts, 30 , p. 27-68.

1995 : «Étude sédimentologique du remplissage de l'abri Pataud ", in BRICKF. H. M. (dir.), Le Paléolithique supérieur de l'abri Pataud (Dordogne) : les fouilles de H. L. Movius Jr. Paris, éd. de la Maison des sciences de l'homme, (Documents d'archéologie française, $50)$, p. $31-65$.

FELlaG $\mathrm{H}$.

1996 : Contribution à l'étude des paléoenvironnements et des paléoclimats de la fin du Pléistocène mojen et du Pléistocène supérieur du sud-ouest de la France. Analyse pollinique des remplissages des grottes de Suard, Bourgeois-Delaunay, Fontéchevade (Charente), et de l'abri Pataud (Dordogne). Thèse de doctorat du Muséum national d'histoire naturelle, Paris, 205 p.

1998: «Apport de l'analyse pollinique à la connaissance du paléoenvironnement du Paléolithique supérieur de l'abri Pataud (Dordogne, France) ». Bulletin de la Société préhistorique française, 95, 2, p. 171-181.

Genteste J.-M.

1989 : “Économie des ressources lithiques dans le Moustérien du sudouest de la France ", in L'homme de Néandertal -6- La Subsistance. Liège, (Études et recherches archéologiques de l'université de Liège, 35), p. 75-97.

GREGoRIani S.

1996 : Lindustrie osseuse et la parure des niveaux aurignaciens de l'abri Pataud (Les Eyzies-de-Tayac, Dordogne), mémoire de DEA du Muséum national d'histoire naturelle, Paris, $156 \mathrm{p}$.

GLTHRIE R. D.

1983 : «Osseous projectile points : biological considerations affecting raw 
material selection and design among paleolithic and paleoindian peoples ", in Ci.LTTON-Brock J., Grigison C. (eds), Animals and Archaeology -1-Hunters and their Prey. Oxford, British Archacological Reports, International Series, 163, p. 273-294.

HAHN J.

1988: «Fiche : Sagaie à base fendue ", in Delporte H., HahN J., MONS L., Pinçon G., Sonnfili.le-Bordes D. DE, Fiches typologiques de l'industrie osseuse préhistorique, Cahier I: Sagaies. Aix-enProvence, éd. de l'Université de Provence.

Julien M., Baffier D., Liol.oos D.

2002 : “L'outillage en matières dures animales ", in SchMIIDER B. (dir.), L'Aurignacien de la grolte du Renne. Les fouilles d'André Leroi-Gourhan à Arcysur-Cure (Yonne). Paris, CNRS Éditions, (XXXIV" suppl. à Callia Préhistoire), p. 217-250.

KARNAY G. (DIR.)

1999 : Carte géologique de la France à l'échelle 1/50 000, pli 807, Le Bugue. Orlćans, éd. du BRGM.

\section{KNECHT H.}

1991a : Technological innovation and design during the early upper Paleolithic: a study of organic projectiles technologies. Doctoral Dissertation, Department of Anthropology, New York University.

1991b: «The role of innovation in changing early upper Paleolithic organic projectile technologies ". Techniques et Culture, 17-18, p. 115-144.

1993a: Splits and wedges: The Techniques and Technology of Early Aurignacian Antler Working, in Kvecht H., Pike-Tay A., White R. (eds), Before Lascaux. The complex record of the early upper Paleolithic, New York, éd. Boca Raton, CRC Press, p. 137-162.

1993b : " Early Upper Paleolithic Approches to Antler Projectile Technology ", in PritrkiN G. L., Bricker H., Mellars P. (eds),
Hunting and Animal Exploitation in the Later Paleolithic and Mesolithic of Eurasia. Archacological Papers of the American Anthropological Association, 4, p. 33-47.

KoNIK S.

1999 : Les dépôts de pente du Périgord Noir: distribution et mise en place; origine des matériaux et étapes de l'évolution des versants. Thèse de doctorat, univ. Paris I Panthéon-Sorbonne, 473 p.

LF BRUN-RICALINS F.

1989 : “Contribution à l'étude des pièces esquillées : la présence de percuteurs à "cupules" ". Bulletin de la Société préhistorique française, 86, 7, p. 196-201.

LEROY-Prost C.

1975 : « L'industrie osseuse aurignacienne. Essai régional de classification : Poitou, Charentes, Périgord ", Gallia Préhistoire, 18, 1, p. 65-156.

2002 : "Fiche : Objets sur meule de bois de Cervidés ", in Patol-Matuis M. (dir.), Fiches typologiques de l'industrie. osseuse préhistorique, Cahier $X$ : Retouchoirs, compresseurs, percuteurs... Os à impressions et éraillures. Paris, éd. de la Société préhistorique française, p. 105-115.

I.FVINE: M. A.

1983 : Mortality models and the interpretation of horse population structure, in BAILFY (. (ed.), HunterGatherer economy in Prehistory: $a$ European perspective. London, Cambridge University Press, p. 23-46.

L.JOI.IOS D.

1999 : Variabilité et caractéristiques $d u$ travail des matières osseuses au début de l'Aurignacien - Approche lechnologique et économique. Thèse de doctorat, univ. Paris X, Préhistoire et Technologie, $360 \mathrm{p}$.

LMMAN R. L.

1994 : Vertebrate Taphonomy. London, Cambridge University Press, 524 p.

Maikba G., Giacobini G.

2002 : "Fiche : Éclats diaphysaires avec marques transversales d'utilisation ", in PATOU-Mathis M. (dir.), Fiches typologiques de l'industrie osseuse préhistorique, Cahier $X$ : Retouchoirs, compresseurs, percuteurs... Os à impressions et éraillures. Paris, éd. de la Société préhistorique française, p. 29-37.

\section{Milliter F. L.}

1974 : Biology of the Kaminuriak population of barren-ground caribou-2- Dentition as an indicator of age and sex : composition and socialization of the population. Ottawa, Canadian Wildlife Service, Report Series, 31, 88 p.

Movius H. L. JR.

1977 : Excavation of the abri Pataud, Les Eyzies (Dordogne) : Stratigraphy. American School of Prehistoric Research, Peabody Museum, Harvard University, Cambridge, Massachussets, 31, 167 p.

Movics H. L. JR. (F.D.)

1975 : Excavation of the abri Pataud, Les Eyzies (Dordogne) : Contributors. American School of Prehistoric Research, Peabody Museum, Harvard University, Cambridge, Massachussets, 30, $305 \mathrm{p}$.

OUtRaM A., Rowley-CONWY P.

1998 : "Meat and Marrow Utility Indices for Horse (Equus) ». Journal of Archaeological Science, 25, 9, p. 839-849.

Patoli-Mathis M. (DIR.)

2002 : Fïches typologiques de l'industrie osseuse préhistorique, Cahier $X$ : Retouchoirs, compresseurs, percuteurs... Os à impressions et éraillures. Paris, éd. de la Sociëtè prëhistorique française, $136 \mathrm{p}$.

Peyrony D.

1928 : "Pièces à languette de l'Aurignacien moyen ". in Congrès de l'Association française pour l'avancement des sciences, 52" session, La Rochelle, p. $439-441$.

Sonneviliti-Bordes D. DE, Perrot J. 1953: " Essai d'adaptation des méthodes statistiques au Paléolithique 
supérieur. Premiers résultats". Bulletin de la Société préhistorique française, L, p. 323-333.

SpIESS A. E.

1979 : Reindeer and Caribou hunters : an archeological study. New York Academic Press, 312 p.

\section{TABORIN Y.}

1995 : «Formes et décors des éléments de parure en ivoire du Paléolithique français ", in HAHN J., MENU M., TABORIN Y., WALTER P., WIDERMANN F. (éds), Le travail et l'usage de l'ivoire au Paléolithique supérieur. Actes de la tablc ronde, Ravello (Italie), 29-31 mai 1992, Ravello, Istituto poli- graphico e zecca dello stato, Libreria dello stato, p. 63-83.

THÉRY-PARISOT I.

1998 : Économie du combustible et paléoécologie en contexte glaciaire et périglaciaire, Paléolithique moyen et supérieur du Sud de la France (anthracologie, expérimentation, taphonomie). Thèse de doctorat, univ. Paris I Panthéon-Sorbonne, $500 \mathrm{p}$.

Vogei J. C., Waterbol.k H. T.

1967 : "Groningen Radiocarbon Dates VII ». Radiocarbon, 9, p. 107-155.

WHITE R.

1985 : Upper Paleolithic Land Use in the Perigord. A Topographic Approach to
Subsistence and Settlement. Oxford, British Archaeological Reports, International Series, 253, $252 \mathrm{p}$.

1993 : " Technological and Social Dimensions of "Aurignacian-Age" Body Ornaments across Europe ", in Kvecht H., PIKe-TaY A., White R. (eds), Before Lascaux. The complex record of the early upper Paleolithic. New York, éd. Boca Raton: CRC Press, p. 277-299.

2002 : “ Observations technologiques sur les objets de parure ", in Schmidir B. (dir.), L'Aurignacien de la grotte $d u$ Renne. Les fouilles d'André LeroiGourhan à Arcy-sur-Cure (Yonne). Paris, CNRS Éditions, (XXXIV" suppl. à (̇allia Préhistoire), p. 257-266. 